\title{
Peritoneal carcinomatosis of gastro-intestinal origin
}

Citation for published version (APA):

Thomassen, I. (2014). Peritoneal carcinomatosis of gastro-intestinal origin. [Doctoral Thesis, Maastricht University]. Maastricht University. https://doi.org/10.26481/dis.20141121it

Document status and date:

Published: 01/01/2014

DOI:

10.26481/dis.20141121it

Document Version:

Publisher's PDF, also known as Version of record

\section{Please check the document version of this publication:}

- A submitted manuscript is the version of the article upon submission and before peer-review. There can be important differences between the submitted version and the official published version of record.

People interested in the research are advised to contact the author for the final version of the publication, or visit the DOI to the publisher's website.

- The final author version and the galley proof are versions of the publication after peer review.

- The final published version features the final layout of the paper including the volume, issue and page numbers.

Link to publication

\footnotetext{
General rights rights.

- You may freely distribute the URL identifying the publication in the public portal. please follow below link for the End User Agreement:

www.umlib.nl/taverne-license

Take down policy

If you believe that this document breaches copyright please contact us at:

repository@maastrichtuniversity.nl

providing details and we will investigate your claim.
}

Copyright and moral rights for the publications made accessible in the public portal are retained by the authors and/or other copyright owners and it is a condition of accessing publications that users recognise and abide by the legal requirements associated with these

- Users may download and print one copy of any publication from the public portal for the purpose of private study or research.

- You may not further distribute the material or use it for any profit-making activity or commercial gain

If the publication is distributed under the terms of Article $25 \mathrm{fa}$ of the Dutch Copyright Act, indicated by the "Taverne" license above, 
Peritoneal carcinomatosis of gastro-intestinal origin

Irene Thomassen 
The printing of this thesis was supported by:
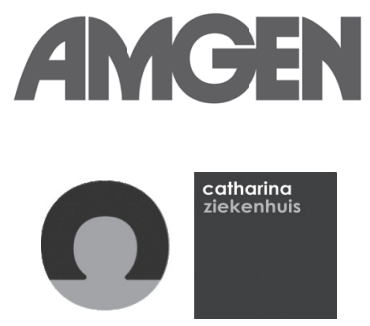

COVIDIEN
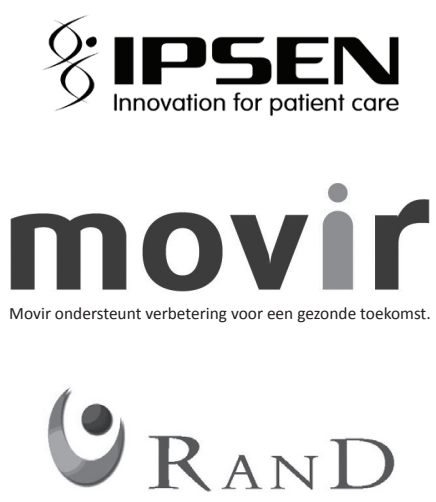

$\underset{\text { BEACHCLUB }}{\text { SUNRISE }}$

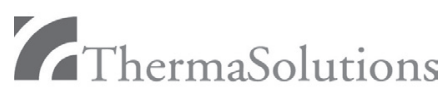

\section{Bart. \\ $\& \quad R E S E A R C H$}

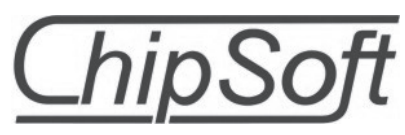

K KNL

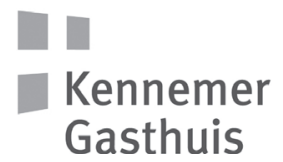

OLYMPUS

Your Vision, Our Future

\section{Roche}

\section{Takeda}

WILL PHARMA

\section{Colofon}

(C) Irene Thomassen, Haarlem, 2014

Printed by: Drukwerkconsultancy, www.drukwerkconsultancy.nl

Cover design and lay-out: Marlies van Hoof, www.madebymarlies.nl

ISBN 978-90-9028564-1 


\title{
Peritoneal carcinomatosis of gastro-intestinal origin
}

\author{
PROEFSCHRIFT
}

ter verkrijging van de graad van doctor aan de Universiteit Maastricht, op gezag van de Rector Magnificus, Prof. Dr. L.L.G. Soete volgens het besluit van het College van Decanen,

in het openbaar te verdedigen op vrijdag 21 november 2014 om 12.00 uur

door

Irene Thomassen

Geboren op 27 december 1986

te Eindhoven 


\section{Promotores}

Prof. Dr. H.J.T. Rutten

Prof. Dr. V.E.P.P. Lemmens

\section{Copromotor}

Dr. I.H.J.T. de Hingh

\section{Manuscriptcommissie}

Dr. V. Verwaal, Netherlands Cancer Institute - Antoni van Leeuwenhoek ziekenhuis Prof. dr. V.C.G. Tjan - Hijnen, Maastricht Universitair Medisch Centrum

Prof. dr. C.H.C. Dejong, Maastricht Universitair Medisch Centrum

Dr. B. van Ramshorst, Antonius ziekenhuis Nieuwegein

\section{Paranimfen}

Drs. J.L. Thijs

Drs. A. Madani 


\section{TABLE OF CONTENTS}

$\begin{array}{ll}\text { Introduction } & 7\end{array}$

Chapter $1 \quad$ Peritoneal carcinomatosis is less frequently diagnosed 17 during laparoscopic surgery compared to open surgery in patients with colorectal cancer in the Netherlands

Chapter 2 Incidence, prognosis and treatment options for patients with synchronous peritoneal carcinomatosis and liver metastases from colorectal origin

Chapter 3 Metachronous peritoneal carcinomatosis after curative treatment of colorectal cancer

Chapter $4 \quad$ Peritoneal carcinomatosis of gastric origin: a population61 based study on incidence, survival and risk factors

Chapter $5 \quad$ Incidence, prognosis, and possible treatment strategies of 77 peritoneal carcinomatosis of pancreatic origin.

A population-based study

Chapter 6

Population-based incidence, treatment, and survival of 89 patients with peritoneal metastases of unknown origin

Chapter $7 \quad$ Chemotherapy as palliative treatment of peritoneal 103 carcinomatosis of gastric origin

Summary and future perspectives

Samenvatting

About the author

Publications

Dankwoord 


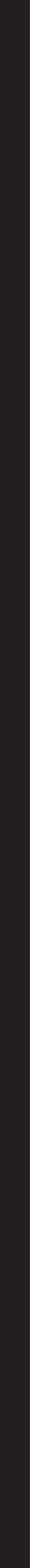




\section{Introduction}

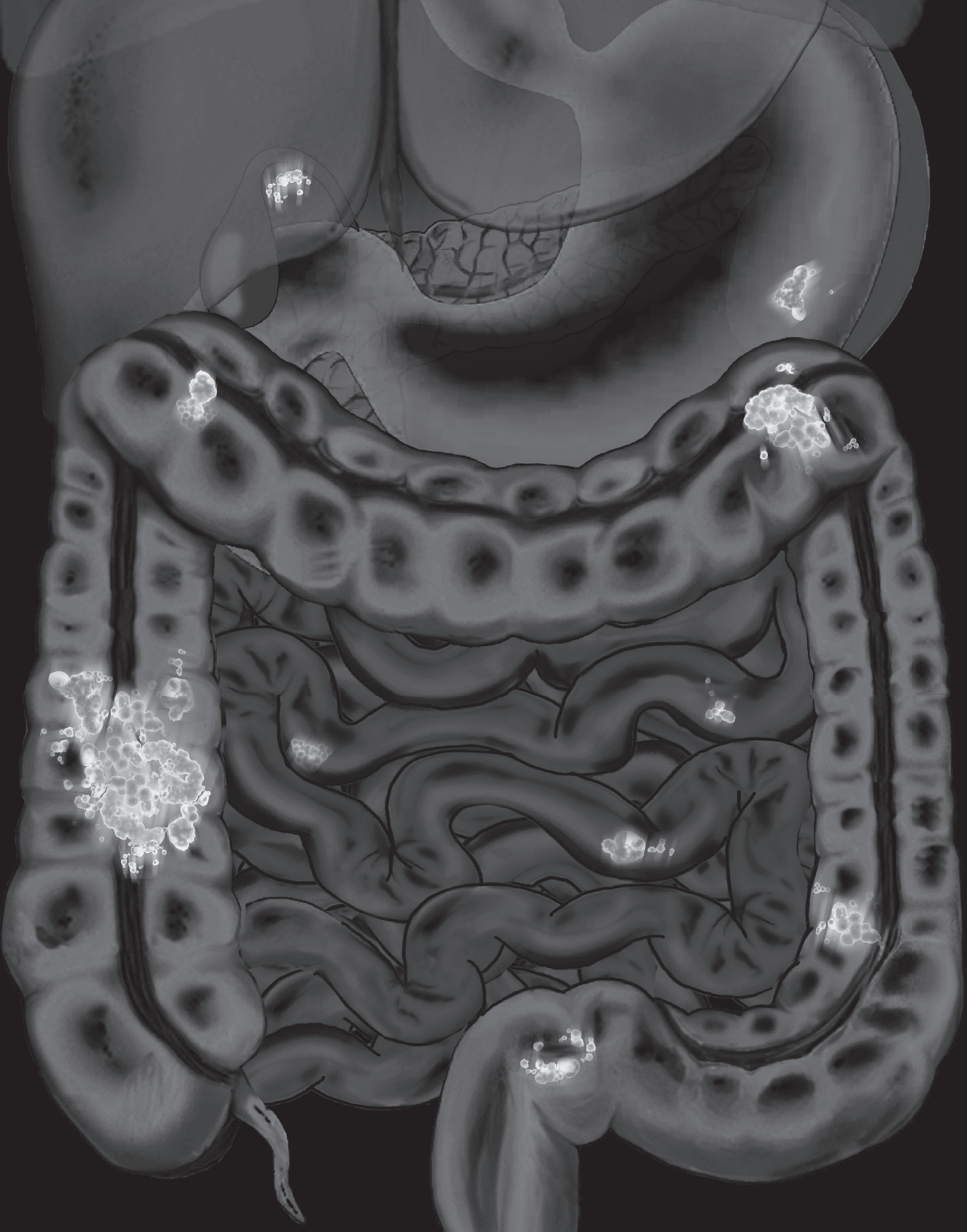





\section{Introduction}

Peritoneal carcinomatosis (PC) is defined as the presence of malignant cells in the peritoneal cavity. ${ }^{1,2}$ The spread of malignant cells into the peritoneal cavity is a result of tumor cells detaching from the primary tumor mass. This can be caused by spontaneous exfoliation of tumor cells that have invaded the serosa. One of the underlying mechanisms is downregulation of E-cadherin, an intercellular adhesion molecule that keeps cells together. ${ }^{2,3}$ The detachment of tumor cells can also be caused by iatrogenic or spontaneous perforation of the tumor or from transected lymphatics and blood vessels during surgical resection. These free cancer cells then spread through the peritoneal cavity and are moved by gravity, peristaltic movement of the bowel and negative pressure created by diaphragm movement. These cancer cells then attach to other organs and surfaces which is mediated by CD44 adhesion molecules. The biology of the cancer cells affects to which structure these cells will attach. After attachment to the peritoneum and penetrating the mesothelial barrier, these cells adhere to the submesothelial connective tissue. In addition, peritoneal cancer dissemination can also occur through a translymphatic process where free cancer cells gain access, and attach to the subperitoneal lymphatic spaces through lymphatic stomata. ${ }^{3} \mathrm{After}$ implantation of these cancer cells, angiogenesis occurs and these cancer cells multiply. Tumor implantation and growth may subsequently lead to invasion of any organ or structure covered by the peritoneum. Preferred sites for peritoneal implants are the omentum, mesentery, bowel surface, pouch of Douglas, right paracolic gutter, and diaphragm. ${ }^{4,5}$ Intraperitoneal fluid accumulation may develop as a result of the occlusion of lymphatic drainage and excessive fluid production caused by increased capillary permeability, resulting in massive amounts of ascites. ${ }^{6}$

Prior to the 1980 s PC received little interest and curative treatment was not an option, leaving patients with an horrendous prognosis. Since then, PC gained more interest triggered by the observation that a subgroup of cancer patients with metastatic disease presented with peritoneal implants but without systemic metastases. Three different routes of dissemination of cancer were identified: hematogenous, lymphatic and metastases to peritoneal surfaces. Since then PC was considered as a loco-regional disease rather than systemic disease and more research was performed to find an effective treatment for these patients. This resulted in a multi-modality strategy combining cytoreductive surgery (CRS) with heated intraperitoneal chemotherapy (HIPEC). Selection criteria included limited PC, good clinical condition and no systemic disease. For this procedure, the resection of grossly involved organs was required, and a peritonectomy procedure should be performed. ${ }^{7,} 8$ Then HIPEC was administered to eradicate microscopic disease, since it is hypothesized that $2.5 \mathrm{~mm}$ is the maximum penetration depth of chemotherapeutic agents. ${ }^{9}$ The heat is thought to potentiate the cytotoxic properties of the chemotherapeutics. Chemotherapeutic agents and doses vary widely between centers worldwide, with mitomycin $C$ and oxaliplatin being the most frequently used agents. ${ }^{7}$ Using this technique, a median survival rate of up to 63 months has been described, with limited postoperative mortality and morbidity. ${ }^{9-15}$ 
Since tumor load and tumor response rate are hard to measure in patients with PC, these patients do not meet the inclusion criteria for randomized trials. Usually Computed Tomography (CT) or Positron Emission Tomography (PET) are used to diagnose PC. However, the sensitivity of CT varies between $60-90 \%$ of lesions greater than $5 \mathrm{~cm}$, but decreases to $10-30 \%$ for lesions smaller than $1 \mathrm{~cm} .{ }^{16-18}$ Also, the peritoneal spread of tumor cells characteristically follows the anatomic outline of normal abdominal structures, making radiologic detection more challenging. ${ }^{7}$ Both imaging techniques have a low sensitivity for small lesions, therefore inspection of the abdominal cavity during surgery is performed concomitantly., 19

In recent years more data on PC of colorectal origin became available. Population-based epidemiological studies have shown that the incidence of synchronous PC was 4.3-4.8\%.1, 20 Risk factors to develop PC included a right-sided tumor, advanced T-stage, advanced N-stage, poor differentiation grade and younger age at diagnosis., 7,20 Systemic chemotherapy has been studied as treatment for PC, showing that 5-Fluorouacil (5-FU) and leucovorin have a disappointing response and poor prognosis compared to other metastatic sites. ${ }^{7}$ Overall, a median survival of 6 to 8 months has been accomplished by treatment with systemic chemotherapy. ${ }^{21-24}$

The first part of this thesis aims to complement current literature regarding PC of colorectal origin. In chapter $\mathbf{1}$ a study is presented aiming to detect a difference in diagnosis of PC using different surgical techniques in patients undergoing curative surgery. Different surgical techniques provide a different extent of exposure, and during laparoscopic surgery tactile information cannot be obtained. Whether a difference in adequacy of diagnosis of PC exists between both surgical techniques, is not previously studied. However, early diagnosis of PC is of utmost importance for successful treatment.

When patients are diagnosed with PC, selection for CRS and HIPEC is important to offer treatment only to patients that will benefit most from this procedure. Traditionally, patients with synchronous liver metastases (LM) and PC do not qualify for this treatment, since LM are hematogenously spread and are not considered locoregional disease. The combination of liver metastases and PC may result in a dilemma in young, fit and motivated patients presenting with both resectable LM and PC. In selected centers around the world, combined LM and PC are now treated with CRS and IPC and liver metastasectomy, showing that this procedure can be performed safely and prolonging survival. However, the extent of this problem remains questionable, since no data on true incidence of patients with combined LM and PC are available in literature. Therefore in chapter 2 population-based incidence and prognosis of patients with combined PC and LM were described. In addition, literature was reviewed for results of treatments with curative intent.

Another underexposed topic is patients presenting with metachronous metastases. The incidence and risk factors for developing metachronous PC from colorectal cancer, as well as survival since diagnosis of PC were therefore described in chapter 3. Data on metachronous 
metastases were collected between 2010 and 2011 of patients with a non-metastasized colorectal tumor diagnosed between 2003 and 2008. It is important to characterize patients at high risk for developing metastases since with such knowledge a more effective follow-up strategy and possible treatment option may be revealed.

Apart from PC of colorectal origin which is now increasingly characterized, the majority of PC patients have PC originating from a different primary tumor. Figure 1 and 2 show the distribution of the tumor of origin, in all patients with PC diagnosed between 1995 and 2008. In males, PC was most frequently diagnosed in patients with colon cancer, gastric cancer, an unknown primary tumor and pancreatic cancer. In females, most patients presented with ovarian cancer, colon cancer, unknown primary tumor, gastric cancer and pancreatic cancer. Relatively little is known about the incidence of patients with PC from different origins, therefore the second part of this thesis characterizes PC from different origins.

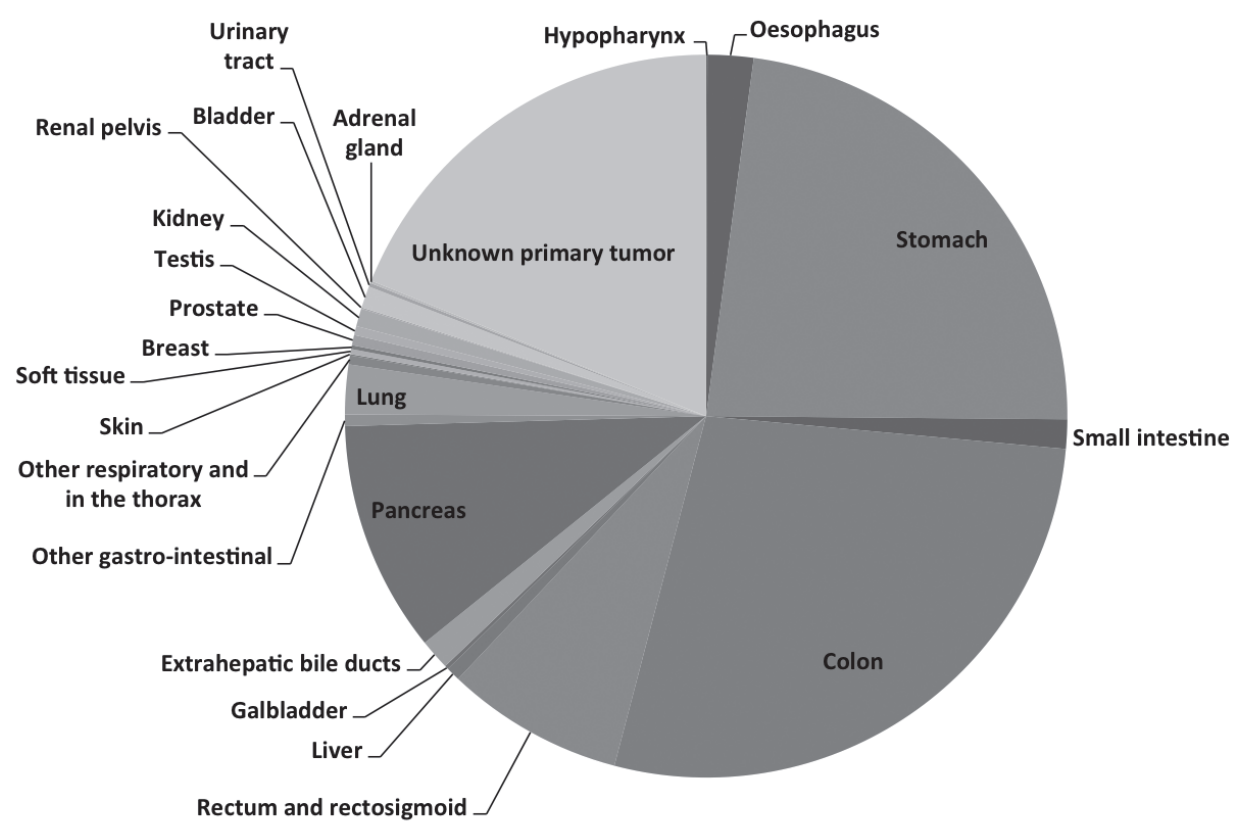

Figure 1. Proportional distribution of synchronous peritoneal carcinomatosis in males, according to localization of the primary tumor. 


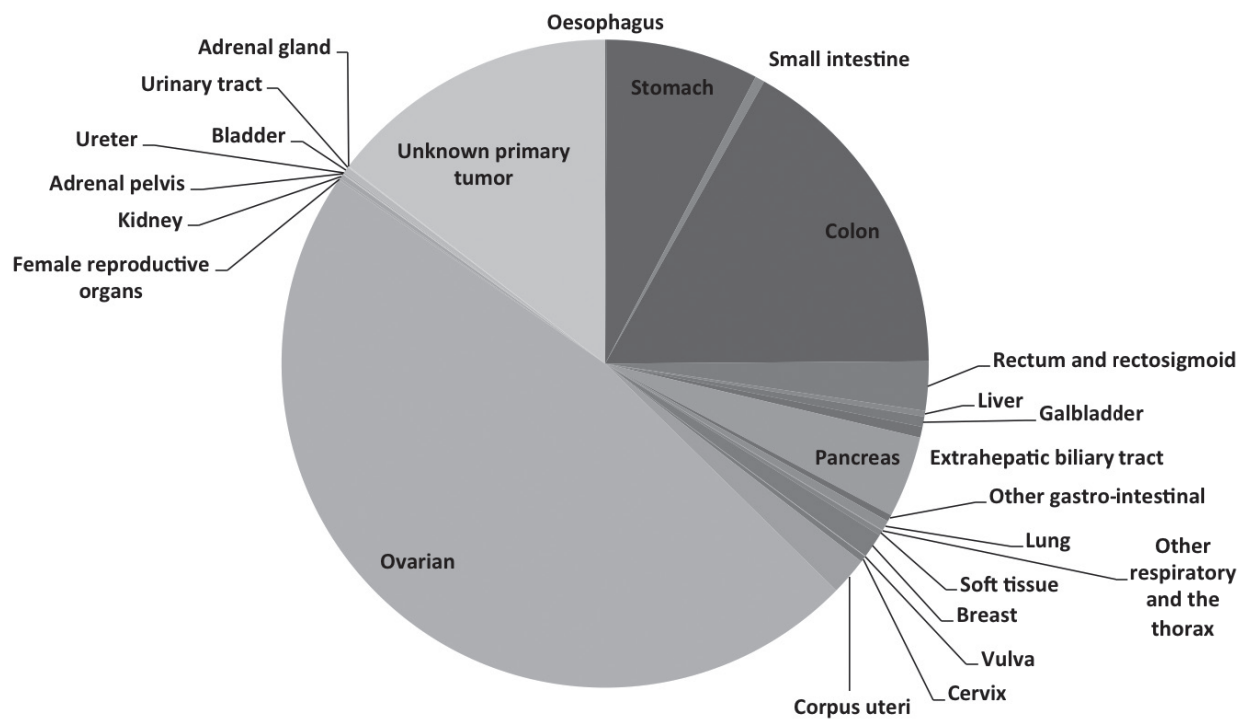

Figure 2. Proportional distribution of synchronous peritoneal carcinomatosis in females, according to localisation of the primary tumor.

Gastric cancer is known for its aggressive natural history and is the second main cause of death from cancer worldwide. ${ }^{25}$ The population-based registry of the Eindhoven Cancer Center was used to provide data on the incidence, risk-factors and survival of patients with PC of gastric origin, as described in chapter 4 . In addition, incidence, treatment, and prognosis of $\mathrm{PC}$ of pancreatic origin was described in chapter $\mathbf{5}$. The incidence of pancreatic cancer is steadily increasing in many countries around the world. ${ }^{26}$ Early signs and symptoms are often nonspecific, therefore most patients present with locally advanced disease and metastases in various organs at the time of diagnosis. ${ }^{27,}{ }^{28}$ To analyze this group of patients, all patients with non-endocrine pancreatic cancer diagnosed between 1995 and 2009 in the area of the Eindhoven Cancer Registry were analyzed. This same analysis was performed for patients with unknown primary tumors (UPT) as described in chapter 6. UPT is the third most common primary tumor in patients with PC. In contrast to other types of cancer, these patients present with PC after which the primary tumor has to identified. The primary tumor can remain unidentified despite extensive diagnostic testing or because some patients cannot undergo these tests because of a bad clinical condition. Characterization of these patients is very important since treatment of PC focuses on the origin of the primary tumor. 
In chapters 4, a strong increase in the administration of systemic chemotherapy in more recent years was shown in patients with PC of gastric origin. This is probably explained for by the growing experience with combination chemotherapy in the treatment of advanced gastric cancer, since the REAL-2 and the MAGIC-trial in 2005 and 2006. ${ }^{29,30}$ However, failure of chemotherapy was highest in patients with PC, and ascites showed to be a significant predictor for worse survival. ${ }^{31-33}$ Furthermore, chemotherapy has shown to have only a $15 \%$ response rate in patients with PC, compared to a response rate of $43 \%$ in patients with other types of advanced gastric cancer. ${ }^{34}$ Since population-based data on treatment with chemotherapy, of specific patients with PC, are lacking, trends in chemotherapeutic treatment in patients with PC of gastric origin were described in chapter 7. 


\section{References}

1. Lemmens VE, Klaver YL, Verwaal VJ, Rutten HJ, Coebergh JW, de Hingh IH. Predictors and survival of synchronous peritoneal carcinomatosis of colorectal origin: a population-based study. International journal of cancer Journal international du cancer. 2011; 128(11): 2717-25.

2. Ceelen WP, Bracke ME. Peritoneal minimal residual disease in colorectal cancer: mechanisms, prevention, and treatment. Lancet Oncol. 2009; 10(1): 72-9.

3. Kusamura S, Baratti D, Zaffaroni N, Villa R, Laterza B, Balestra MR, et al. Pathophysiology and biology of peritoneal carcinomatosis. World journal of gastrointestinal oncology. 2010; 2(1): 12-8.

4. Gerber SA, Rybalko VY, Bigelow CE, Lugade AA, Foster TH, Frelinger JG, et al. Preferential attachment of peritoneal tumor metastases to omental immune aggregates and possible role of a unique vascular microenvironment in metastatic survival and growth. The American journal of pathology. 2006; 169(5): 1739-52.

5. Meyers MA. Distribution of intra-abdominal malignant seeding: dependency on dynamics of flow of ascitic fluid. The American journal of roentgenology, radium therapy, and nuclear medicine. 1973; 119(1): 198-206.

6. Tamsma J. The pathogenesis of malignant ascites. Cancer Treat Res. 2007; 134: 109-18.

7. Klaver YL, Lemmens VE, Nienhuijs SW, Luyer MD, de Hingh IH. Peritoneal carcinomatosis of colorectal origin: Incidence, prognosis and treatment options. World J Gastroenterol. 2012; 18(39): 5489-94.

8. Sugarbaker PH. Peritonectomy procedures. Ann Surg. 1995; 221(1): 29-42.

9. Verwaal VJ, van Ruth $\mathrm{S}$, de Bree E, van Sloothen GW, van Tinteren $\mathrm{H}$, Boot $\mathrm{H}$, et al. Randomized trial of cytoreduction and hyperthermic intraperitoneal chemotherapy versus systemic chemotherapy and palliative surgery in patients with peritoneal carcinomatosis of colorectal cancer. J Clin Oncol. 2003; 21(20): 3737-43.

10. Elias D, Lefevre JH, Chevalier J, Brouquet A, Marchal F, Classe JM, et al. Complete cytoreductive surgery plus intraperitoneal chemohyperthermia with oxaliplatin for peritoneal carcinomatosis of colorectal origin. J Clin Oncol. 2009; 27(5): 681-5.

11. Kecmanovic DM, Pavlov MJ, Ceranic MS, Sepetkovski AV, Kovacevic PA, Stamenkovic AB. Treatment of peritoneal carcinomatosis from colorectal cancer by cytoreductive surgery and hyperthermic perioperative intraperitoneal chemotherapy. Eur J Surg Oncol. 2005; 31(2): 147-52.

12. Pilati $P$, Mocellin S, Rossi CR, Foletto M, Campana L, Nitti D, et al. Cytoreductive surgery combined with hyperthermic intraperitoneal intraoperative chemotherapy for peritoneal carcinomatosis arising from colon adenocarcinoma. Ann Surg Oncol. 2003; 10(5): 508-13.

13. Piso $\mathrm{P}$, Dahlke $\mathrm{MH}$, Ghali N, lesalnieks I, Loss M, Popp F, et al. Multimodality treatment of peritoneal carcinomatosis from colorectal cancer: first results of a new German centre for peritoneal surface malignancies. International journal of colorectal disease. 2007; 22(11): 1295-300.

14. Schneebaum S, Arnold MW, Staubus A, Young DC, Dumond D, Martin EW, Jr. Intraperitoneal hyperthermic perfusion with mitomycin C for colorectal cancer with peritoneal metastases. Ann Surg Oncol. 1996; 3(1): 44-50.

15. Shen P, Hawksworth J, Lovato J, Loggie BW, Geisinger KR, Fleming RA, et al. Cytoreductive surgery and intraperitoneal hyperthermic chemotherapy with mitomycin $C$ for peritoneal carcinomatosis from nonappendiceal colorectal carcinoma. Annals of surgical oncology. 2004; 11(2): 178-86.

16. Klaver YL, Lemmens VE, de Hingh IH. Outcome of surgery for colorectal cancer in the presence of peritoneal carcinomatosis. Eur J Surg Oncol. 2013.

17. Koh JL, Yan TD, Glenn D, Morris DL. Evaluation of preoperative computed tomography in estimating peritoneal cancer index in colorectal peritoneal carcinomatosis. Ann Surg Oncol. 2009; 16(2): 327-33.

18. de Bree E, Koops W, Kroger R, van Ruth S, Witkamp AJ, Zoetmulder FA. Peritoneal carcinomatosis from colorectal or appendiceal origin: correlation of preoperative CT with intraoperative findings and evaluation of interobserver agreement. J Surg Oncol. 2004; 86(2): 64-73.

19. Huebner RH, Park KC, Shepherd JE, Schwimmer J, Czernin J, Phelps ME, et al. A meta-analysis of the literature for whole-body FDG PET detection of recurrent colorectal cancer. J Nucl Med. 2000; 41(7): 1177-89. 
20. Segelman J, Granath F, Holm T, Machado M, Mahteme H, Martling A. Incidence, prevalence and risk factors for peritoneal carcinomatosis from colorectal cancer. Br J Surg. 2012; 99(5): 699-705.

21. Klaver YL, Lemmens VE, Creemers GJ, Rutten HJ, Nienhuijs SW, de Hingh IH. Population-based survival of patients with peritoneal carcinomatosis from colorectal origin in the era of increasing use of palliative chemotherapy. Ann Oncol. 2011; 22(10): 2250-6.

22. Jayne DG, Fook S, Loi C, Seow-Choen F. Peritoneal carcinomatosis from colorectal cancer. Br J Surg. 2002; 89(12): 1545-50.

23. Chu DZ, Lang NP, Thompson C, Osteen PK, Westbrook KC. Peritoneal carcinomatosis in nongynecologic malignancy. A prospective study of prognostic factors. Cancer. 1989; 63(2): 364-7.

24. Kohne $\mathrm{CH}$, Cunningham D, Di Costanzo F, Glimelius B, Blijham G, Aranda E, et al. Clinical determinants of survival in patients with 5-fluorouracil-based treatment for metastatic colorectal cancer: results of a multivariate analysis of 3825 patients. Ann Oncol. 2002; 13(2): 308-17.

25. Crew KD, Neugut Al. Epidemiology of gastric cancer. World J Gastroenterol. 2006; 12(3): 354-62.

26. Clark CJ, Traverso LW. Positive peritoneal lavage cytology is a predictor of worse survival in locally advanced pancreatic cancer. Am J Surg. 2010; 199(5): 657-62.

27. Seelig SK, Burkert B, Chromik AM, Tannapfel A, UhI W, Seelig MH. Pancreatic resections for advanced M1-pancreatic carcinoma: the value of synchronous metastasectomy. HPB Surg. 2010; 2010: 579672.

28. Blastik M, Plavecz E, Zalatnai A. Pancreatic carcinomas in a 60-year, institute-based autopsy material with special emphasis of metastatic pattern. Pancreas. 2011; 40(3): 478-80.

29. Chong G, Cunningham D. Can cisplatin and infused 5-fluorouracil be replaced by oxaliplatin and capecitabine in the treatment of advanced oesophagogastric cancer? The REAL 2 trial. Clinical oncology (Royal College of Radiologists (Great Britain)). 2005; 17(2): 79-80.

30. Cunningham D, Allum WH, Stenning SP, Thompson JN, Van de Velde CJ, Nicolson M, et al. Perioperative chemotherapy versus surgery alone for resectable gastroesophageal cancer. N Engl J Med. 2006; 355(1): 11-20.

31. Yonemura $Y$, Elnemr A, Endou $Y$, Ishibashi $H$, Mizumoto A, Miura M, et al. Effects of neoadjuvant intraperitoneal/systemic chemotherapy (bidirectional chemotherapy) for the treatment of patients with peritoneal metastasis from gastric cancer. International journal of surgical oncology. 2012; 2012: 148420.

32. Lu Z, Lu M, Zhang X, Li J, Zhou J, Gong J, et al. Advanced or metastatic gastric cancer in elderly patients: clinicopathological, prognostic factors and treatments. Clin Transl Oncol. 2012.

33. Ajani JA, Ota DM, Jessup JM, Ames FC, McBride C, Boddie A, et al. Resectable gastric carcinoma. An evaluation of preoperative and postoperative chemotherapy. Cancer. 1991; 68(7): 1501-6.

34. Ross $P$, Nicolson $M$, Cunningham $D$, Valle J, Seymour $M$, Harper $P$, et al. Prospective randomized trial comparing mitomycin, cisplatin, and protracted venous-infusion fluorouracil (PVI 5-FU) With epirubicin, cisplatin, and PVI 5-FU in advanced esophagogastric cancer. J Clin Oncol. 2002; 20(8): 1996-2004. 


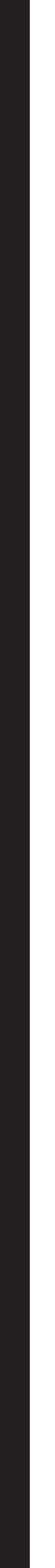




\section{Chapter 1}

Peritoneal carcinomatosis is less frequently diagnosed during laparoscopic surgery compared to open surgery in patients with colorectal cancer

Irene Thomassen, Yvette RBM van Gestel, Arend GJ Aalbers, Thijs R van Oudheusden, Johannes $\frac{04}{6}$ V. egdam, Valery EPP Lemmens, Ignace HJT de Hingh.

Eur J Surg Oncol. 2014 May;40(5):511-4

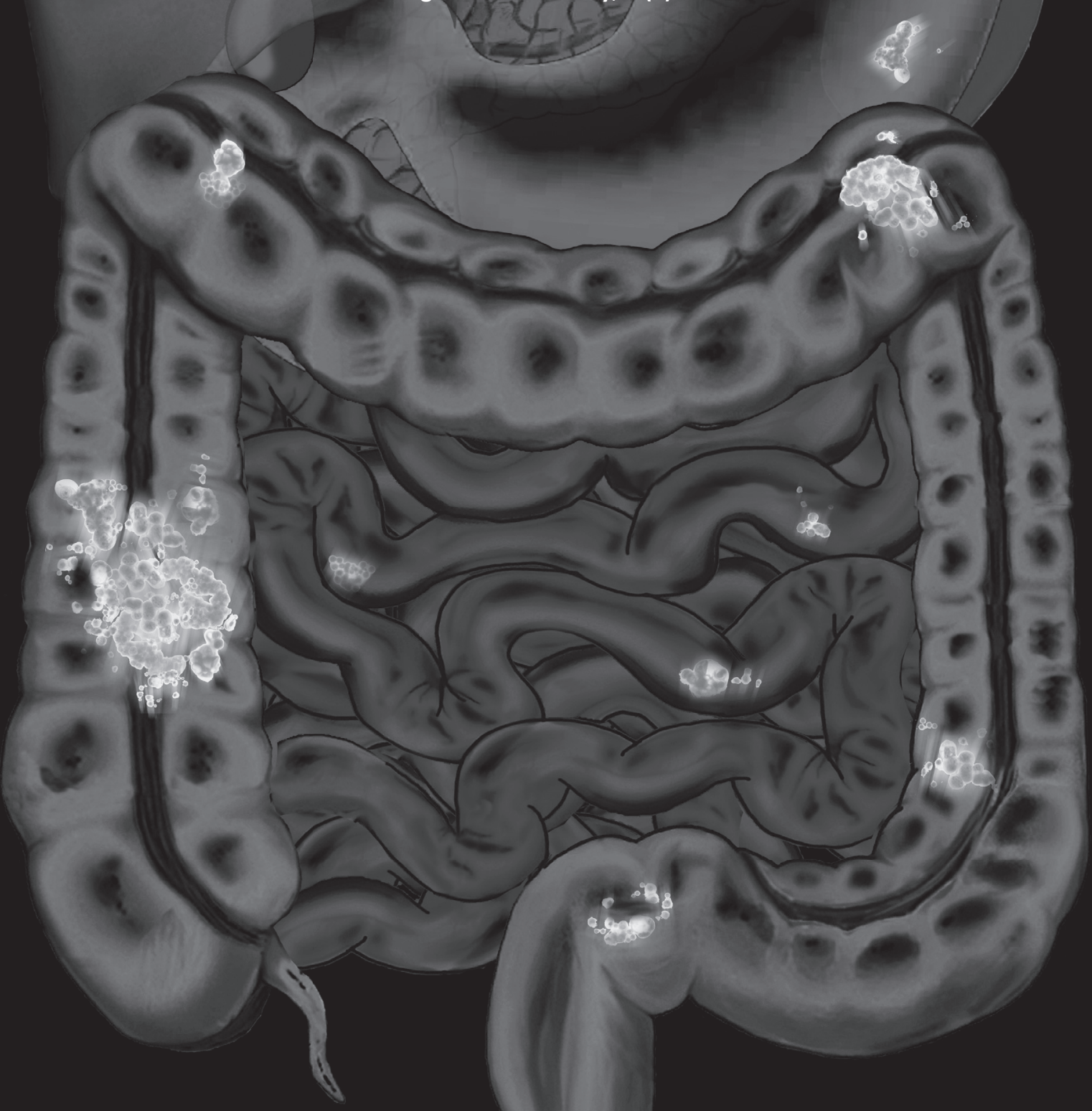





\section{Abstract}

\section{Background}

During resection of a colorectal tumor a careful inspection of the abdomen should be performed to detect metastases. The aim of the current study was to compare the proportions of patients diagnosed with peritoneal carcinomatosis (PC) during laparoscopic resection (LR) and open resection (OR).

\section{Methods}

All patients who underwent resection for colorectal cancer in the Eindhoven Cancer Registry area between 2008 and 2012 were included. Proportions of patients with PC were compared between surgical techniques. Multivariate logistic regression analysis was performed.

\section{Results}

6687 Patients underwent resection for colorectal cancer, of whom 1631 patients (24\%) underwent LR, 4665 patients (70\%) underwent OR. Conversion took place in 391 patients (19\% of laparoscopic treated patients). PC was diagnosed in $1.4 \%$ of patients undergoing LR, in $5.0 \%$ of patients undergoing OR, and in $3.3 \%$ of patients in whom LR was converted to OR ( $p<0.001$ ). After adjustment for patient and tumor characteristics (e.g., T- and N-stage), patients who were treated by LR had a lower chance to be diagnosed with PC during surgery than patients undergoing OR (odds ratio $=0.42, p<0.001$ ).

\section{Conclusions}

Patients undergoing surgery for colorectal cancer are less frequently diagnosed with PC during LR in comparison to OR. Since effective treatment is currently available for selected patients with PC, a thorough inspection of the peritoneum during surgery is of paramount importance to offer these patients a chance for long-term survival and even cure. 


\section{Introduction}

During colorectal cancer surgery, a systematic inspection of the abdominal cavity should be performed prior to resection of the tumor, in order to screen for previously undetected synchronous metastatic disease such as small liver metastases or peritoneal carcinomatosis (PC). Timely detection of PC is of increasing importance with new treatment strategies now offering a chance of long-time survival or even cure in selected patients with PC, especially in early stages. ${ }^{1-5}$

Recently, laparoscopic colorectal cancer surgery was successfully and safely introduced in the hospitals of the Netherlands. ${ }^{6}$ Indeed, laparoscopic resection (LR) was associated with a lower risk of mortality, major morbidity, complications, prolonged hospital stay and irradical resection as compared to open resections (OR). However, no data were given on intra-operative findings with regard to synchronous metastases.

PC typically consists of small lesions of tumor attached to sites that may be difficult to visualize during surgery, such as the right diaphragm behind the liver and the Douglas pouch. Other preferred sites include the omentum, the mesentery and falciform ligament. ${ }^{7}$

Currently, it is unknown whether the type of surgical approach has an influence on the proportion of patients being diagnosed with synchronous PC. Therefore, the aim of the current study was to investigate whether the surgical approach (LR vs OR) affected the detection of PC.

\section{Methods}

The Eindhoven Cancer Registry registers all newly diagnosed cancer patients in the southern part of the Netherlands. This area includes 10 community hospitals, 6 pathology departments and 2 radiotherapy institutions, comprising 2.4 million inhabitants. Since the Eindhoven Cancer Registry collects data on laparoscopic surgery since 2008 , the study included colorectal cancer patients diagnosed between 2008 and 2012. Patients who were diagnosed with PC prior to surgery were excluded. All patients underwent LR, OR or surgery initiated as LR converted to OR. Information on patient and tumor characteristics was routinely extracted from the medical records by specially trained administrators of the cancer registry. By means of an independent case ascertainment method, the completeness of the registration is estimated to exceed $95 \% .{ }^{8}$ In case of unknown $\mathrm{pN}, \mathrm{cN}$ was used and in case of unknown (y) pT, cT was used for analyses. The decision to perform OR or LR was highly dependent on hospital and surgeon and was mainly based on a history of abdominal surgery and extent of the tumor. Reasons for conversion included adhesions, ingrowth of the tumor into other organs or abdominal wall and in one patient surgery was converted due to bleeding. Urgency of the surgery was only registered for colonic and rectosigmoid cancer patients and not for patients with rectal cancer since emergency procedures are relatively rare in these patients. If the resection was planned less then 12 hours before the start of the operation it was classified as "acute". 


\section{Statistical analysis}

Differences in proportions treated by LR and OR were compared using a Chi-square test. Logistic regression analysis, correcting for age, comorbidity, socioeconomic status, T-stage, $\mathrm{N}$-stage and differentiation grade of tumor was used to calculate odds ratios and their $95 \%$ confidence intervals (Cls) for the diagnosis of PC. A subanalysis was performed including these patients to adjust for type of surgery by adding this variable to the logistic regression model. All tests of statistical significance were two sided. SAS/STAT statistical software (SAS system 9.3, SAS Institute, Cary, NC) was used for all analyses.

\section{Results}

Between 2008 and 20126687 patients underwent surgery for colorectal cancer. LR was performed in 1631 patients (24\%) and 4665 patients (70\%) underwent OR. In 391 patients (19\% of laparoscopically treated patients) the surgical approach was converted from LR to OR. Patient characteristics are shown in table 1, showing differences between surgical methods in age, gender, number of comorbid conditions, acute or planned surgery, T-stage and N-stage $(p<0.05)$.

During open surgery, $5.0 \%$ of the patients were diagnosed with PC as compared to $1.4 \%$ of the patients undergoing LR ( $p<0.001$, table 2 ). PC was diagnosed in $3.3 \%$ of the patients in whom the laparoscopic procedure was converted to open surgery. PC was diagnosed more frequent in patients undergoing conversion compared to patients undergoing $L R(p=0.010)$.

After adjusting for sex, age, the presence of co-morbidity, socioeconomic status, T-stage, $\mathrm{N}$-stage, tumor differentiation grade, and tumor localization (colon vs rectum), patients undergoing LR had a significant lower chance to be diagnosed with PC compared to patients undergoing open surgery (odds ratio $0.42,95 \% \mathrm{Cl} 0.26-0.67$, table 3 ). After adjusting for acute surgery the odds ratio for the diagnosis of $\mathrm{PC}$ was 0.45 ( $95 \% \mathrm{Cl} 0.27-0.74$ ) in patients treated with $\mathrm{LR}$, and 0.69 (95\% $\mathrm{Cl} 0.36-1.31$ ) in patients with converted $\mathrm{LR}$, both compared to $\mathrm{OR}$. 
Table 1. General characteristics of patients undergoing resection for colorectal cancer between 2008 and 2012 in the South of the Netherlands.

\begin{tabular}{|c|c|c|c|c|c|c|c|}
\hline & \multicolumn{2}{|c|}{$\begin{array}{c}\text { Open } \\
\text { resection } \\
(n=4665)\end{array}$} & \multicolumn{2}{|c|}{$\begin{array}{l}\text { Laparoscopic } \\
\text { resection } \\
(n=1631)\end{array}$} & \multicolumn{2}{|c|}{$\begin{array}{c}\text { Conversion } \\
(n=391)\end{array}$} & \multirow[b]{2}{*}{ p-value } \\
\hline & $\mathbf{N}$ & (\%) & $\mathbf{N}$ & (\%) & $\mathbf{N}$ & (\%) & \\
\hline Age (yrs) & & & & & & & $<.001$ \\
\hline$<60$ & 801 & 17 & 336 & 21 & 61 & 16 & \\
\hline $60-69$ & 1298 & 28 & 468 & 29 & 107 & 27 & \\
\hline 70-79 & 1669 & 36 & 582 & 36 & 140 & 36 & \\
\hline$>80$ & 897 & 19 & 245 & 15 & 83 & 21 & \\
\hline Gender & & & & & & & .036 \\
\hline Male & 2573 & 55 & 907 & 56 & 242 & 62 & \\
\hline Female & 2092 & 45 & 724 & 44 & 149 & 38 & \\
\hline Number of comorbid conditions & & & & & & & .017 \\
\hline 0 & 1323 & 28 & 529 & 32 & 96 & 25 & \\
\hline 1 & 1301 & 28 & 440 & 27 & 111 & 28 & \\
\hline$\geq 2$ & 1967 & 42 & 643 & 39 & 178 & 46 & \\
\hline Unknown & 74 & 2 & 19 & 1 & 6 & 2 & \\
\hline Type of surgery* & & & & & & & $<.001$ \\
\hline Acute & 393 & 12 & 20 & 2 & 11 & 4 & \\
\hline Planned & 2989 & 88 & 1152 & 98 & 272 & 96 & \\
\hline T stage of primary tumor & & & & & & & $<.001$ \\
\hline $\mathrm{T} 1$ & 251 & 5 & 165 & 10 & 28 & 7 & \\
\hline $\mathrm{T} 2$ & 895 & 19 & 385 & 24 & 72 & 18 & \\
\hline T3 & 2752 & 59 & 955 & 59 & 226 & 58 & \\
\hline $\mathrm{T} 4$ & 709 & 15 & 102 & 6 & 63 & 16 & \\
\hline $\mathrm{Tx}$ & 58 & 1 & 24 & 1 & 2 & 1 & \\
\hline $\mathrm{N}$ stage of primary tumor & & & & & & & $<.001$ \\
\hline No & 2051 & 44 & 909 & 56 & 195 & 50 & \\
\hline $\mathrm{N} 1$ & 773 & 17 & 273 & 17 & 75 & 19 & \\
\hline$\geq \mathrm{N} 2$ & 207 & 4 & 67 & 4 & 14 & 4 & \\
\hline $\mathrm{Nx}$ & 1634 & 35 & 382 & 23 & 107 & 27 & \\
\hline Localization of primary tumor & & & & & & & .566 \\
\hline Colon & 3318 & 71 & 1139 & 70 & 273 & 70 & \\
\hline Rectum & 1347 & 29 & 492 & 30 & 118 & 30 & \\
\hline
\end{tabular}

*Only available in colon and rectosigmoid patients 
Table 2. Type of surgical procedure and number and proportion of patients in whom PC was diagnosed during surgery according to T-stage.

\begin{tabular}{|c|c|c|c|c|c|c|}
\hline & \multicolumn{2}{|c|}{$\begin{array}{c}P C \\
n=267\end{array}$} & \multicolumn{2}{|c|}{$\begin{array}{c}\text { No PC } \\
n=6420\end{array}$} & \multirow{2}{*}{$\begin{array}{c}\begin{array}{c}\text { Total } \\
n=6687\end{array} \\
n\end{array}$} & \multirow[t]{2}{*}{ p-value } \\
\hline & $\mathbf{n}$ & $\%$ & $\mathrm{n}$ & $\%$ & & \\
\hline T1-2 & & & & & & 0.35 \\
\hline Open resection & 5 & 0.4 & 1141 & 99.6 & 1146 & \\
\hline Laparoscopic resection & 5 & 0.9 & 545 & 99.1 & 550 & \\
\hline Converted laparoscopy & 0 & 0 & 100 & 100 & 100 & \\
\hline T3 & & & & & & $<0.001$ \\
\hline Open resection & 72 & 2.6 & 2680 & 97.4 & 2752 & \\
\hline Laparoscopic resection & 6 & 0.6 & 949 & 99.4 & 955 & \\
\hline Converted laparoscopy & 3 & 1.3 & 223 & 98.7 & 226 & \\
\hline T4 & & & & & & 0.13 \\
\hline Open resection & 126 & 17.8 & 583 & 82.2 & 709 & \\
\hline Laparoscopic resection & 10 & 9.8 & 92 & 90.2 & 102 & \\
\hline Converted laparoscopy & 10 & 15.9 & 53 & 84.1 & 63 & \\
\hline TX & & & & & & $<0.001$ \\
\hline Open resection & 28 & 48.3 & 30 & 51.7 & 58 & \\
\hline Laparoscopic resection & 2 & 8.3 & 22 & 91.7 & 24 & \\
\hline Converted laparoscopy & $\mathrm{o}$ & 0 & 2 & 100 & 2 & \\
\hline
\end{tabular}

PC: peritoneal carcinomatosis

Table 3. The chance to be diagnosed with PC according to type of colorectal surgery.

\begin{tabular}{lcccc}
\hline & $\begin{array}{c}\text { Odds ratio } \\
(\mathbf{n}=6688)\end{array}$ & $\mathbf{9 5 \%} \mathrm{Cl}$ & $\begin{array}{c}\text { Odds ratio* } \\
(\mathbf{n}=5038)\end{array}$ & $\mathbf{9 5 \% \mathrm { Cl } ^ { * }}$ \\
\hline Open procedure & 1.0 & & 1.0 & \\
Laparoscopy & 0.42 & $0.26-0.67$ & 0.45 & $0.27-0.74$ \\
Conversion & 0.65 & $0.35-1.20$ & 0.69 & $0.36-1.31$ \\
\hline
\end{tabular}

Adjusted for gender, age, comorbidity, socioeconomic status, T-stage, N-stage, location and differentiation grade of tumor

* Also adjusted for acute or planned surgery

$\mathrm{Cl}$ : confidence interval 


\section{Discussion}

This study shows that PC is less frequently diagnosed during laparoscopic surgery as compared to open surgery for colorectal cancer. In patients presenting with colorectal cancer, preoperative imaging by computed tomography (CT) is performed prior to surgery to characterize the primary tumor and to screen for synchronous metastases. The sensitivity of $\mathrm{CT}$ is high for lesions greater than $1 \mathrm{~cm}$, but decreases to $10-30 \%$ for lesions smaller than $1 \mathrm{~cm}$, being the typical size of tumor nodules in PC..$^{9-11}$ Similarly, Positron Emission Tomography (PET) has been shown to be of value in detecting metastases but not for small lesions. ${ }^{12}$ Therefore, inspection of the abdominal cavity during surgery is of utmost importance to detect metastases. This staging procedure should be performed precisely as small liver metastases can easily be missed. Also, PC typically consists of very small tumor nodules often located on parts of the peritoneum that are difficult to visualize. Indeed, recent data showed that no less than $77 \%$ of the patients with PC were diagnosed unexpectedly during surgery. ${ }^{9}$ The exposure of the peritoneal cavity is different in LR and OR, including the loss of tactile information in LR which facilitates a quick and easy way to manually explore the entire abdomen for PC in OR. This may partially explain the results of the current study in which a markedly lower proportion of LR patients was diagnosed with PC as compared to OR patients.

To date, specific data on the proportion of colorectal cancer patients diagnosed with PC in relation to different surgical approaches are lacking. Few studies have previously investigated proportions of metastases diagnosed during $L R$ and $O R$, however these studies did not focus on PC and were presented in early years of laparoscopic experience. In accordance with our findings, the COLOR-trial, which investigated long-term survival after laparoscopic surgery versus open surgery for colon cancer, reported that $2.8 \%$ of the patients undergoing LR and $5.2 \%$ of the patients undergoing OR were diagnosed with metastases during surgery. ${ }^{13}$ Also Lacy et al. ${ }^{14}$ reported a lower incidence of intra-operative diagnosis of metastases in LR (4.5\%) as compared to OR (5.6\%). Finally, the Clinical Outcomes of Surgical Therapy Study group reported $3.7 \%$ stage IV disease in the open group as compared to $2.2 \%$ in the laparoscopic group. ${ }^{15}$

One might argue that the current finding may be caused by patient selection, rather than by operation technique. Indeed, more patients in the OR-group were diagnosed with a T4 tumor which is a known risk factor for the development of PC. ${ }^{16}$ Therefore, a logistic regression analysis was performed correcting for known risk factors, including T-stage, N-stage and acute or planned resection. After adjusting for these factors a statistically significant and clinically relevant lower chance remained to be diagnosed with PC during LR compared to OR (OR 0.45). Another bias may have been the detection of peritoneal disease on preoperative imaging. Although there is no real rationale to do so, it may be postulated that such finding may deter a surgeon from performing a laparoscopic approach, hence resulting in more $P C$ in the OR group. To rule out this potential source of bias, all patients in whom PC was diagnosed prior to surgery were excluded from this study. 
To date, this is the first population-based study to show that the chance to detect synchronous PC is depends on the surgical approach. The early identification of PC is of increasing importance since recently treatment options for $\mathrm{PC}$ have become available. Whereas palliative chemotherapy has disappointing results in these patients, ${ }^{17-21}$ the recent introduction of complete cytoreductive surgery (CRS) combined with intraperitoneal chemotherapy (IPC) has shown promising results including long-term survivors. ${ }^{1-3}$ Strict selection of patients is crucial to achieve favorable results, and selection criteria typically include age, general condition of the patient and especially the ability to radically resect all macroscopic visible peritoneal metastases. Therefore early detection, while patients still have limited PC, seems of utmost importance to offer these patients the best chance for treatment.

We presume that in principle, PC can be diagnosed equally effective in open or laparoscopic surgery. In fact, laparoscopy may be even superior to detect PC in hard to visualize predilection sites of PC such as the right diaphragm behind the liver and the Douglas pouch. However, tactile information facilitating a quick and relatively easy way to screen these sites is lacking in laparoscopic surgery. The results of the current study should raise awareness for this phenomenon and stress the need for a systemic evaluation of the peritoneal cavity prior to tumor resection regardless of the surgical approach.

In conclusion, laparoscopic surgery for colorectal cancer has been successfully introduced in clinical practice with regard to operation safety and short-term outcome parameters. However, the results of the current study showed that PC is currently less frequently diagnosed during LR compared to OR in patients during surgery for colorectal cancer. Given the possibility to treat these patients with curative intent if diagnosed at an early stage, an extensive and thorough inspection of the peritoneal cavity during surgery for colorectal cancer should be performed in all occasions. With increased awareness, such inspection may be equally effective to detect PC regardless of an open or laparoscopic approach. 


\section{References}

1. Elias D, Lefevre JH, Chevalier J, Brouquet A, Marchal F, Classe JM, et al. Complete cytoreductive surgery plus intraperitoneal chemohyperthermia with oxaliplatin for peritoneal carcinomatosis of colorectal origin. J Clin Oncol. 2009; 10;27:681-5.

2. Verwaal VJ, van Ruth S, Witkamp A, Boot H, van Slooten G, Zoetmulder FA. Long-term survival of peritoneal carcinomatosis of colorectal origin. Annals of surgical oncology. 2005;12:65-71.

3. Shen $P$, Thai $K$, Stewart JH, Howerton R, Loggie BW, Russell GB, et al. Peritoneal surface disease from colorectal cancer: comparison with the hepatic metastases surgical paradigm in optimally resected patients. Ann Surg Oncol. 2008 ; 15:3422-32.

4. Klaver YL, Lemmens VE, Nienhuijs SW, Luyer MD, de Hingh IH. Peritoneal carcinomatosis of colorectal origin: Incidence, prognosis and treatment options. World J Gastroenterol. 2012 21;18:5489-94.

5. Goere D, Malka D, Tzanis D, Gava V, Boige V, Eveno C, et al. Is there a possibility of a cure in patients with colorectal peritoneal carcinomatosis amenable to complete cytoreductive surgery and intraperitoneal chemotherapy? Annals of surgery. 2013;257:1065-71.

6. Kolfschoten NE, van Leersum NJ, Gooiker GA, Marang van de Mheen PJ, Eddes EH, Kievit J, et al. Successful and Safe Introduction of Laparoscopic Colorectal Cancer Surgery in Dutch hospitals. Annals of surgery. 2013;257:916-21

7. Kusamura S, Baratti D, Zaffaroni N, Villa R, Laterza B, Balestra MR, et al. Pathophysiology and biology of peritoneal carcinomatosis. World journal of gastrointestinal oncology. 2010;2:12-8.

8. Schouten LJ, Hoppener P, van den Brandt PA, Knottnerus JA, Jager JJ. Completeness of cancer registration in Limburg, The Netherlands. International journal of epidemiology. 1993;22:369-76.

9. Klaver Y, Lemmens V, Hingh de I. Outcome of surgery for colorectal cancer in the presence of peritoneal carcinomatosis. Eur J Surg Oncol. 2013;39:734-4

10. Koh JL, Yan TD, Glenn D, Morris DL. Evaluation of preoperative computed tomography in estimating peritoneal cancer index in colorectal peritoneal carcinomatosis. Ann Surg Oncol. 2009;16:327-33.

11. de Bree E, Koops W, Kroger R, van Ruth S, Witkamp AJ, Zoetmulder FA. Peritoneal carcinomatosis from colorectal or appendiceal origin: correlation of preoperative CT with intraoperative findings and evaluation of interobserver agreement. J Surg Oncol. 2004 1;86:64-73.

12. Huebner RH, Park KC, Shepherd JE, Schwimmer J, Czernin J, Phelps ME, et al. A meta-analysis of the literature for whole-body FDG PET detection of recurrent colorectal cancer. J Nucl Med. 2000;41:117789.

13. Buunen M, Veldkamp R, Hop WC, Kuhry E, Jeekel J, Haglind E, et al. Survival after laparoscopic surgery versus open surgery for colon cancer: long-term outcome of a randomised clinical trial. Lancet Oncol. 2009;10:44-52.

14. Lacy AM, Garcia-Valdecasas JC, Delgado S, Castells A, Taura P, Pique JM, et al. Laparoscopy-assisted colectomy versus open colectomy for treatment of non-metastatic colon cancer: a randomised trial. Lancet. 2002 29;359:2224-9.

15. A comparison of laparoscopically assisted and open colectomy for colon cancer. The New England journal of medicine. 2004 13;350:2050-9.

16. Lemmens VE, Klaver YL, Verwaal VJ, Rutten HJ, Coebergh JW, de Hingh IH. Predictors and survival of synchronous peritoneal carcinomatosis of colorectal origin: A population-based study. Int J Cancer. 2011;128:2717-25.

17. Bloemendaal AL, Verwaal VJ, van Ruth $\mathrm{S}$, Boot $\mathrm{H}$, Zoetmulder FA. Conventional surgery and systemic chemotherapy for peritoneal carcinomatosis of colorectal origin: a prospective study. Eur J Surg Oncol. 2005;31:1145-51.

18. Chu DZ, Lang NP, Thompson C, Osteen PK, Westbrook KC. Peritoneal carcinomatosis in nongynecologic malignancy. A prospective study of prognostic factors. Cancer. [Research Support, Non-U.S. Gov't]. 1989;63:364-7.

19. Sadeghi B, Arvieux C, Glehen O, Beaujard AC, Rivoire M, Baulieux J, et al. Peritoneal carcinomatosis from non-gynecologic malignancies: results of the EVOCAPE 1 multicentric prospective study. Cancer. [Multicenter Study Research Support, Non-U.S. Gov't]. 2000;88:358-63. 
20. Jayne DG, Fook S, Loi C, Seow-Choen F. Peritoneal carcinomatosis from colorectal cancer. Br J Surg. 2002;89:1545-50.

21. Klaver YL, Lemmens VE, Creemers GJ, Rutten HJ, Nienhuijs SW, de Hingh IH. Population-based survival of patients with peritoneal carcinomatosis from colorectal origin in the era of increasing use of palliative chemotherapy. Ann Oncol. 2011;22:2250-6. 


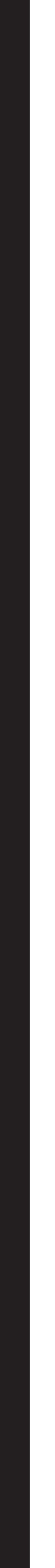




\section{Chapter 2}

Incidence, prognosis and treatment options for patients with synchronous peritoneal carcinomatosis and liver metastases from colorectal origin

Irene Thomassen, Yyette RBM van Gestel, Valery EPP Lemmens, Ignace HJT de Hingh.

Dis Colon Rectum. 2013 Dec;56(12):1373-80

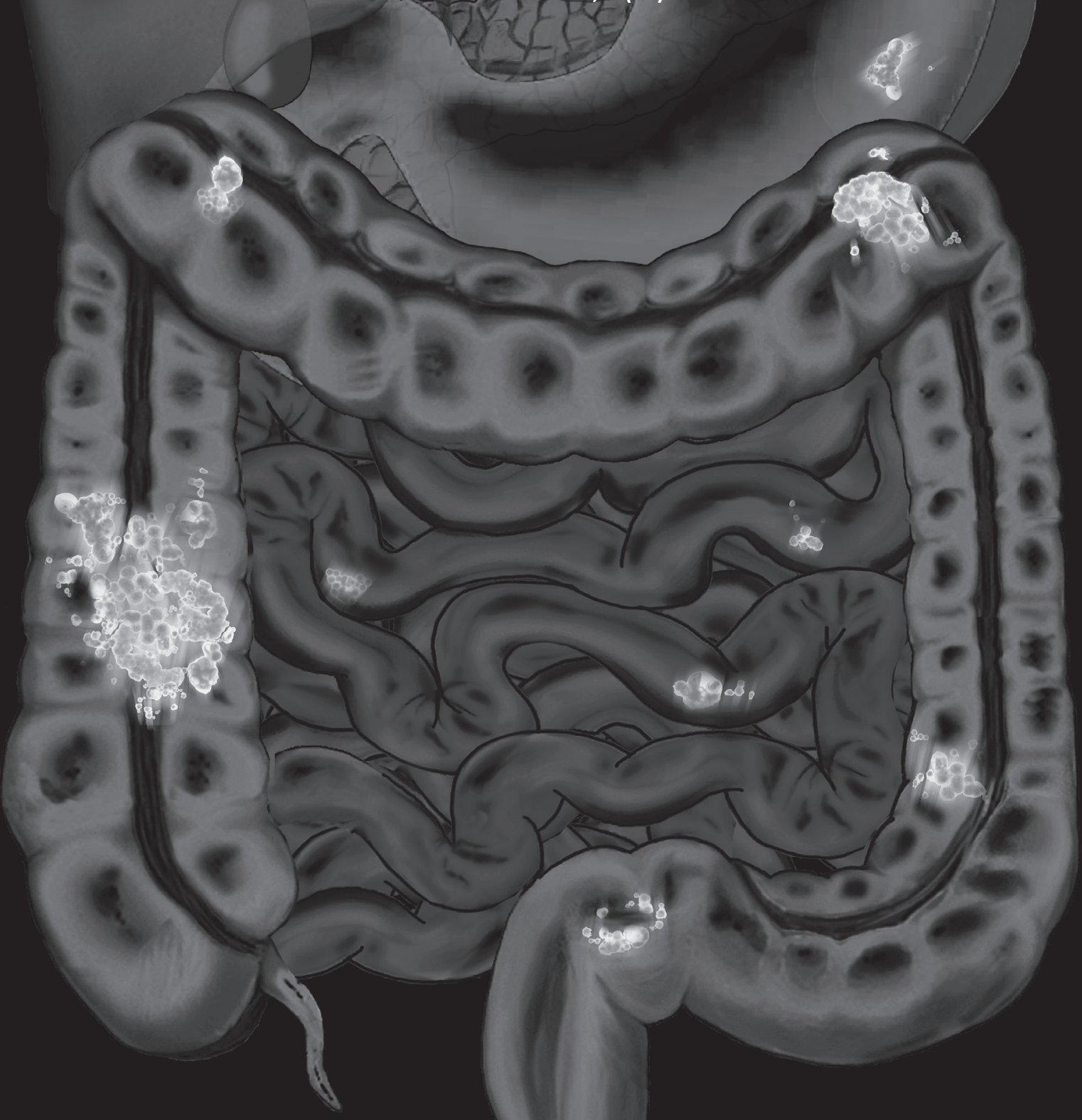





\section{Abstract}

\section{Background}

Peritoneal carcinomatosis and liver metastases are common metastatic sites in colorectal cancer patients. Quite frequently patients present with both synchronous liver and peritoneal metastases, which may result in a dilemma regarding the optimal treatment.

\section{Objective}

In the absence of reliable data, the aim of the current study was to provide population-based data on such patients and to review the literature for possible treatment options.

\section{Design}

Retrospective analysis of prospective database and review

\section{Patients}

All patients diagnosed between 1995 to 2010 with synchronous peritoneal carcinomatosis and liver metastases were identified from the Eindhoven Cancer Registry.

\section{Outcome measures}

Incidence and survival were analyzed. Next, the literature was reviewed for papers reporting on the results of treatment with curative intent.

\section{Results}

In total 27,632 patients were diagnosed with colorectal cancer, of whom 5,638 patients (20\%) presented with metastasized disease. Synchronous liver metastasis and peritoneal carcinomatosis were present in 440 patients, being $11 \%$ of patients with liver metastases, $34 \%$ of patients with peritoneal carcinomatosis, $8 \%$ of patients with metastasized disease and $2 \%$ of all patients diagnosed with colorectal cancer. Median survival for patients with liver metastasis and peritoneal carcinomatosis was 5 months, as compared to 95 months for non-metastasized patients. No improvement in survival was noted over time. None of the patients underwent treatment with curative intent during this period.

\section{Conclusions}

Both liver metastasis and peritoneal carcinomatosis were present in $8 \%$ of patients presenting with metastasized colorectal cancer. Population based survival was only 5 months, with none of the patients undergoing treatment with curative intent. Median survival rates of up to 36 months after treatment with curative intent as published in the literature may be regarded as promising for selected patients. 


\section{Introduction}

Peritoneal carcinomatosis (PC) and liver metastases (LM) are common metastatic sites in colorectal cancer patients. At the time of diagnosis, $\mathrm{PC}$ is present in almost $5 \%$ of patients and LM in $11 \%$ of patients. ' For a long time, metastasized colorectal cancer has been considered incurable and suitable for palliative chemotherapy at most. Recent advancements in surgical oncology have challenged this view. Nowadays, partial hepatectomy is widely accepted as standard of care in selected patients with colorectal LM resulting in a favorable long-term outcome. ${ }^{2,3}$ Patients with PC may now be offered a chance for long-term survival or even cure with a multi-modality treatment, combining cytoreductive surgery (CRS) with heated intraperitoneal chemotherapy (HIPEC). ${ }^{4}$ Strict selection of patients is crucial to achieve favorable results. Selection criteria typically include age and general condition of the patient and the ability to radically resect all metastatic disease. The latter usually implies that the metastatic disease is confined to only one distant organ or region. Therefore, patients with LM in whom extra-hepatic disease is diagnosed are usually not deemed suitable for a metastasectomy with curative intent. Similarly, PC-patients with metastatic disease outside the abdominal cavity are excluded from HIPEC treatment in most centers.

The combination of PC and LM may result in a dilemma in young, fit and motivated patients presenting with both resectable LM and PC. Already in 1999 Elias et al ${ }^{5}$ published that concurrent metastasectomy of the liver and HIPEC may be performed safely. However, in the absence of evidence of the efficacy of this combined treatment, most patients, outside a few expert centers, are currently offered palliative chemotherapy instead.

Currently, in the area of the Eindhoven Cancer Registry both liver surgery and HIPEC are offered to selected patients with LM or PC. Until 2010 only palliative chemotherapy was offered to patients presenting with both metastatic sites. In the absence of data on combined LM and PC, the aim of the current study was to provide population-based data on the incidence, prognosis and results of palliative treatment in these patients. Next, the literature was reviewed for results of combined treatment modalities with curative intent.

\section{Methods}

All newly diagnosed patients with colorectal cancer in the Southern part of the Netherlands are registered by the Eindhoven Cancer Registry (ECR) comprising of 2.4 million inhabitants. This area includes six pathology departments, 10 community hospitals and two radiotherapy institutions. All patients diagnosed between 1995 and 2010 with colorectal cancer in the ECR-region were included. ' Information on patient and tumor characteristics was routinely extracted from the medical records by specially trained administrators of the cancer registry. Anatomical sites of distant metastases were registered according to ICD-O (International Classification of Disease-Oncology). Distant metastases were registered at time of diagnosis only. By means of an independent case ascertainment method, the completeness of the cancer registration is estimated to exceed $95 \% .{ }^{6}$ The vital status of all patients diagnosed until December 31st, 2010 was assessed on January 1st, 2011 by merging with the Municipal 
Administrative Databases in which all deceased and emigrated persons in The Netherlands are registered.

\section{Statistical analysis}

Period of diagnosis was categorized into three groups, 1995-1999, 2000-2004, and 20052010. Differences in treatment between these periods were compared using a Chi-square test. Survival time was defined as the time from diagnosis until death; patients still alive at January 1st 2011 were censored. Crude survival of patients with LM and PC according to period of diagnosis was determined by the Kaplan-Meier method and compared using a log-rank test. A log-rank test was also used to compare survival proportion between patients who received chemotherapy and those who did not. Cox regression analysis was used to determine the relationship between chemotherapy and 2-year mortality. A hazard ratio (HR) was provided with the $95 \%$ confidence interval $(\mathrm{Cl})$. All tests of statistical significance were two sided. SAS/STAT statistical software (SAS system 9.3, SAS Institute, Cary, NC) was used for all analyses.

\section{Literature review}

To review the literature concerning the curative treatment of synchronous $L M$ and PC the Medline database, CINAHL, Embase, including e-links to related articles, and the clinical trail registry of the Cochrane Collaboration were searched. The strategy was by free text words: peritoneal carcinomatosis, liver metastasis and colorectal cancer. No language restriction was used. All references were crosschecked for literature that was not found in the database.

\section{Results}

From 1995 to 2010 a total of 27.632 patients were diagnosed with colorectal cancer in the ECR with 5.638 patients (20\%) presenting with synchronous metastatic disease. Metastasized patients presented most often with LM (74\%) or PC (23\%). In 440 patients both synchronous LM and PC were diagnosed, being $11 \%$ of all patients with $L M, 34 \%$ of patients with $P C, 8 \%$ of al patients with metastasized disease and $2 \%$ of all patients with colorectal cancer (figure 1 ).

Patient characteristics are shown in Table 1. The percentage of patients with combined LM and PC was highest in patients with the primary tumor located in the coecum or sigmoid colon. Patients with combined LM and PC had a more advanced primary tumor and lymph node stage, and more frequently a poorly/ undifferentiated differentiation grade of the primary tumor. Patients who were treated with palliative surgery were compared to patients who did not undergo surgery, also shown in table 1. A significant difference in age, period of diagnosis, localisation of primary tumor and differentiation grade of the primary tumor was shown (respectively $p=0.031, p=0.003, p=0.001$ and $p<0.001$ ). 


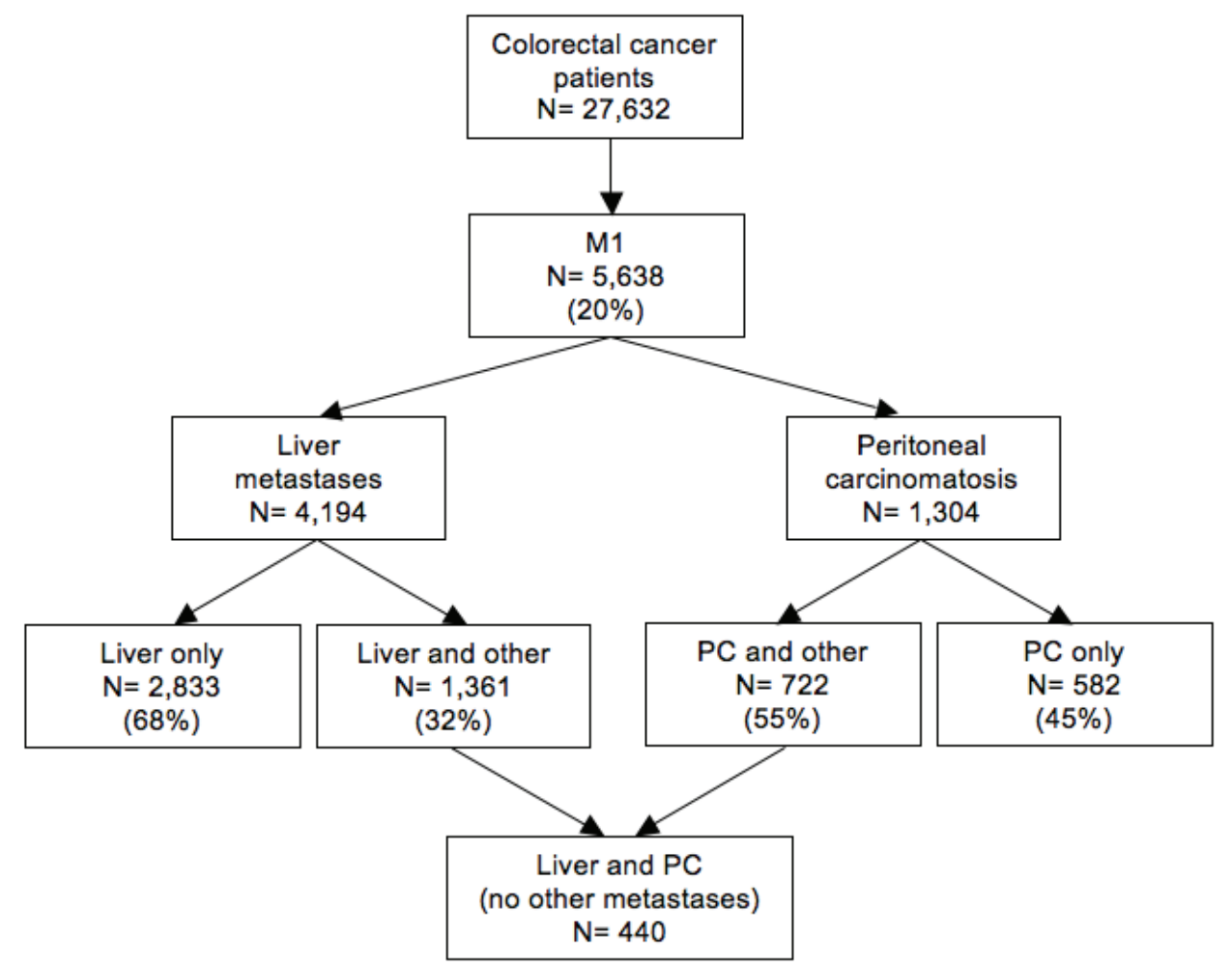

Figure 1. patients with colorectal cancer and metastasis between 1995 and 2010 in the Eindhoven Cancer Registry region.

Table 1. Patient characteristics of colorectal cancer patients with synchronous LM and PC

\begin{tabular}{lcccc}
\hline & Total & $\begin{array}{c}\text { Patients who } \\
\text { underwent } \\
\text { palliative } \\
\text { surgery }\end{array}$ & $\begin{array}{c}\text { Patients not } \\
\text { surgically } \\
\text { treated }\end{array}$ & \\
\hline N=440 $\left(\%^{+}\right)$ & $\mathbf{N}=\mathbf{2 1 9}\left(\%^{\text {\$ })}\right.$ & $\mathbf{N = 2 2 1}\left(\%^{\text {s}}\right)$ & p-value \\
\hline Gender & & & & $\mathbf{0 . 3 3 7}$ \\
\hline Male & $231(53)$ & $120(52)$ & $111(48)$ & \\
Female & $209(47)$ & $99(47)$ & $110(53)$ & \\
Age & & & & $\mathbf{0 . 0 3 1}$ \\
$<60$ & $111(25)$ & $66(59)$ & $45(41)$ & \\
$60-69$ & $130(30)$ & $66(51)$ & $64(49)$ & \\
$70-79$ & $139(32)$ & $65(47)$ & $74(53)$ & \\
$>79$ & $60(14)$ & $22(37)$ & $38(63)$ & \\
\hline
\end{tabular}

Table 1. continues on next page 


\begin{tabular}{|c|c|c|c|c|}
\hline \multicolumn{4}{|l|}{ Comorbidity } & \multirow[t]{2}{*}{0.060} \\
\hline none & $136(31)$ & $75(55)$ & $61(45)$ & \\
\hline 1 & $125(28)$ & $61(49)$ & $64(51)$ & \\
\hline$\geq 2$ & $104(24)$ & 41 (39) & $63(61)$ & \\
\hline Unknown & $75(17)$ & $30(58)$ & $22(42)$ & \\
\hline \multicolumn{4}{|l|}{ Period of diagnosis } & 0.003 \\
\hline 1995-1999 & $105(24)$ & $63(60)$ & $42(40)$ & \\
\hline 2000-2004 & $134(30)$ & $73(54)$ & $61(46)$ & \\
\hline $2005-2010$ & $201(46)$ & $83(41)$ & 118 (59) & \\
\hline \multicolumn{4}{|c|}{ Localisation of primary tumor } & 0.001 \\
\hline Coecum & $95(22)$ & $58(61)$ & 37 (39) & \\
\hline Appendix & $3(1)$ & $3(100)$ & $\mathrm{o}(0)$ & \\
\hline Ascending colon & $56(13)$ & $30(54)$ & $26(46)$ & \\
\hline Hepatic flexure & $21(5)$ & $10(48)$ & $11(52)$ & \\
\hline Transverse colon & $23(5)$ & $12(52)$ & $11(48)$ & \\
\hline Splenic flexure & $18(4)$ & $6(33)$ & $12(67)$ & \\
\hline Descending colon & $17(4)$ & $8(47)$ & $9(53)$ & \\
\hline Sigmoid & $110(25)$ & $63(57)$ & $47(43)$ & \\
\hline Overlapping lesion/ NOS & $13(3)$ & $5(42)$ & $7(58)$ & \\
\hline Rectosigmoid & $30(7)$ & $12(40)$ & $18(60)$ & \\
\hline Rectum & $54(12)$ & $12(22)$ & $42(78)$ & \\
\hline \multicolumn{4}{|c|}{ Differentiation grade of primary tumor } & $<.001$ \\
\hline Well/ moderately & $173(39)$ & $116(67)$ & $57(33)$ & \\
\hline Poorly/ undifferentiated & $121(28)$ & $81(70)$ & $40(30)$ & \\
\hline Unknown & $146(33)$ & $22(15)$ & $124(85)$ & \\
\hline \multicolumn{4}{|l|}{ T stage of primary tumor } & N.A. \\
\hline $\mathrm{T}_{1}$ & - & - & - & \\
\hline $\mathrm{T} 2$ & $3(1)$ & $3^{A}(100)$ & $\mathrm{O}^{\mathrm{B}}(\mathrm{O})$ & \\
\hline T3 & $147(33)$ & $130^{\mathrm{A}}(88)$ & $17^{\mathrm{B}}(12)$ & \\
\hline $\mathrm{T} 4$ & $150(34)$ & $84^{A}(56)$ & $66^{\mathrm{B}}(44)$ & \\
\hline $\mathrm{Tx}$ & $140(32)$ & $2^{A}(1)$ & $138^{B}(99)$ & \\
\hline \multicolumn{4}{|l|}{$\mathbf{N}$ stage of primary tumor } & N.A. \\
\hline No & $19(4)$ & $14^{A}(74)$ & $5^{B}(26)$ & \\
\hline $\mathrm{N} 1$ & $114(26)$ & $77^{A}(68)$ & $37^{B}(32)$ & \\
\hline $\mathrm{N} 2+$ & $106(24)$ & $95^{A}(90)$ & $11^{B}(10)$ & \\
\hline $\mathrm{Nx}$ & $201(46)$ & $33^{A}(16)$ & $168^{B}(84)$ & \\
\hline
\end{tabular}

+: Column percentage, \$: Row percentage, A: Pathological, B: Clinical, N.A.: Not applicable, NOS: not otherwise specified 
Treatment of patients with LM and PC was analyzed and compared over time to recognize trends in treatment, as shown in Table 2. In the period of 1995-1999 the percentage of patients with combined LM and PC was 1,5\% of all colorectal cancer patients and in 20002005 and $2005-2010$ this was $1,6 \%$. None of the patients underwent combined treatment of both metastatic sites with curative intent. In the earliest period, palliative resection to relief symptoms was performed in $60 \%$ of patients but this decreased significantly over time to $41 \%(p<0.01)$. In contrast, the amount of patients receiving palliative chemotherapy increased significantly over time from $22 \%$ in the earliest period to $49 \%$ of the patients in the most recent period. ( $p<0.001$ ) Metastasectomy of LM and palliative radiotherapy for rectal cancer to relief symptoms was performed only incidentally and did not change over time. ( $p=0.56$ and $p=0.82$ respectively).

Median survival of patients with PC and LM was 4.6 months in the earliest period increasing slightly to 5.0 months in the most recent period, but this increase was not statistically significant, nor clinically relevant (Figure 2, $p=0.09$ ). Median survival of patients who underwent palliative resection did not improve over time (7.9 months for each period). As shown in Figure 3, crude survival of patients receiving palliative chemotherapy was significantly better than those not receiving chemotherapy ( 2.6 vs. 12 months, $p<0.001$ ). In multivariate analysis after adjusting for age, gender, period of diagnosis, co-morbidity, differentiation grade, and resection patients who were treated with chemotherapy had a reduced risk to die within 2 years after colorectal cancer diagnosis compared to patients who did not receive chemotherapy $(\mathrm{HR}=0.24,95 \% \mathrm{Cl} 0.18-0.31)$.

Table 2. Palliative treatment of patients with PC and LM $(n=440)$

\begin{tabular}{|c|c|c|c|c|c|c|c|c|}
\hline & & \multicolumn{2}{|c|}{ 1995-1999 } & \multicolumn{2}{|c|}{ 2000-2004 } & \multicolumn{2}{|c|}{ 2005-2010 } & \multirow[t]{2}{*}{ p-value* } \\
\hline & & $N=105$ & $\%$ & $N=134$ & $\%$ & $\mathrm{~N}=\mathbf{2 0 1}$ & $\%$ & \\
\hline \multirow[t]{2}{*}{ Palliative resection } & Yes & 63 & 60 & 73 & 54 & 83 & 41 & $<0.01$ \\
\hline & No & 42 & 40 & 61 & 46 & 118 & 59 & \\
\hline \multirow[t]{2}{*}{ Metastasectomy } & Yes & 1 & 1 & 4 & 3 & 5 & 2 & 0.56 \\
\hline & No & 104 & 99 & 130 & 97 & 196 & 98 & \\
\hline \multirow[t]{2}{*}{ Radiotherapy } & Yes & 5 & 5 & 8 & 6 & 9 & 4 & 0.82 \\
\hline & No & 100 & 95 & 126 & 94 & 192 & 96 & \\
\hline \multirow[t]{2}{*}{ Chemotherapy } & Yes & 23 & 22 & 50 & 37 & 98 & 49 & $<0.001$ \\
\hline & No & 82 & 78 & 84 & 63 & 103 & 51 & \\
\hline
\end{tabular}

*P-value was calculated using Chi-square test 


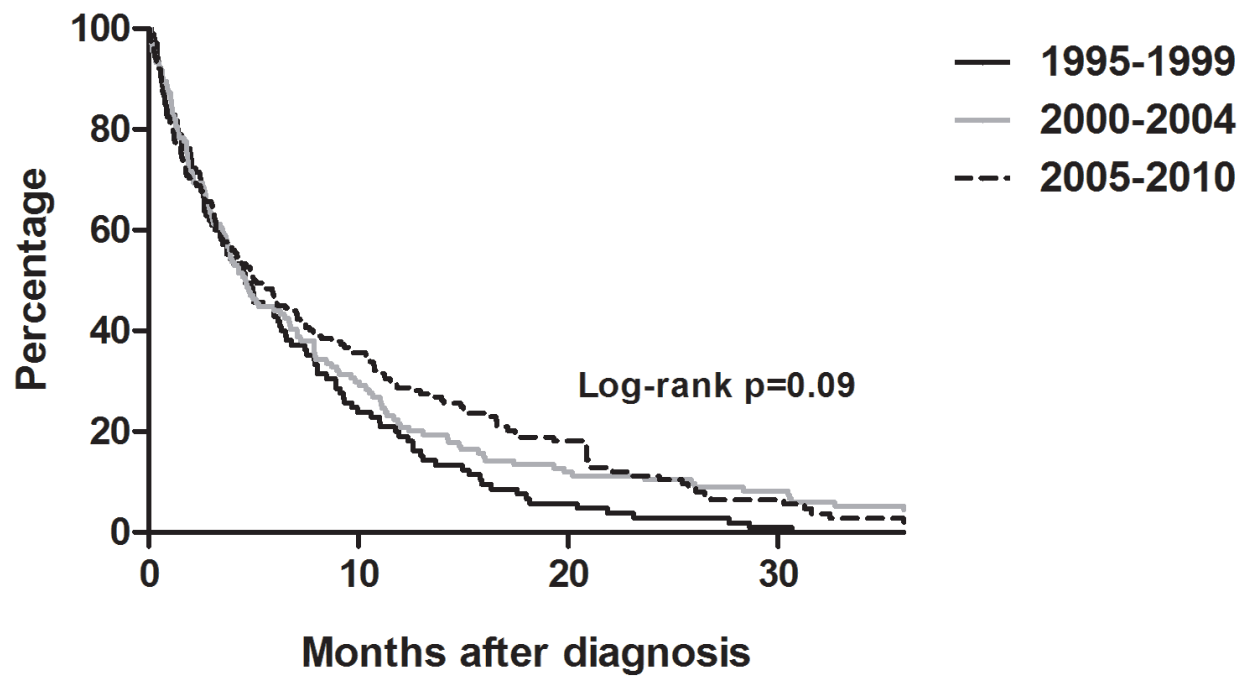

Figure 2. Crude survival of patients with combined liver metastasis and peritoneal carcinomatosis according to period.

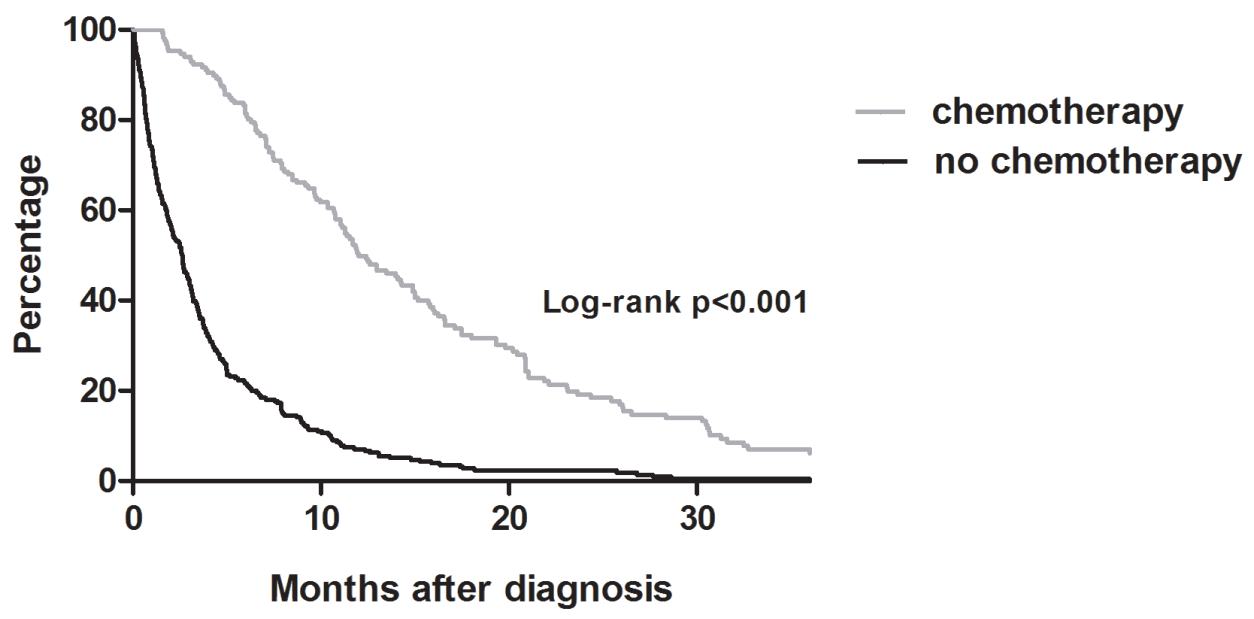

Figure 3. Crude survival of patients with combined liver metastasis and peritoneal carcinomatosis with and without palliative chemotherapy. 


\section{Review of the literature}

In total, 21 papers were identified reporting on the outcome of combined treatment with curative intent of both PC and LM (table 3). Treatment consisted of CRS and intra-peritoneal chemotherapy (IPC) for PC and partial hepatectomy or radio-frequency ablation (RFA) for LM. Different IPC-regimens were used either intra-operatively or in the early post-operative period using different chemotherapeutic agents. Some of the papers report on the same patient population. Table 4 summarizes the results with regards to survival from only the most recent papers from each institution. In total, 244 patients in 7 studies were described who underwent combined treatment with curative intent for both synchronous and metachronous LM and PC. Reported median survival rates in these patients ranged from 6 to 36 months. In these papers, also 1576 patients were described receiving treatment for PC as the only metastatic site with median survival rates ranging from 14 to 49 months. In 4 studies, survival was worse in patients undergoing treatment for both PC and LM as compared to patients with PC alone, reaching statistical significance in three studies. ${ }^{9,17,21}$ In the other three studies survival was comparable between both groups..$^{10,20,24}$

Table 3. Studies describing survival of patients with PC and LM

\begin{tabular}{|c|c|c|c|c|c|}
\hline Author & Year & $\begin{array}{c}P C+L M \\
\text { (n) }\end{array}$ & Treatment LM & $\begin{array}{l}\text { Treatment } \\
\text { PC }\end{array}$ & Type of chemo \\
\hline Bretcha et al. ${ }^{7}$ & 2010 & 5 & Operative & IO / EP & MMC, 5FU, OX \\
\hline Carmignani et al. ${ }^{8}$ & 2004 & 11 & Operative & IO / EP & OX, CIS \\
\hline Cavaliere et al. ${ }^{9}$ & 2010 & 9 & Operative & 10 & $\mathrm{MMC}, 5 \mathrm{FU}$ \\
\hline Chua et al. ${ }^{10}$ & 2009 & 16 & Operative / RFA & IO / EP & MMC, 5FU \\
\hline Chua et al. ${ }^{11}$ & 2011 & 9 & NA & 10 & NA \\
\hline Eliaset al. ${ }^{5}$ & 1999 & 12 & Operative & EP & MMC, 5FU, DOX \\
\hline Elias et al. ${ }^{12}$ & 2001 & 22 & Operative & $E P$ & $\mathrm{MMC}, 5 \mathrm{FU}$ \\
\hline Elias et al. ${ }^{13}$ & 2006 & 24 & Operative / RFA & IO / EP & $\mathrm{MMC}, 5 \mathrm{FU}, \mathrm{CIS}$ \\
\hline Elias et al. ${ }^{14}$ & 2009 & 77 & Operative & $10 / E P$ & $\begin{array}{l}\text { MMC, CIS, OX, } \\
\text { IR, } 5 \text { FU, LEU }\end{array}$ \\
\hline Elias et al. ${ }^{15}$ & 2010 & 70 & Operative & $10 / E P$ & $\begin{array}{l}\text { MMC, OX, LEU, } \\
5 F U\end{array}$ \\
\hline Glehen et al. ${ }^{16}$ & 2004 & 61 & Operative / RFA & $10 /+E P$ & $\mathrm{MMC}, \mathrm{OX}, 5 \mathrm{FU}$ \\
\hline Glehen et al. ${ }^{17}$ & 2010 & 117 & Operative & $1 \mathrm{O} /+\mathrm{EP}$ & $\begin{array}{l}\mathrm{MMC}, \mathrm{CIS}, \mathrm{OX} \\
5 \mathrm{FU}\end{array}$ \\
\hline Glockzin et al. ${ }^{18}$ & 2011 & 22 & Operative & 10 & MMC, DOX \\
\hline Gomez portilla et al. ${ }^{19}$ & 2006 & 11 & Operative & $10 /+E P$ & $\begin{array}{l}\text { MMC, CIS, TAX, } \\
5 \mathrm{FU}\end{array}$ \\
\hline Kianmanesh et al. ${ }^{20}$ & 2007 & 16 & Operative & 10 & $\mathrm{MMC}, \mathrm{CIS}$ \\
\hline
\end{tabular}

Table 3. continues on next page 


\begin{tabular}{|c|c|c|c|c|c|}
\hline Esquivel et al. ${ }^{21}$ & $\begin{array}{l}\text { In } \\
\text { press }\end{array}$ & 61 & Operative / RFA & IO / EP & NA \\
\hline Shen et al. ${ }^{22}$ & 2004 & 10 & Operative / RFA & 10 & MMC \\
\hline Tentes et al. ${ }^{23}$ & 2011 & 2 & Operative & $10 / E P$ & MMC, OX \\
\hline Varban et al. ${ }^{24}$ & 2009 & 14 & $\begin{array}{l}\text { Operative / RFA } \\
\text { / cryosurgery }\end{array}$ & 10 & MMC \\
\hline Yan et al. ${ }^{25}$ & 2006 & 4 & Operative & $10+E P$ & $\mathrm{MMC}, 5 \mathrm{FU}, \mathrm{FLO}$ \\
\hline
\end{tabular}

NA: not applicable, IO: intra-operative, EP: early post-operative, MMC: mitomycin C, 5FU: 5-fluorouracil, OX: oxaliplatin, CIS: cisplatinum, DOX: doxorubicin, IR: irinotecan, LEU: leucovorin, TAX: taxol, FLO: floxuridine

Table 4. Most recent articles per centre describing median survival after curative treatment of combined LM and PC.

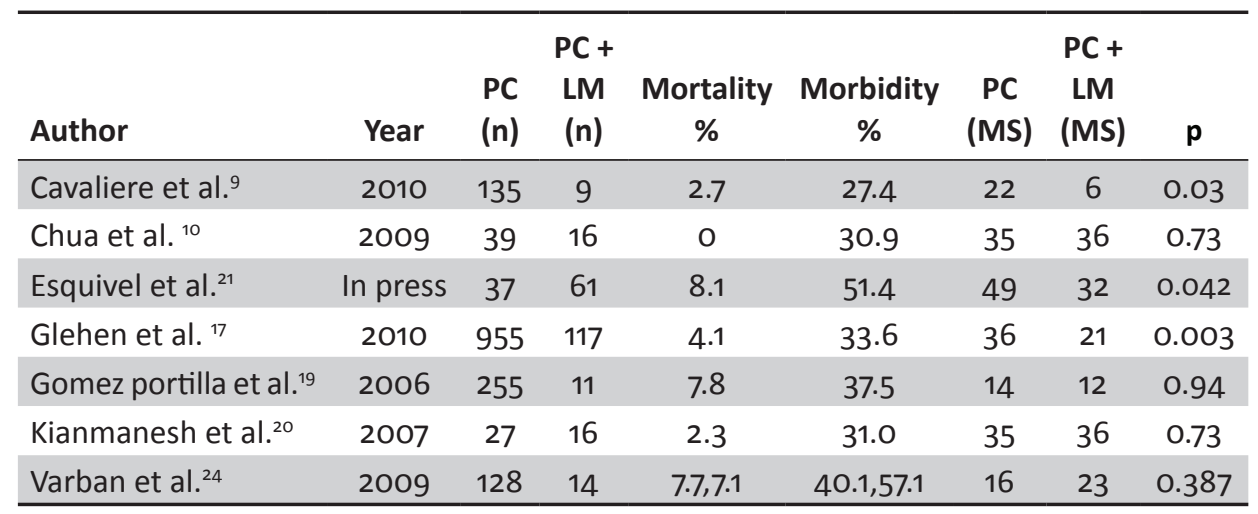

MS: median survival

\section{Discussion}

PC and LM are frequent sites of metastases from colorectal carcinoma but data on the incidence of the combination of these two metastatic sites has not been described previously and there is relatively little reliable data available on treatment and prognosis. The current population-based study aimed to characterize this particular patient group in an era with emerging treatment possibilities for these patients. We found that synchronous PC and LM is present in $8 \%$ of patients with metastasized colorectal cancer, being $2 \%$ of all patients diagnosed with colorectal cancer. The median survival of these patients was only 5 months and did not increase significantly over time.

Traditionally the combination of PC and LM has been considered unsuitable for curative therapy and usually palliative chemotherapy was given. Indeed it is shown that modern palliative systemic chemotherapy increases survival in patients with metastatic colorectal cancer. However, most of these data were obtained from studies including predominantly patients with LM. ${ }^{26}$ In contrast, very little is known about the effect of systemic chemotherapy 
in patients with PC. No data from prospective studies are available that have studied this particular patient group. Results of retrospective studies mostly on 5-FU based therapies reveal a disappointing response to systemic chemotherapy and poor prognosis. ${ }^{27-30}$ Recently, a pooled analysis of North-American and European trials confirms that the presence of PC results in a worse survival as compared to other metastatic sites. ${ }^{31,32}$ However, recent data suggest that modern chemotherapeutic regimens, including oxaliplatin or irinotecan may improve survival in PC patients, but this effect may be partly due to patient selection. ${ }^{33,34}$

In the current study, a significant increase in the use of chemotherapy was noted, from $22 \%$ in the earliest period to $49 \%$ in the most recent period. Besides, as we demonstrated previously, the type of chemotherapy changed as well from 5-FU based single agent chemotherapy to modern combination therapies including biological agents. ${ }^{35}$ Patients treated with chemotherapy had an improved 2-year survival as compared to patients not treated with chemotherapy. However, the survival of the entire study-population did not improve during the study period. Therefore, the better survival in patients treated with chemotherapy may be - at least partially - explained by patient selection. In addition, median survival of patients who underwent palliative resection did not improve over time.

Given the poor prognosis of the patients treated with palliative chemotherapy, it is interesting to review the results of more aggressive treatment modalities such as CRS and HIPEC combined with metastasectomy or RFA. For this procedure patient selection was performed including functional status, age, tumor biology, malignant disease confined to the abdominal cavity, size and number of LM, and normal organ function. In 1999 Elias et al. ${ }^{5}$ were the first to describe the combination of hepatectomy with CRS and IPC, and concluded that this treatment was well tolerated and safe although the incidence of biliary leakage was higher compared to standard hepatectomy. Since then, only few and small studies have been published regarding this treatment. Glehen et al. ${ }^{16}$ stated that the resection of LM in addition to treatment of $\mathrm{PC}$ has no significant effect on post-operative complications. Chua et al. ${ }^{11}$ compared palliative treatment for combined LM and PC with curative treatment with hepatectomy, CRS and IPC, which has shown to significantly improve survival from 9 months to 38 months respectively. ( $p<.001$ ) In multiple studies a factor for the extent of success was the amount of LM. ${ }^{12,21,36}$ Esquivel et al ${ }^{21}$ observed a median survival of 27 months in patients with $\geq 3$ LM compared to 40 months in patients with 1 or 2 LM. Overall, the additional presence of LM in patients with PC has conflicting results on survival; it has shown to worsen survival compared to $P C$ as the only metastatic site ${ }^{9,16,22,37}$ while other studies showed no significant difference in survival. ${ }^{10,14,15,19,20,24,25,38}$ When analyzing all studies describing the treatment of combined PC and LM the outcome of curative treatment varies in median survival from 6 to 36 months. It should be kept in mind that in these studies both patients with synchronous and metachronous metastatic disease were included. Patients with metachronous presentation may have a better prognosis due to a better tumor biology as compared to patients with synchronous disease, being the patients that were included in the present population based study. ${ }^{39}$ 
In conclusion, LM and PC are frequent sites of metastasis in colorectal cancer patients and the combination of both sites is present in $8 \%$ of patients with metastasized disease. There is an increasing tendency to treat these patients with palliative chemotherapy but survival remains very poor. The median survival rates of up to 36 months after treatment with curative intent as published in the literature may be regarded as promising, but one has to keep in mind that such results are currently obtainable in highly selected patients only. Given the frequency of this phenomenon, the present absence of data on this patient group and the poor prognosis, further studies regarding the optimal treatment of these patients are definitely warranted. 


\section{References}

1. Lemmens VE, Klaver YL, Verwaal VJ, Rutten HJ, Coebergh JW, de Hingh IH. Predictors and survival of synchronous peritoneal carcinomatosis of colorectal origin: a population-based study. Int J Cancer. 2011;128:2717-2725.

2. Al-Asfoor A, Fedorowicz Z, Lodge M. Resection versus no intervention or other surgical interventions for colorectal cancer liver metastases. Cochrane Database Syst Rev. 2008:CD006039.

3. Scheele J, Altendorf-Hofmann A. Resection of colorectal liver metastases. Langenbecks Arch Surg. 1999;384:313-327.

4. Verwaal VJ, Zoetmulder FA. Follow-up of patients treated by cytoreduction and chemotherapy for peritoneal carcinomatosis of colorectal origin. Eur J Surg Oncol. 2004;30:280-285.

5. Elias $D$, Dube $P$, Bonvalot $S$, et al. Treatment of liver metastases with moderate peritoneal carcinomatosis by hepatectomy and cytoreductive surgery followed by immediate post-operative intraperitoneal chemotherapy: feasibility and preliminary results. Hepato-gastroenterology. 1999;46:360-363.

6. Schouten LJ, Hoppener P, van den Brandt PA, Knottnerus JA, Jager JJ. Completeness of cancer registration in Limburg, The Netherlands. Int J Epidemiol. 1993;22:369-376.

7. Bretcha-Boix P, Farre-Alegre J, Sureda M, Dussan C, Perez Ruixo JJ, Brugarolas Masllorens A. Cytoreductive surgery and perioperative intraperitoneal chemotherapy in patients with peritoneal carcinomatosis of colonic origin: outcomes after 7 years' experience of a new centre for peritoneal surface malignancies. Clinical \& translational oncology : official publication of the Federation of Spanish Oncology Societies and of the National Cancer Institute of Mexico. 2010;12:437-442.

8. Carmignani CP, Ortega-Perez G, Sugarbaker PH. The management of synchronous peritoneal carcinomatosis and hematogenous metastasis from colorectal cancer. Eur J Surg Oncol. 2004;30:391398.

9. Cavaliere F, De Simone M, Virzi S, et al. Prognostic factors and oncologic outcome in 146 patients with colorectal peritoneal carcinomatosis treated with cytoreductive surgery combined with hyperthermic intraperitoneal chemotherapy: Italian multicenter study S.I.T.I.L.O. Eur J Surg Oncol. 2011;37:148-154.

10. Chua TC, Yan TD, Zhao J, Morris DL. Peritoneal carcinomatosis and liver metastases from colorectal cancer treated with cytoreductive surgery perioperative intraperitoneal chemotherapy and liver resection. Eur J Surg Oncol. 2009;35:1299-1305.

11. Chua TC, Morris DL, Saxena A, et al. Influence of modern systemic therapies as adjunct to cytoreduction and perioperative intraperitoneal chemotherapy for patients with colorectal peritoneal carcinomatosis: a multicenter study. Ann Surg Oncol. 2011;18:1560-1567.

12. Elias D GA, El Otmany A, Bonvalot S, Meshaka P, Attalah D, Lasser P. Treatment of liver metastases associated with moderate peritoneal carcinomatosis by hepatectomy and cytoreductive surgery followed by immediate intraperitoneal chemotherapy: results in 22 cases. I. Journal of surgical investigation. 2001;3:31-36.

13. Elias D, Benizri E, Pocard M, Ducreux M, Boige V, Lasser P. Treatment of synchronous peritoneal carcinomatosis and liver metastases from colorectal cancer. Eur J Surg Oncol. 2006;32:632-636.

14. Elias D, Gilly F, Boutitie F, et al. Peritoneal colorectal carcinomatosis treated with surgery and perioperative intraperitoneal chemotherapy: retrospective analysis of 523 patients from a multicentric French study. J Clin Oncol. 2010;28:63-68.

15. Elias D, Glehen O, Pocard M, et al. A comparative study of complete cytoreductive surgery plus intraperitoneal chemotherapy to treat peritoneal dissemination from colon, rectum, small bowel, and nonpseudomyxoma appendix. Ann Surg. 2010;251:896-901.

16. Glehen O, Gilly FN, Boutitie F, et al. Toward curative treatment of peritoneal carcinomatosis from nonovarian origin by cytoreductive surgery combined with perioperative intraperitoneal chemotherapy: a multi-institutional study of 1,290 patients. Cancer. 2010;116:5608-5618.

17. Glehen $O$, Schreiber V, Cotte $E$, et al. Cytoreductive surgery and intraperitoneal chemohyperthermia for peritoneal carcinomatosis arising from gastric cancer. Archives of surgery. Jan 2004;139(1):20-26.

18. Glockzin G, Renner P, Popp FC, et al. Hepatobiliary procedures in patients undergoing cytoreductive surgery and hyperthermic intraperitoneal chemotherapy. Ann Surg Oncol. 2011;18:1052-1059. 
19. Gomez Portilla A, Barrios P, Rufian S, et al. Management of peritoneal surface malignancy with cytoreductive surgery and perioperative intraperitoneal chemotherapy. Eur J Surg Oncol. 2006;32:628631.

20. Kianmanesh R, Scaringi S, Sabate JM, et al. Iterative cytoreductive surgery associated with hyperthermic intraperitoneal chemotherapy for treatment of peritoneal carcinomatosis of colorectal origin with or without liver metastases. Ann Surg. 2007;245:597-603.

21. Esquivel J ED, Barath D, Kusamura S, Debaco M. Should patients with peritoneal carcinomatosis of colorectal origin with synchronous liver metastases be treated with curative intent? A case-control study. In press.

22. Shen $\mathrm{P}$, Hawksworth J, Lovato J, et al. Cytoreductive surgery and intraperitoneal hyperthermic chemotherapy with mitomycin $\mathrm{C}$ for peritoneal carcinomatosis from nonappendiceal colorectal carcinoma. Ann Surg Oncol. 2004;11:178-186.

23. Tentes AA, Spiliotis ID, Korakianitis OS, Vaxevanidou A, Kyziridis D. Adjuvant perioperative intraperitoneal chemotherapy in locally advanced colorectal carcinoma: preliminary results. ISRN surgery. 2011;2011:529876.

24. Varban O, Levine EA, Stewart JH, McCoy TP, Shen P. Outcomes associated with cytoreductive surgery and intraperitoneal hyperthermic chemotherapy in colorectal cancer patients with peritoneal surface disease and hepatic metastases. Cancer. 2009;115:3427-3436.

25. Yan TD, Chu F, Links M, Kam PC, Glenn D, Morris DL. Cytoreductive surgery and perioperative intraperitoneal chemotherapy for peritoneal carcinomatosis from colorectal carcinoma: non-mucinous tumour associated with an improved survival. Eur J Surg Oncol. 2006;32:1119-1124.

26. Golfinopoulos V, Salanti G, Pavlidis N, loannidis JP. Survival and disease-progression benefits with treatment regimens for advanced colorectal cancer: a meta-analysis. Lancet Oncol. 2007;8:898-911.

27. Klaver YL, Lemmens VE, Nienhuijs SW, Luyer MD, de Hingh IH. Peritoneal carcinomatosis of colorectal origin: Incidence, prognosis and treatment options. World J Gastroenterol. 2012;18:5489-5494.

28. Chu DZ, Lang NP, Thompson C, Osteen PK, Westbrook KC. Peritoneal carcinomatosis in nongynecologic malignancy. A prospective study of prognostic factors. Cancer. 1989;63:364-367.

29. Sadeghi B, Arvieux C, Glehen O, et al. Peritoneal carcinomatosis from non-gynecologic malignancies: results of the EVOCAPE 1 multicentric prospective study. Cancer. 2000;88:358-363.

30. Jayne DG, Fook S, Loi C, Seow-Choen F. Peritoneal carcinomatosis from colorectal cancer. Br J Surg. 2002;89:1545-1550.

31. Franko J, Shi $Q$, Goldman CD, et al. Treatment of colorectal peritoneal carcinomatosis with systemic chemotherapy: a pooled analysis of north central cancer treatment group phase III trials N9741 and N9841. J Clin Oncol. 2012;30:263-267.

32. Klaver YL, Simkens LH, Lemmens VE, et al. Outcomes of colorectal cancer patients with peritoneal carcinomatosis treated with chemotherapy with and without targeted therapy. Eur J Surg Oncol. 2012;38:617-623.

33. Klaver YL, Lemmens VE, Creemers GJ, Rutten HJ, Nienhuijs SW, de Hingh IH. Population-based survival of patients with peritoneal carcinomatosis from colorectal origin in the era of increasing use of palliative chemotherapy. Ann Oncol. 2011;22:2250-2256.

34. Elias D, Lefevre JH, Chevalier J, et al. Complete cytoreductive surgery plus intraperitoneal chemohyperthermia with oxaliplatin for peritoneal carcinomatosis of colorectal origin. J Clin Oncol. 2009;27:681-685.

35. Klaver YL, Leenders BJ, Creemers GJ, et al. Addition of Biological Therapies to Palliative Chemotherapy Prolongs Survival in Patients With Peritoneal Carcinomatosis of Colorectal Origin. Am J Clin Oncol. 2013;36:157-61

36. Elias D, Raynard B, Farkhondeh F, et al. Peritoneal carcinomatosis of colorectal origin. Gastroenterologie clinique et biologique. 2006;30:1200-1204.

37. Glehen O, Cotte E, Schreiber V, Sayag-Beaujard AC, Vignal J, Gilly FN. Intraperitoneal chemohyperthermia and attempted cytoreductive surgery in patients with peritoneal carcinomatosis of colorectal origin. Br J Surg. 2004;91:747-754. 
38. Sugarbaker $\mathrm{PH}$, Schellinx ME, Chang $\mathrm{D}$, Koslowe $\mathrm{P}$, von Meyerfeldt $\mathrm{M}$. Peritoneal carcinomatosis from adenocarcinoma of the colon. World journal of surgery. 1996;20:585-591; discussion 592.

39. Tsai MS, Su YH, Ho MC, et al. Clinicopathological features and prognosis in resectable synchronous and metachronous colorectal liver metastasis. Ann Surg Oncol. 2007;14:786-794. 


\section{Chapter 3}

Metachronous peritoneal carcinomatosis after curative treatment of colorectal cancer

Yvette RBM van Gestel, Irene Thomassen, Valery EPP Lemmens, Johannes FM Pruijt, Myrthe PP van Herk-Sukel, Harm JT Rutten, Geert-Jan Creemers, Ignace HJT de Hingh.

8.:.

Eur J Surg Oncol. 2014 Aug;40(8):963-9

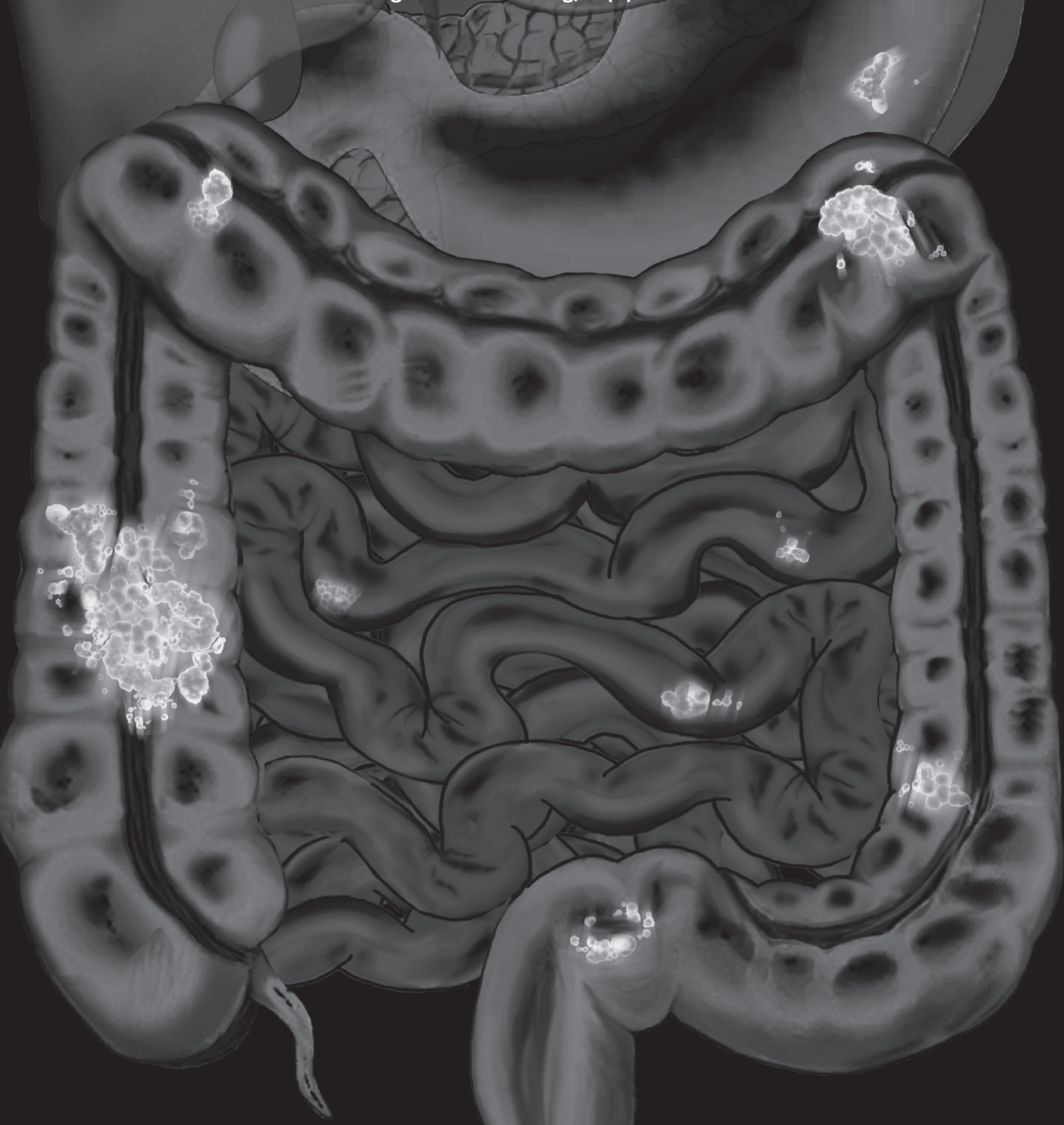





\section{Abstract}

\section{Introduction}

Population-based data on metachronous peritoneal carcinomatosis (PC) after curative resection of colorectal origin are scarce. The aim of this study was to investigate the incidence of and risk factors for developing metachronous PC from colorectal cancer as well as survival since diagnosis of PC.

\section{Methods}

Data on metachronous metastases were collected between 2010 and 2011 for all patients diagnosed with Mo colorectal cancer between 2003 and 2008 in the Dutch Eindhoven Cancer Registry. Median follow-up was 5.0 years. Survival was defined as time from metastases diagnosis to death.

\section{Results}

Of the 5671 colorectal cancer patients, 1042 (18\%) were diagnosed with metachronous metastases of whom 197 (19\%) developed metachronous PC. The peritoneal surface was the only site of metastasis in $81(41 \%)$ patients while 116 (59\%) patients were diagnosed with both PC and metastases elsewhere. Median survival after diagnosis of PC was 6 months compared to 15 months for patients with distant metastases in other organs. Patients with an advanced primary tumour stage, positive lymph nodes at initial diagnosis, primary mucinous adenocarcinoma, positive resection margin and a primary tumour located in the colon were at increased risk of developing metachronous PC.

\section{Conclusion}

Of the colorectal cancer patients who developed metachronous metastases, approximately one fifth is diagnosed with PC. Prognosis of these patients is poor with a median survival of 6 months after diagnosis. Identifying patients at high risk for developing metachronous PC is important as it may contribute to more accurate patient information, tailor-made follow-up schemes, and more adequate treatment. 


\section{Introduction}

The single most important and ultimately life-threatening feature of malignant disease is the ability to metastasize towards other organs. At initial diagnosis approximately $20-25 \%$ of colorectal cancer patients present with metastasized disease, mostly affecting the liver. ${ }^{1-3}$ Besides liver metastases, another common site of metastases is the peritoneum. At the time of colorectal cancer diagnosis, peritoneal carcinomatosis (PC) is present in about $4-7 \%$ of the patients. ${ }^{3-5}$ The prognosis of these patients is poor with a median survival of only a couple of months. ${ }^{3,5,6}$ Consequently, PC was regarded as a disease only to be palliated until recent years. Management of peritoneal surface malignancies has changed due to new and improved treatment approaches such as aggressive cytoreductive surgery in combination with hyperthermic intraperitoneal chemotherapy (HIPEC) with promising results. ${ }^{7,8}$ However, survival after these procedures is related to the extent of disease and amount of residual tumour after cytoreduction. Besides, PC is frequently accompanied by metastases in other organs $^{3-5}$ which may significantly compromise treatment options. To date, some studies have investigated epidemiological and clinical features of synchronous PC. However, populationbased data on metachronous PC after curative resection of colorectal cancer are scarce. Information on the incidence and survival of metachronous PC as well as identification of risk factors for the development of PC may be useful with respect to tailor-made follow-up schemes. This may lead to early diagnosis of PC and selection of patients who may benefit from aggressive treatment. The aim of this study was to investigate the incidence and survival of metachronous PC of colorectal origin, and to identify risk factors for the development of metachronous PC.

\section{Patients and methods}

\section{Patient selection and data}

Data were retrieved from the Eindhoven Cancer Registry (ECR) which collects data of all patients with newly diagnosed cancer in a large part of the Southern Netherlands. The area comprises approximately 2.4 million inhabitants, 6 pathology departments, 10 hospitals, and 2 radiotherapy institutions. Trained registry managers prospectively collect data on patient and tumour characteristics from the medical records after notification by pathologists and medical registration offices between 6 and 12 months after diagnosis. This uniform and independent data collection guarantees high quality of the data. Independent research has demonstrated that the completeness of cancer registration is estimated to exceed 95\%. ${ }^{9}$ Primary tumour stage was based on the TNM Classification of Malignant Tumours by the international Union Against Cancer (UICC), $7^{\text {th }}$ edition. ${ }^{10}$ For all consecutive colorectal cancer patients who were diagnosed between 2003-2008 with Mo disease who underwent curative resection including laparoscopic surgery $(n=5671)$, additional data on metachronous metastases were retrospectively collected in the period 2010-2011. A diagnosis of PC 2 months or more after initial diagnosis was considered as metachronous PC. However, the majority of PC diagnoses (94\%) occurred at least 6 months after colorectal cancer diagnosis. Median follow-up (from initial diagnosis to end of data collection) was 5.0 years (range 1.2-8.8 years). 
Date of diagnosis and data on (up to 3 ) localization of the metastases were registered. The site(s) of metastases was registered according to the International Classification of Diseases for Oncology (ICD-O). ${ }^{11}$ The most accurate diagnostic procedure to diagnose metastases was recorded (e.g. puncture/ biopsy over imaging).

On January 1, 2012 vital status was completed for all patients obtained through merging with the Dutch Municipal Administrative Database in which all deceased and emigrated persons are registered.

\section{Statistical analysis}

Patient and tumour characteristics of patients with metastases were compared using the $\mathrm{Chi}^{2}$ test. Univariable and multivariable Cox regression analyses were used to investigate patient and tumour characteristics associated with the development of metachronous PC. This time-to-event analysis provides hazard ratio's (HRs) with their 95\% confidence intervals (Cls). The HR is a ratio of the chance of an event (diagnosis of PC) to occur or not. In our study the HR was considered as an estimate of relative risk. Time to diagnosis of metachronous metastases was calculated from diagnosis of the primary tumour to the date of diagnosis of metastases. For patients diagnosed with PC, time to diagnosis of PC was used (which could be the second or third site of metastases). PC was diagnosed as the first metastasis in 144 (73\%) of the patients with PC. A sensitivity analysis was performed in which the diagnosis of the first metastasis was used for all patients. Adjustments were made for age, gender, comorbidity, primary tumour stage, primary lymph node stage, differentiation grade of primary tumour, localization of primary tumour, primary tumour histology, and adjuvant chemotherapy (all at time of/ with respect to initial diagnosis). Crude survival proportions for patients with PC and patients with other metastases were determined using the KaplanMeier method and compared using a Log-rank test. Survival was calculated as time from diagnosis of metastases to death or end of follow-up period (December 2011). For patients with PC and other affected organs, time from diagnosis of PC was used to calculate survival and for patients with other (multiple) affected organs, diagnosis of the first metastasis was used. Statistical analyses were performed using SAS $/$ STAT $^{\circ}$ statistical software (SAS system 9.3, SAS Institute, Cary, North Carolina, USA). All tests were two sided and p-value $<0.05$ was considered to be significant.

\section{Results}

\section{Basic characteristics}

The distribution of patient and tumour characteristics of the 5671 patients with colorectal cancer is presented in Table 1. The majority of the patients was men, aged between 70-79 years and had one or more comorbid conditions. The majority of the primary tumours were non-mucinous adenocarcinomas with an advanced tumour stage, well differentiated, and most often located in the sigmoid colon or rectum. Most patients had no positive lymph nodes at initial diagnosis and the resection margin was microscopically free of malignancy in nearly all patients (R1 $3 \%$, and unknown $4 \%$ ). The characteristics of the patients who 
were diagnosed with metachronous metastases $(\mathrm{N}=1042,18 \%)$ are described in Table 2 as well as the proportion of PC.

\section{Diagnosis of peritoneal carcinomatosis}

During follow-up, 197 patients developed metachronous PC; i.e. 3.5\% of the total population and $19 \%$ of the patients who developed metastatic disease. PC was diagnosed in 171 (27\%) patients with colon cancer and in $26(6 \%)$ patients with rectal cancer $(p<0.001)$. Diagnosis of PC was confirmed by histopathology in $103(53 \%)$ patients, 78 (39\%) patients were diagnosed by imaging (e.g. CT, MRI, PET, ultrasound), 15 (8\%) patients at surgery, and 1 patient was diagnosed with PC based on clinical symptoms (ascites). No significant differences in PC rates were observed according to age, comorbidity, and differentiation grade (Table 2). PC rates were highest among women, patients with primary mucinous adenocarcinomas, tumour stage $\mathrm{T} 4$, lymph node stage $\mathrm{N} 2$, and among patients with a positive resection margin.

\section{Time to diagnosis of peritoneal carcinomatosis}

Median time to diagnosis of metachronous PC was 18 months (range 2.5-88 months) and was 16 months for colon and 21 months for rectal cancer patients. The majority (83\%) of the metachronous PC was detected within the first 3 years after initial diagnosis and nearly all were diagnosed within 5 years (98\%). Of the 197 patients with PC, the peritoneum was the only affected site in $81(41 \%)$ patients whereas $62(32 \%)$ patients had metastasic spread to the peritoneum and one other organ (mostly the liver), and 54 (27\%) patients presented with PC and metastases in 2 or more other organs (Figure 1). Of the patients with PC and one other affected organ, the liver was involved in $53 \%$ which accounted for $18 \%$ of all patients with PC. PC was diagnosed as the first metachronous metastasis (with or without metastases elsewhere) in 144 patients (73\%) of those with PC. Among patients with PC diagnosed later during follow-up $(n=53,27 \%)$, median time between the diagnosis of the first metastasis and PC was 6.8 months.

Table 1. Characteristics of patients diagnosed with colorectal cancer $(N=5671)$

\begin{tabular}{lc}
\hline $\mathbf{N}=5671$ & Distribution of characteristics $\mathbf{N}$ (\%) \\
\hline Age & \\
$<60$ & $1132(20)$ \\
$60-69$ & $1583(28)$ \\
$70-79$ & $1957(34)$ \\
$\geq 80$ & $999(18)$ \\
Gender & \\
Women & $2669(47)$ \\
Men & $3002(53)$ \\
Number of comorbid conditions & \\
\hline O & $1781(31)$ \\
\hline
\end{tabular}

Table 1 continues on next page 


\begin{tabular}{|c|c|}
\hline$\geq 1$ & $3541(63)$ \\
\hline Unknown & $349(6)$ \\
\hline \multicolumn{2}{|l|}{ Localisation of primary tumour } \\
\hline Caecum & $717(13)$ \\
\hline Colon ascendens & $647(11)$ \\
\hline Flexura hepatica & $239(4)$ \\
\hline Colon transversum & $290(5)$ \\
\hline Flexura splenica & $176(3)$ \\
\hline Colon descendens & $149(3)$ \\
\hline Sigmoid colon & $1450(25)$ \\
\hline Rectosigmoid & $371(7)$ \\
\hline Rectum & $1574(28)$ \\
\hline Overlapping lesions/ NOS & $58(1)$ \\
\hline \multicolumn{2}{|l|}{ T stage of primary tumour* } \\
\hline T1-2 & $1594(28)$ \\
\hline T3 & $3590(63)$ \\
\hline T4 & $487(9)$ \\
\hline \multicolumn{2}{|l|}{$\mathrm{N}$ stage of primary tumour* } \\
\hline No & $3598(64)$ \\
\hline $\mathrm{N} 1$ & $1376(24)$ \\
\hline $\mathrm{N} 2$ & $565(10)$ \\
\hline $\mathrm{Nx}$ & $132(2)$ \\
\hline \multicolumn{2}{|c|}{ Differentiation grade of primary tumour } \\
\hline Well/ moderately differentiated & $3976(70)$ \\
\hline Poorly/ undifferentiated & $841(15)$ \\
\hline Unknown & $863(15)$ \\
\hline \multicolumn{2}{|l|}{ Histology of primary tumour } \\
\hline Non-mucinous adenocarcinoma & $4996(88)$ \\
\hline Mucinous adenocarcinoma & $675(12)$ \\
\hline \multicolumn{2}{|l|}{ Resection margin of primary tumour } \\
\hline Ro & $5251(93)$ \\
\hline $\mathrm{R} 1$ & $200(3)$ \\
\hline $\mathrm{Rx}$ & $220(4)$ \\
\hline \multicolumn{2}{|l|}{ Adjuvant chemotherapy } \\
\hline No & $4435(78)$ \\
\hline Yes & $1236(22)$ \\
\hline
\end{tabular}

${ }^{*} \mathrm{cT}$ in case of missing $\mathrm{pT}$ and $\mathrm{cN}$ in case of $\mathrm{pN}$ 
Table 2. Characteristics of colorectal cancer patients diagnosed with metachronous metastases ( $\mathrm{N}=1042)$ and the proportion of patients with PC

\begin{tabular}{|c|c|c|c|}
\hline $\mathrm{N}=1042$ & $\begin{array}{c}\text { Distribution of } \\
\text { characteristics N (\%) }\end{array}$ & PC (\%) & p-value \\
\hline Age & & & 0.36 \\
\hline$<60$ & $234(22)$ & 19 & \\
\hline $60-69$ & $309(30)$ & 18 & \\
\hline $70-79$ & $373(36)$ & 17 & \\
\hline$\geq 80$ & $126(12)$ & 25 & \\
\hline Gender & & & $<0.05$ \\
\hline Women & $463(44)$ & 22 & \\
\hline Men & $579(56)$ & 16 & \\
\hline Number of comorbid conditions & & & 0.81 \\
\hline 0 & $341(33)$ & 20 & \\
\hline$\geq 1$ & $618(59)$ & 18 & \\
\hline Unknown & $83(8)$ & 20 & \\
\hline Localisation of primary tumour & & & $<0.001$ \\
\hline Coecum & $128(12)$ & 37 & \\
\hline Colon ascendens & $106(10)$ & 28 & \\
\hline Flexura hepatica & $30(3)$ & 33 & \\
\hline Colon transversum & $48(5)$ & 31 & \\
\hline Flexura splenica & $27(3)$ & 22 & \\
\hline Colon descendens & $27(3)$ & 33 & \\
\hline Sigmoid colon & $259(25)$ & 19 & \\
\hline Rectosigmoid & $69(7)$ & 14 & \\
\hline Rectum & $332(32)$ & 5 & \\
\hline Overlapping lesions/ NOS & $16(2)$ & 44 & \\
\hline T stage of primary tumour* & & & $<0.001$ \\
\hline T1-2 & $127(12)$ & 8 & \\
\hline T3 & $753(72)$ & 18 & \\
\hline $\mathrm{T} 4$ & $162(16)$ & 30 & \\
\hline $\mathrm{N}$ stage of primary tumour* & & & $<0.05$ \\
\hline No & $383(37)$ & 17 & \\
\hline $\mathrm{N} 1$ & $408(39)$ & 17 & \\
\hline $\mathrm{N} 2$ & $234(22)$ & 25 & \\
\hline $\mathrm{Nx}$ & $17(2)$ & 12 & \\
\hline
\end{tabular}

Table 2 continues on next page 


\begin{tabular}{lccc}
\hline Differentiation grade of primary tumour & & & 0.50 \\
Well/ moderately differentiated & $651(63)$ & 18 & \\
Poorly/ undifferentiated & $222(21)$ & 22 & \\
Unknown & $169(16)$ & 18 & \\
Histology of primary tumour & & & $<0.001$ \\
\hline Non-mucinous adenocarcinoma & $912(88)$ & 16 & \\
Mucinous adenocarcinoma & $130(12)$ & 38 & \\
Resection margin of primary tumour & & & $<0.05$ \\
Ro & $891(86)$ & 18 & \\
R1 & $84(8)$ & 31 & \\
Rx & $67(6)$ & 21 & \\
Adjuvant chemotherapy & & & 0.07 \\
No & $681(65)$ & 17 & \\
Yes & $361(35)$ & 22 & \\
\hline *T in & & & \\
\hline
\end{tabular}

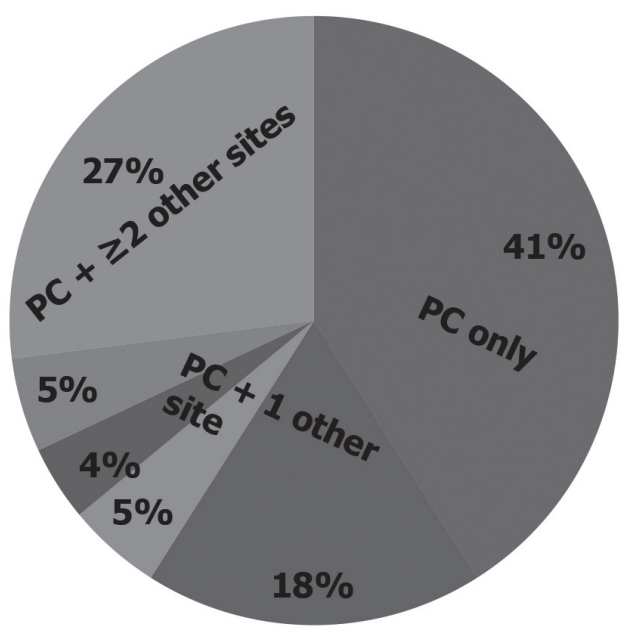

- PC only $(n=81)$

$\square \mathrm{PC}+\operatorname{liver}(\mathrm{n}=33)$

aC + lungs $(\mathbf{n = 1 0})$

- PC + lymph nodes $(n=8)$

$\square \mathrm{PC}+$ other $(\mathrm{n}=11)$

PC $+\geq 2$ other sites $(n=54)$

Figure 1. PC with and without other sites of metastases 


\section{Risk factors}

Table 3 presents univariate associations between patient and tumour characteristics and the chance to be diagnosed with metachronous PC. After adjustment, patients with an advanced primary tumour stage ( $\mathrm{T} 4 \mathrm{vs}$. $\mathrm{T} 3 \mathrm{HR} 1.93,95 \% \mathrm{Cl} 1.34-2.76$ ), a positive lymph node stage at initial diagnosis ( $\mathrm{N} 1$ vs No $\mathrm{HR} 2.46,95 \% \mathrm{Cl} 1.68-3.60$ and $\mathrm{N} 2$ vs. No $\mathrm{HR} 5.24,95 \% \mathrm{Cl} 3.41-$ 8.06), a primary mucinous adenocarcinoma ( $\mathrm{HR} 1.83,95 \% \mathrm{Cl} 1.29-2.59)$, a positive resection margin of primary tumour ( $\mathrm{HR} 2.93,95 \% \mathrm{Cl} 1.86-4.61)$, an unknown resection margin (HR $1.75,95 \% \mathrm{Cl} 1.00-3.07)$, and an unknown differentiation grade ( $\mathrm{HR} 1.67,95 \% \mathrm{Cl} 1.07-2.59)$ had an increased risk for developing metachronous PC (Table 3 ). In contrast, patients with a less invasive tumour stage ( $\mathrm{T} 1-2 \mathrm{vs}$. $\mathrm{T} 3 \mathrm{HR} 0.26,95 \% \mathrm{Cl} 0.14-0.51$ ) had a reduced risk for metachronous PC as well as patients with a primary tumour located in the siWgmoid (HR $0.65,95 \% \mathrm{Cl} 0.43-0.98)$, rectosigmoid ( $\mathrm{HR} 0.36,95 \% \mathrm{Cl} 0.18-0.72$ ) and rectum $(\mathrm{HR} 0.18,95 \% \mathrm{Cl}$ 0.10-0.33) compared with a primary tumour located in the caecum. A sensitivity analysis in which time to diagnosis of the first metachronous metastasis was used for all patients revealed similar results.

\section{Survival}

Median crude survival after diagnosis of PC was 6.0 months (range 4.6-7.6 months) compared to 15.2 months (range 13.7-17.1 months) after distant recurrence in other organs (log-rank $\mathrm{p}<0.001$ ) (Figure 2). After adjustment for patient and tumour characteristics and adjuvant chemotherapy, patients with PC have an increased mortality risk within 2 years after diagnosis of PC compared to patients with other metastases (first metastasis used) (HR 1.80, 95\% Cl 1.48-2.19). An increased mortality risk for patients with PC was still observed when survival was calculated as time from diagnosis of first metastasis for all patients (HR $1.47,95 \% \mathrm{Cl} 1.20-1.79)$.

Table 3. Risk for developing metachronous PC

\begin{tabular}{|c|c|c|}
\hline$N=5671$ & $\begin{array}{l}\text { Univariable analysis } \\
\qquad(95 \% \mathrm{Cl})\end{array}$ & $\begin{array}{c}\text { Multivariable analysis* } \\
(95 \% \mathrm{Cl})\end{array}$ \\
\hline \multicolumn{3}{|l|}{ Age } \\
\hline$<60$ & 1.00 & 1.00 \\
\hline $60-69$ & $0.96(0.65-1.43)$ & $1.01(0.68-1.51)$ \\
\hline $70-79$ & $0.99(0.68-1.46)$ & $1.01(0.67-1.52)$ \\
\hline$\geq 80$ & $1.15(0.73-1.82)$ & $1.01(0.60-1.70)$ \\
\hline \multicolumn{3}{|l|}{ Gender } \\
\hline Women & 1.00 & 1.00 \\
\hline Men & $0.81(0.61-1.07)$ & $1.03(0.78-1.38)$ \\
\hline \multicolumn{3}{|c|}{ Number of comorbid conditions } \\
\hline 0 & 1.00 & 1.00 \\
\hline$\geq 1$ & $0.96(0.71-1.29)$ & $0.88(0.64-1.20)$ \\
\hline
\end{tabular}

Table 3 continues on next page 


\begin{tabular}{|c|c|c|}
\hline Unknown & $1.34(0.78-2.29)$ & $1.05(0.61-1.80)$ \\
\hline \multicolumn{3}{|l|}{ Localisation of primary tumour } \\
\hline Caecum & 1.00 & 1.00 \\
\hline Colon ascendens & $0.69(0.43-1.09)$ & $0.72(0.45-1.14)$ \\
\hline Flexura hepatica & $0.64(0.32-1.27)$ & $0.71(0.36-1.40)$ \\
\hline Colon transversum & $0.84(0.47-1.50)$ & $0.88(0.49-1.58)$ \\
\hline Flexura splenica & $0.55(0.24-1.29)$ & $0.58(0.25-1.36)$ \\
\hline Colon descendens & $0.89(0.44-1.82)$ & $0.98(0.48-2.02)$ \\
\hline Sigmoid colon & $0.48(0.32-0.72)$ & $0.65(0.43-0.98)$ \\
\hline Rectosigmoid & $0.36(0.18-0.72)$ & $0.36(0.18-0.72)$ \\
\hline Rectum & $0.14(0.08-2.25)$ & $0.18(0.10-0.33)$ \\
\hline Overlapping lesions/ NOS & $2.02(0.91-4.48)$ & $2.29(1.02-5.15)$ \\
\hline \multicolumn{3}{|l|}{ T stage of primary tumour* } \\
\hline $\mathrm{T} 1-2$ & $0.15(0.08-0.28)$ & $0.26(0.14-0.51)$ \\
\hline T3 & 1.00 & 1.00 \\
\hline $\mathrm{T} 4$ & $3.24(2.33-4.50)$ & $1.93(1.35-2.76)$ \\
\hline \multicolumn{3}{|l|}{$\mathrm{N}$ stage of primary tumour* } \\
\hline No & 1.00 & 1.00 \\
\hline $\mathrm{N} 1$ & $2.89(2.07-4.05)$ & $2.46(1.68-3.60)$ \\
\hline $\mathrm{N} 2$ & $7.08(4.99-10.06)$ & $5.24(3.41-8.06)$ \\
\hline $\mathrm{Nx}$ & $0.86(0.21-3.52)$ & $1.18(0.29-4.88)$ \\
\hline \multicolumn{3}{|c|}{ Differentiation grade of primary tumour } \\
\hline Well/ moderately differentiated & 1.00 & 1.00 \\
\hline Poorly/ undifferentiated & $2.22(1.59-3.11)$ & $1.15(0.81-1.64)$ \\
\hline Unknown & $1.10(0.74-1.65)$ & $1.67(1.07-2.59)$ \\
\hline \multicolumn{3}{|l|}{ Histology of primary tumour } \\
\hline Non-mucinous adenocarcinoma & 1.00 & 1.00 \\
\hline Mucinous adenocarcinoma & $2.56(1.85-3.53)$ & $1.83(1.29-2.59)$ \\
\hline \multicolumn{3}{|l|}{ Resection margin of primary tumour } \\
\hline Ro & 1.00 & 1.00 \\
\hline $\mathrm{R} 1$ & $6.63(4.37-10.05)$ & $2.93(1.86-4.61)$ \\
\hline Rx & $2.59(1.50-4.47)$ & $1.75(1.00-3.07)$ \\
\hline \multicolumn{3}{|l|}{ Adjuvant chemotherapy } \\
\hline No & 1.00 & 1.00 \\
\hline Yes & $2.29(1.72-3.04)$ & $0.74(0.51-1.08)$ \\
\hline
\end{tabular}

*Adjustments were made for age, gender, comorbidity, primary tumour stage, primary lymph node stage, differentiation grade of primary tumour, localization of primary tumour, primary tumour histology, and chemotherapy 


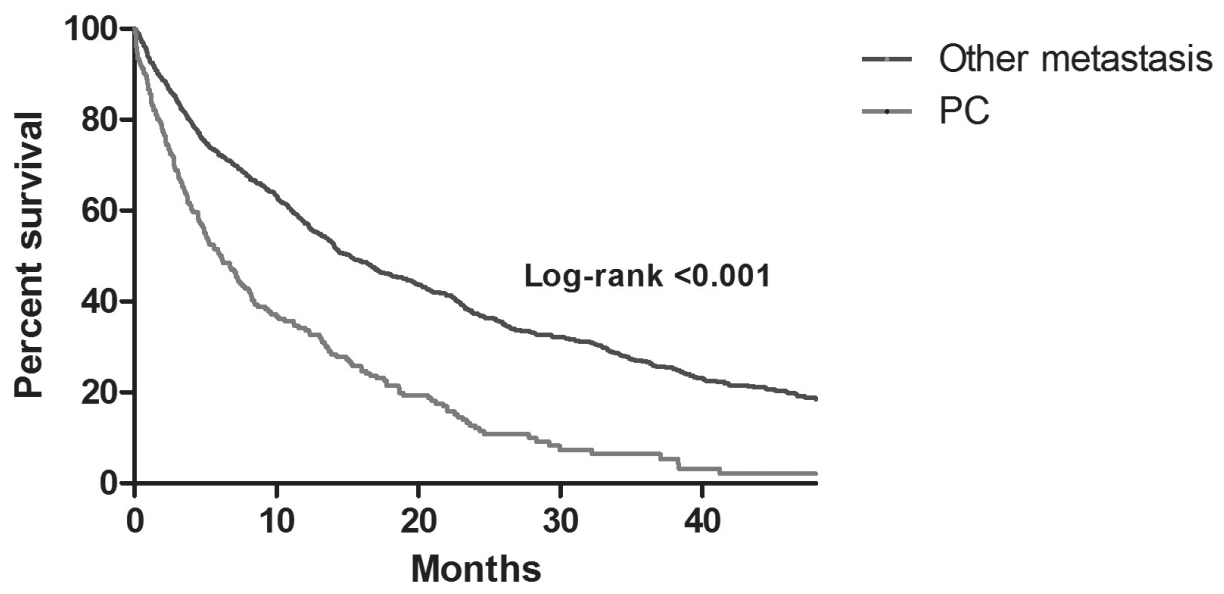

Figure 2. Survival since diagnosis of PC or other metastasis among colorectal cancer patients diagnosed between 2003 and $2008(n=1042)$

\section{Discussion}

The results of this population-based study demonstrated that $3.5 \%$ of the patients with colorectal cancer who were free of metastases at diagnosis were diagnosed with PC during follow-up (median follow-up 5.0 years). Approximately 1 out of 5 patients who developed metachronous metastases presented with PC. We have previously demonstrated that $4.8 \%$ of patients with colorectal cancer were diagnosed with synchronous PC, accounting for $24 \%$ of patients diagnosed with $\mathrm{M} 1$ disease. ${ }^{3}$ All together, more than $40 \%$ of colorectal cancer patients who develop (synchronous or metachronous) metastases will be diagnosed with PC at some time during their disease which is in accordance with previous single centre studies. ${ }^{12}$ Importantly, data on metachronous metastases are scarce, especially population-based data. However, these studies provide insights of clinical daily practice which may lead to improved outcome of these patients. To date, only one population-based study investigated the incidence of PC from colorectal cancer of whom $4,2 \%$ presented with metachronous PC. ${ }^{4}$

\section{Distribution of peritoneal carcinomatosis}

In the present study, PC was more frequently diagnosed among patients with colon cancer $(27 \%)$ than rectal cancer (6\%), which is in line with others., ${ }^{43}$ It is suggested that PC is caused by shedding of tumour cells from the primary tumour leading to intraperitoneal seeding. It is therefore conceivable that colonic tumours situated in the peritoneal cavity more often give rise to PC than rectal tumours situated under the peritoneal fold. In addition, intraperitoneal spread may also be induced by release of tumour cells during surgery by blood or lymph node leakage or as a result of a positive circumferential resection margin. ${ }^{12,14}$ The latter was confirmed in the present study as a positive resection margin was associated with an increased risk for developing metachronous PC. Furthermore, patients with an advanced primary tumour and lymph node stage were at increased risk for developing metachronous 
PC which has been demonstrated previously. ${ }^{4,5}$ Submucosal invasion allows vascular and lymphatic infiltration which may result in metastatic spread of tumour cells.

\section{Treatment of peritoneal carcinomatosis}

Survival of patients with metachronous PC is poor with only 6 months from PC diagnosis which is in line with the results of the EVOCAPE 1 study. ${ }^{15}$ Cytoreductive surgery combined with hypertermic intraperitoneal chemotherapy (HIPEC) for PC from colorectal cancer appears to be the most effective treatment in terms of survival in selected patients. ${ }^{6,8,16}$ As cytoreductive surgery with HIPEC has been shown to be most effective in patients with limited and resectable disease, early diagnosis of PC seems of vital importance. ${ }^{8,12}$ Second look surgery to diagnose PC at an early stage was previously performed in a cohort of highrisk asymptomatic patients and has shown promising results, identifying $56 \%$ of the patients with PC in a treatable stage. ${ }^{17}$ In addition, the use of prophylactic HIPEC in order to prohibit the development of metachronous PC may be considered in high risk patients, such as patients with an advanced tumour stage as was recently described by Sammartino et al. ${ }^{18}$ However, only a highly selected group of patients who are considered to be fit for surgery with limited disease and comorbidity are eligible for cytoreductive surgery and HIPEC so the majority of patients with PC will receive palliative care only. Knowledge on risk factors for developing metachronous PC as well as identification of patients who might benefit from aggressive interventions such as cytoreductive surgery and HIPEC is therefore important. This may contribute to improved tailor-made follow-up and early detection of recurrent disease when treatment is feasible and most effective.

\section{Time to diagnosis of peritoneal carcinomatosis}

Median time to diagnosis of metachronous PC was 18 months. Few studies investigated time to recurrent disease. Two studies reported comparable results with a median time of 14 months ${ }^{13}$ and 16 months ${ }^{4}$. Interestingly, we observed a shorter period to diagnosis of PC for colon (16 months) than for rectal (21 months) cancer patients. This may be due to various follow-up strategies used in these patients or the fact that colon cancer is frequently diagnosed in a more advanced stage in comparison with rectal cancer. As a consequence of lead time bias, time from primary diagnosis to PC seems shorter for patients with a more advanced tumour stage. ${ }^{19}$ In addition, differences in (unidentified) tumour characteristics may play an important role. However, due to the limited number of (rectal cancer) patients with PC, we were not able to confirm this hypothesis. Given that the majority of the PC diagnosis was detected within the first 3 years after colorectal cancer diagnosis, intensive surveillance for metachronous PC is therefore particularly important within these first years.

\section{Strengths and weaknesses}

As data collection on recurrences is very costly and time consuming, high-quality populationbased data on recurrent disease are rarely available in large-scale observational data. ${ }^{20}$ The present population-based study has the advantage of avoiding selection bias by including a long-term series of consecutive patients and therefore reflects current clinical practice. Importantly, all data were collected by independent registration clerks which prevents bias 
which may occur when data collection relies on clinicians. However, this study has also limitations. As currently available imaging modalities such as CT or MRI have low sensitivity for the detection of $\mathrm{PC}^{21,22}$, reliable information can only be obtained through surgical exploration of the abdomen. Consequently, diagnosis of PC may be missed especially in patients with disseminated disease who will only be treated palliatively. In addition, although a latency period of 3 months was used to define metachronous PC and the majority of PC diagnoses occurred at least 6 months after initial diagnosis, the possibility of pre-existing PC could not be concluded with certainty.

In conclusion, approximately one fifth of initially $\mathrm{MO}$ colorectal cancer patients who developed metastases during follow-up is diagnosed with PC. Prognosis of these patients is poor with a median survival of 6 months after PC diagnosis. Population-based data on metachronous PC are scarce while this type of study reflects clinical daily practice which may help to understand the natural history and development of metachronous PC and may lead to improved outcome. Early diagnosis and identification of patients at high risk for developing metachronous PC is important as selected patients may profit from potentially curative treatments such as cytoreductive surgery combined with HIPEC. 


\section{References}

1. http://seer.cancer.gov/statfacts.

2. Lemmens $V$, van Steenbergen $L$, Janssen-Heijnen $M$, Martijn $H$, Rutten $H$, Coebergh JW. Trends in colorectal cancer in the south of the Netherlands 1975-2007: rectal cancer survival levels with colon cancer survival. Acta Oncol 2010; 49:784-96.

3. Lemmens VE, Klaver YL, Verwaal VJ, Rutten HJ, Coebergh JW, de Hingh IH. Predictors and survival of synchronous peritoneal carcinomatosis of colorectal origin: a population-based study. Int J Cancer 2011; 128:2717-25.

4. Segelman J, Granath F, Holm T, Machado M, Mahteme H, Martling A. Incidence, prevalence and risk factors for peritoneal carcinomatosis from colorectal cancer. Br J Surg 2012; 99:699-705.

5. Jayne DG, Fook S, Loi C, Seow-Choen F. Peritoneal carcinomatosis from colorectal cancer. Br J Surg 2002; 89:1545-50.

6. Verwaal VJ, van Ruth S, Witkamp A, Boot H, van Slooten G, Zoetmulder FA. Long-term survival of peritoneal carcinomatosis of colorectal origin. Ann Surg Oncol 2005; 12:65-71.

7. Elias D, Blot F, El Otmany A, et al. Curative treatment of peritoneal carcinomatosis arising from colorectal cancer by complete resection and intraperitoneal chemotherapy. Cancer 2001; 92:71-6.

8. Verwaal VJ, van Ruth S, de Bree E, et al. Randomized trial of cytoreduction and hyperthermic intraperitoneal chemotherapy versus systemic chemotherapy and palliative surgery in patients with peritoneal carcinomatosis of colorectal cancer. J Clin Oncol 2003; 21:3737-43.

9. Schouten LJ, Hoppener P, van den Brandt PA, Knottnerus JA, Jager JJ. Completeness of cancer registration in Limburg, The Netherlands. Int J Epidemiol 1993; 22:369-76.

10. UICC. TNM Classification of Malignant Tumours. 7th ed. New York: Wiley-Blackwell. 2009.

11. Fritz AG, Percy C, Jack A, et al. International Classification of Diseases for Oncology, 3rd ed. Geneva. World Health Organization 2000.

12. Koppe MJ, Boerman OC, Oyen WJ, Bleichrodt RP. Peritoneal carcinomatosis of colorectal origin: incidence and current treatment strategies. Ann Surg 2006; 243:212-22.

13. Galandiuk S, Wieand HS, Moertel CG, et al. Patterns of recurrence after curative resection of carcinoma of the colon and rectum. Surg Gynecol Obstet 1992; 174:27-32.

14. Ceelen WP, Bracke ME. Peritoneal minimal residual disease in colorectal cancer: mechanisms, prevention, and treatment. Lancet Oncol 2009; 10:72-9.

15. Sadeghi B, Arvieux C, Glehen O, et al. Peritoneal carcinomatosis from non-gynecologic malignancies: results of the EVOCAPE 1 multicentric prospective study. Cancer 2000; 88:358-63.

16. Glehen $\mathrm{O}$, Kwiatkowski F, Sugarbaker $\mathrm{PH}$, et al. Cytoreductive surgery combined with perioperative intraperitoneal chemotherapy for the management of peritoneal carcinomatosis from colorectal cancer: a multi-institutional study. J Clin Oncol 2004; 22:3284-92.

17. Elias D, Honore C, Dumont F, et al. Results of systematic second-look surgery plus HIPEC in asymptomatic patients presenting a high risk of developing colorectal peritoneal carcinomatosis. Ann Surg 2011; 254:289-93.

18. Sammartino P, Sibio S, Biacchi D, et al. Prevention of Peritoneal Metastases from Colon Cancer in High-Risk Patients: Preliminary Results of Surgery plus Prophylactic HIPEC. Gastroenterol Res Pract 2012; 2012:141585.

19. Holzel D, Eckel R, Emeny RT, Engel J. Distant metastases do not metastasize. Cancer Metastasis Rev 2010; 29:737-50.

20. Sanoff HK, Carpenter WR, Stürmer T. Reply to H. Wong et al. J Clin Oncol 2012; 31:512-3.

21. Jacquet $P$, Jelinek JS, Steves MA, Sugarbaker PH. Evaluation of computed tomography in patients with peritoneal carcinomatosis. Cancer 1993; 72:1631-6.

22. Koh JL, Yan TD, Glenn D, Morris DL. Evaluation of preoperative computed tomography in estimating peritoneal cancer index in colorectal peritoneal carcinomatosis. Ann Surg Oncol 2009; 16:327-33. 


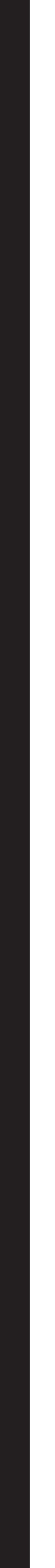




\section{Chapter 4}

Peritoneal carcinomatosis of gastric origin: a populationbased study on incidence, survival and risk factors

Irene Thomassen, Yvette RBM van Gestel, Bert van Ramshorst, Misha D Luyer, Koop Bosscha, Simon W Nienhuijs, Valery EPP Lemmens, Ignace HJT de Hingh.

Fi. Int J Cancer. 2014 Feb 1;134(3):622-8

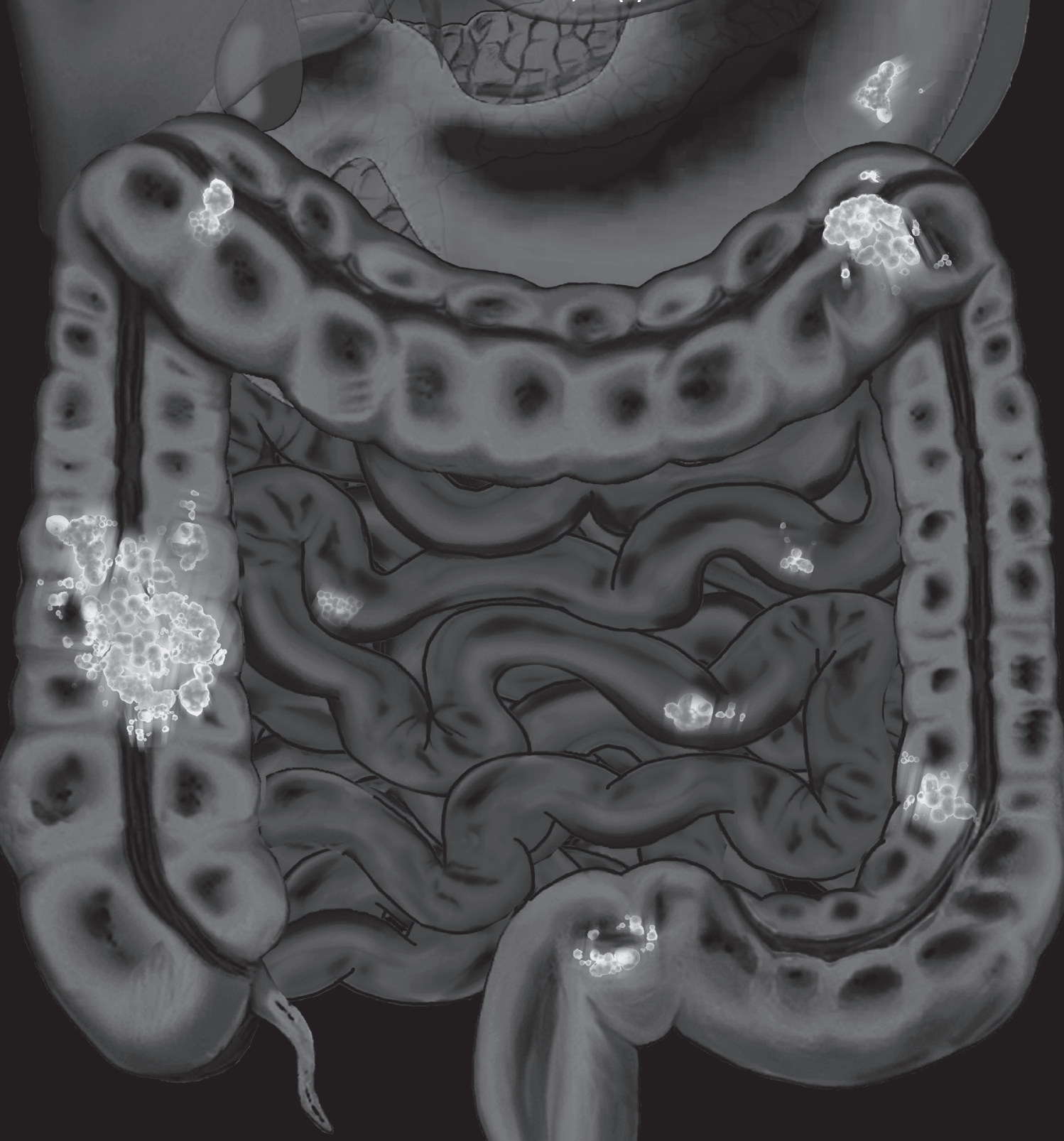





\begin{abstract}
Peritoneal carcinomatosis (PC) is an important cause of morbidity and mortality among patients with gastric cancer. The aim of the current study was to provide reliable populationbased data on the incidence, risk factors and prognosis of PC of gastric origin. All patients diagnosed with gastric cancer in the area of the Eindhoven Cancer Registry between 1995 and 2011 were included. Incidence and survival were computed and risk factors for peritoneal carcinomatosis were determined using multivariate logistic regression analysis. In total, 5,220 patients were diagnosed with gastric cancer, of whom 2,029 (39\%) presented with metastatic disease. PC was present in 706 patients (14\%) of whom 491 patients (9\%) had PC as the only metastatic site. Younger age ( $<60 \mathrm{yrs})$, female gender, advanced T- and $\mathrm{N}$-stage, primary tumour of signet ring cells or linitis plastica, and primary tumours covering multiple anatomical locations of the stomach were all associated with a higher odds ratios of developing PC. Median survival of patients without metastases was 14 months, but only 4 months for patients with PC. PC is a frequent condition in patients presenting with gastric cancer, especially in younger patients with advanced tumour stages. Given the detrimental influence of PC on survival, efforts should be undertaken to further explore the promising results that were obtained in preventing or treating this condition with multi-modality strategies.
\end{abstract}




\section{Introduction}

Gastric cancer is known for its aggressive natural history and is the second main cause of death from cancer worldwide accounting for 740,000 deaths per year. ${ }^{1}$ Incidence rates of gastric cancer vary throughout the world, with two-thirds occurring in developing countries. Peritoneum and liver are the most common metastatic sites among patients with gastric cancer. Peritoneal carcinomatosis (PC) can lead to bowel obstruction and formation of massive amounts of malignant ascites, invariably resulting in death. In spite of its grave consequences, the incidence of PC in gastric cancer is currently unknown. To date, only institution-based data reporting on gastric cancer patients being explored for potentially curative resection or with advanced gastric cancer are available. ${ }^{2-6}$ Population-based data on the incidence of PC from gastric origin are lacking.

Until recently, PC of gastric origin was regarded to be an untreatable condition with a poor quality of life and short life expectancy. However, new chemotherapeutic regimens including 5-FU, anthracyclines and cisplatin demonstrated a benefit in overall survival compared to strategies without these agents, as was shown in a recent meta-analysis. ${ }^{7}$ Furthermore, a combined strategy of cytoreductive surgery and intraperitoneal chemotherapy showed favourable results in highly selected patients. ${ }^{8}$ This multi-modality treatment is currently regarded as the only therapeutic option for selected patients with PC from gastric cancer, reporting 5 -year survival rates ranging from $13 \%$ to $28 \% .^{9-11}$

With the emergence of possible treatment strategies for patients with PC of gastric origin, reliable information on the scope of this condition will become of increasing importance. Therefore, the aim of the current study was to provide reliable population-based data on its incidence and prognosis, and to identify risk factors for the development of PC.

\section{Methods}

The Eindhoven Cancer Registry registers all newly diagnosed cancer patients in the southern part of the Netherlands. This area includes 10 community hospitals, six pathology departments and two radiotherapy institutions, comprising 2.4 million inhabitants. All patients diagnosed between 1995 and 2011 with an adenocarcinoma of gastric origin in the Eindhoven Cancer Registry area were included. Information on patient and tumour characteristics is routinely extracted from the medical records by specially trained administrators of the cancer registry and anatomical sites of distant metastases were registered according to ICD-O (International Classification of Disease-Oncology). Synchronous PC was diagnosed during radiological staging of the primary tumor (CT, PET-CT) or was encountered during surgery for the primary tumor (diagnostic laparoscopy, explorative laparotomy). The database does not contain data on the development of metachronous PC. Comorbidities as hypertension, diabetes and cardiovascular events were registered in the database.

By means of an independent case ascertainment method, the completeness of the registration is estimated to exceed $95 \% .^{12}$ The vital status of all patients was assessed on 
January $1^{\text {st }} 2012$ through merging with the Municipal Administrative Databases in which all deceased and emigrated persons in the Netherlands are registered.

\section{Statistical analysis}

Differences in patient and tumour characteristics were tested by means of a Chi-square test. Period of diagnosis was categorised into four groups; 1995-1998, 1999-2002, 2003-2006 and 2007-2011. Crude survival of patients with gastric cancer according to site of metastasis was determined by the Kaplan-Meier method and compared using a log-rank test. Logistic regression analysis was used to calculate odds ratios and their $95 \%$ confidence interval $(\mathrm{Cl})$ for the development of PC. Survival time was defined as the time from cancer diagnosis until death; patients still alive at January $1^{\text {st }} 2012$ were censored. All tests of statistical significance were two sided. SAS/STAT statistical software (SAS system 9.3, SAS Institute, Cary, NC) was used for all analyses.

\section{Results}

Between 1995 and 2012 5,220 patients were diagnosed with gastric cancer in the Eindhoven Cancer Registry. Of these patients 2,029 patients (39\%) presented with metastatic disease. PC was present in 706 patients ( $14 \%$ of total, $35 \%$ of patients with metastatic disease). Of these patients, 491 patients ( $9 \%$ of total, $24 \%$ of patients with metastatic disease) had PC as the only metastatic site while 215 patients ( $4 \%$ of total, $11 \%$ of patients with metastatic disease) had PC combined with other metastases (Figure 1). Patient characteristics are shown in Table 1. Of the patients with other metastases ( $n=1323)$, liver was affected in $41 \%(n=832)$ of metastatic patients ( $16 \%$ of all patients), and was the only site of metastasis in $27 \%(n=540)$ of metastatic patients ( $10 \%$ of all patients). Other common sites of metastases included the lungs ( $n=170)$, bones $(n=96)$, ovaria $(n=41)$ and brain $(n=39)$. Differences between patients with PC, other metastases, and those without metastases were observed for age, period of cancer diagnosis, number of co-morbidities, localisation of primary tumour, T-stage, $\mathrm{N}$-stage, differentiation grade and tumour morphology. Of all patients, $15 \%$ presented with signet ring cell adenocarcinoma and $5 \%$ with linitis plastica. PC was diagnosed in $20 \%$ and $31 \%$ of the patients with a signet ring cell or linitis plastica tumour morphology, respectively compared with $12 \%$ and $13 \%$ of the patients with other morphology $(p<0.001)$. Female gender, a more advanced primary $\mathrm{T}$ - or $\mathrm{N}$-stage, a primary adenocarcinoma consisting of signet ring cells or linitis plastica and primary tumours covering multiple anatomical locations of the stomach were all associated with higher odds to develop PC (Table 2). In contrast, reduced odds were observed for patients of older age and those with a primary tumour located in the gastric cardia. PC combined with other metastases and PC as only metastatic site had the same risk factors.

Median survival of patients with PC as the only metastatic site was 4.6 months and 3.3 months in patients with PC combined with other metastases. (Table 3). No improvement in median survival was noted over time in patients presenting with PC with or without other metastases. During this period, none of the patients were treated with cytoreductive surgery 
and intraperitoneal chemotherapy. Resection of the primary tumor in the presence of PC resulted in a longer median survival (9.9 vs 3.7 months, table 4 ).

In patients without metastases, $63 \%$ was surgically treated. Patients who did not undergo surgery were older, had worse differentiated tumours and a higher T-stage (all $p<0.0001$ ). Only $3.8 \%$ of these patients were treated with chemotherapy and $5.2 \%$ received radiotherapy. Median survival of patients without metastases was 14.2 months. Those who underwent a resection of the primary tumour $(n=2003,63 \%)$ had a median survival of 30.4 months as compared to 5.0 months for patients in whom no surgery was performed ( $n=1188,37 \%$ ) (Figure 2).

Table 1. General characteristics of patients diagnosed between 1995 and 2012 in the South of the Netherlands with gastric cancer.

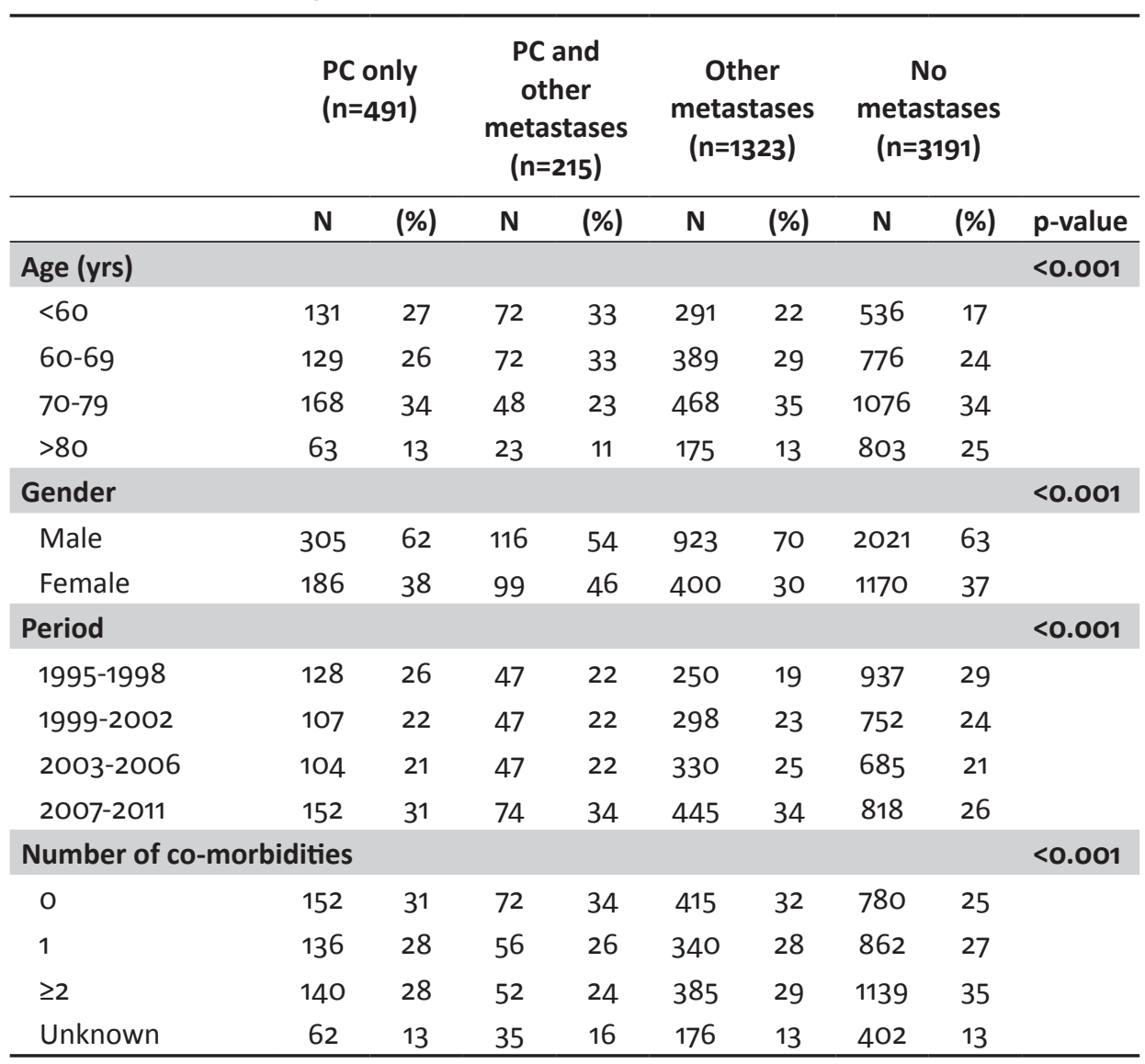

Table 1. continues on next page 


\begin{tabular}{|c|c|c|c|c|c|c|c|c|c|}
\hline \multicolumn{9}{|c|}{ Localisation of primary tumor } & \multirow[t]{2}{*}{$<0.001$} \\
\hline Cardia / fundus & 71 & 14 & 31 & 14 & 473 & 36 & 794 & 25 & \\
\hline Antrum / Body & 197 & 40 & 66 & 31 & 435 & 33 & 1393 & 44 & \\
\hline Pylorus & 26 & 5 & 8 & 4 & 52 & 4 & 249 & 8 & \\
\hline $\begin{array}{l}\text { Overlapping } \\
\text { lesions/ NOS }\end{array}$ & 197 & 40 & 110 & 51 & 363 & 27 & 755 & 24 & \\
\hline \multicolumn{9}{|c|}{ T stage of primary tumor $\mathrm{cT}$ in case of unknown (y)pT } & $<0.001$ \\
\hline To & 1 & 0 & 0 & 0 & 3 & 0 & 22 & 1 & \\
\hline $\mathrm{T} 1$ & 3 & 1 & 2 & 1 & 20 & 2 & 339 & 11 & \\
\hline $\mathrm{T} 2$ & 62 & 13 & 14 & 7 & 94 & 7 & 1093 & 34 & \\
\hline T3 & 78 & 16 & 22 & 10 & 98 & 7 & 584 & 18 & \\
\hline T4 & 111 & 22 & 34 & 16 & 266 & 20 & 232 & 7 & \\
\hline Tx & 236 & 48 & 143 & 66 & 842 & 64 & 921 & 29 & \\
\hline \multicolumn{9}{|c|}{$\mathrm{N}$ stage of primary tumor $\mathrm{cN}$ in case of unknown $\mathrm{pN}$} & $<0.001$ \\
\hline No & 74 & 15 & 21 & 10 & 100 & 8 & 1009 & 32 & \\
\hline $\mathrm{N} 1$ & 56 & 11 & 10 & 5 & 565 & 43 & 809 & 25 & \\
\hline$>\mathrm{N} 2$ & 46 & 9 & 15 & 7 & 152 & 12 & 271 & 8 & \\
\hline $\mathrm{Nx}$ & 315 & 64 & 169 & 79 & 490 & 37 & 1102 & 35 & \\
\hline \multicolumn{9}{|c|}{ Differentiation grade of primary tumor } & $<0.001$ \\
\hline Well/moderately & 84 & 17 & 34 & 16 & 321 & 24 & 873 & 27 & \\
\hline $\begin{array}{l}\text { Poorly/ } \\
\text { undifferentiated }\end{array}$ & 276 & 56 & 105 & 49 & 656 & 50 & 1684 & 53 & \\
\hline Unknown & 131 & 27 & 76 & 35 & 346 & 26 & 634 & 20 & \\
\hline \multicolumn{10}{|c|}{ Tumour morphology } \\
\hline Signet ring cell & 117 & 24 & 44 & 21 & 142 & 11 & 497 & 16 & $<0.001$ \\
\hline Linitis plastica & 65 & 13 & 22 & 10 & 43 & 3 & 155 & 5 & $<0.001$ \\
\hline \multicolumn{10}{|l|}{ Treatment } \\
\hline $\begin{array}{l}\text { Surgical } \\
\text { exploration }\end{array}$ & 33 & 7 & 7 & 3 & 20 & 2 & 33 & 1 & $<0.001$ \\
\hline $\begin{array}{l}\text { Resection of } \\
\text { primary tumour }\end{array}$ & 114 & 24 & 24 & 11 & 186 & 14 & 1998 & 63 & $<0.001$ \\
\hline Metastasectomy & 0 & 0 & 15 & 7 & 16 & 1 & 0 & 0 & $<0.001$ \\
\hline Chemotherapy & 113 & 23 & 54 & 25 & 324 & 24 & 358 & 11 & $<0.001$ \\
\hline Radiotherapy & 27 & 5 & 9 & 4 & 146 & 11 & 208 & 7 & $<0.001$ \\
\hline
\end{tabular}

PC: peritoneal carcinomatosis; LM: liver metastasis, yrs: years; NOS: not otherwise specified

* Number of lymph nodes registered since 1999 


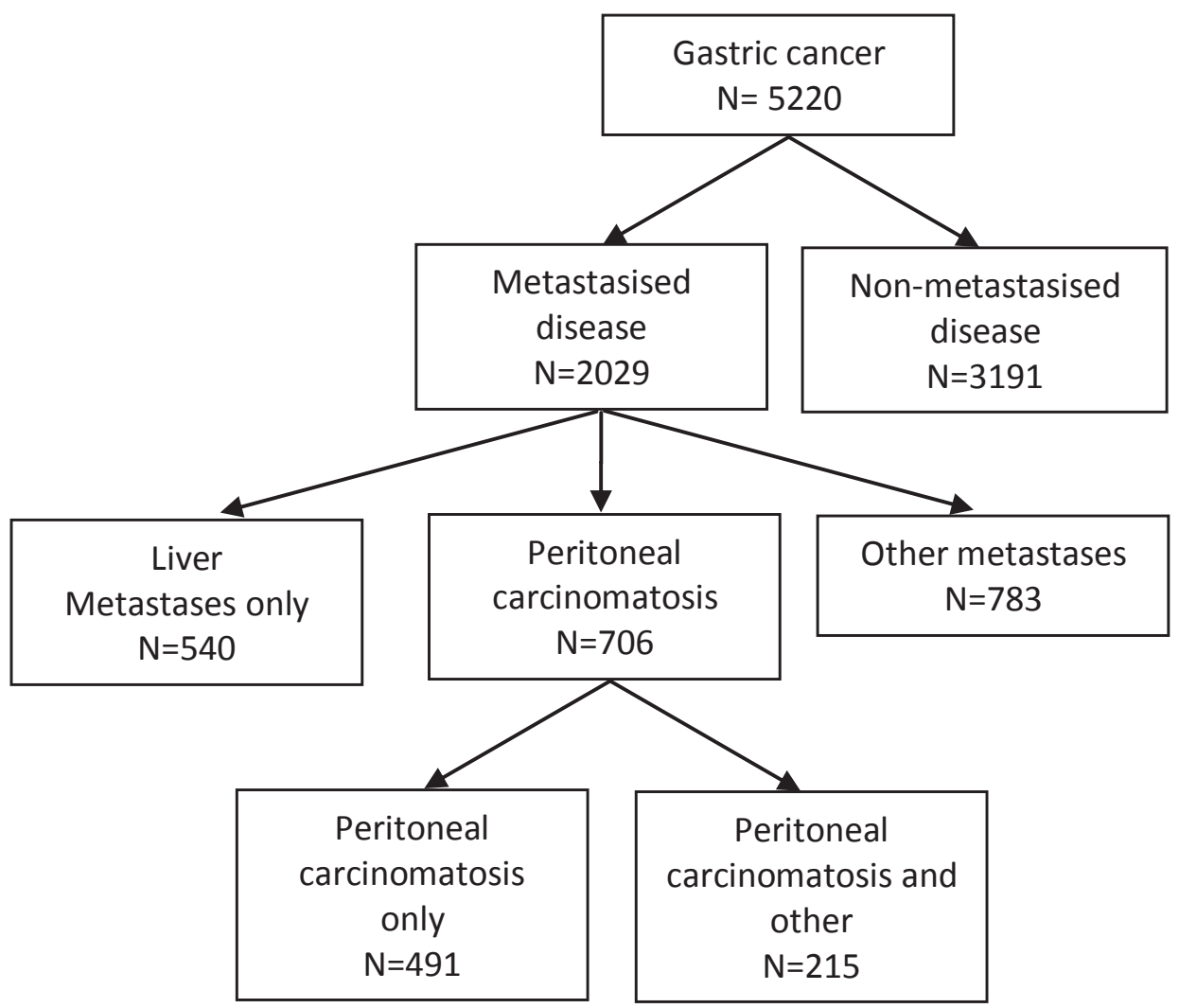

Figure 1. Flowchart of patients diagnosed between 1995 and 2012 in the South of the Netherlands with gastric cancer. 
Table 2. Multivariable logistic regression modeling the risk of peritoneal carcinomatosis among patients with gastric cancer

\begin{tabular}{|c|c|c|c|}
\hline & PC total & PC only & PC other \\
\hline & OR $(95 \% \mathrm{Cl})$ & OR (95\%Cl) & OR (95\% Cl) \\
\hline \multicolumn{4}{|l|}{ Age } \\
\hline$<60$ & 1.0 & 1.0 & 1.0 \\
\hline $60-69$ & $0.7(0.5-0.9)$ & $0.7(0.5-1.0)$ & $0.7(0.5-1.0)$ \\
\hline 70-79 & $0.5(0.4-0.6)$ & $0.7(0.6-1.0)$ & $0.3(0.2-0.4)$ \\
\hline$\geq 80$ & $0.3(0.2-0.3)$ & $0.4(0.3-0.5)$ & $0.2(0.1-0.3)$ \\
\hline \multicolumn{4}{|l|}{ Gender } \\
\hline Male & 1.0 & 1.0 & 1.0 \\
\hline Female & $1.2(1.0-1.5)$ & $1.1(0.9-1.3)$ & $1.6(1.2-2.2)$ \\
\hline \multicolumn{4}{|l|}{ Period of diagnosis } \\
\hline $1995-1998$ & 1.0 & 1.0 & 1.0 \\
\hline 1999-2002 & $0.7(0.6-1.0)$ & $0.7(0.5-1.0)$ & $0.9(0.6-1.4)$ \\
\hline $2003-2006$ & $0.7(0.6-1.0)$ & $0.7(0.6-1.0)$ & $0.8(0.5-1.2)$ \\
\hline 2007-2011 & $1.0(0.8-1.2)$ & $0.9(0.7-1.1)$ & $1.2(0.8-1.8)$ \\
\hline \multicolumn{4}{|l|}{ T stage of primary tumour } \\
\hline $\mathrm{T} 1,2$ & 1.0 & 1.0 & 1.0 \\
\hline T3 & $2.4(1.7-3.3)$ & $2.3(1.6-3.3)$ & $2.2(1.1-4.4)$ \\
\hline $\mathrm{T}_{4}$ & $2.9(2.1-4.0)$ & $2.9(2.0-4.2)$ & $2.3(1.2-4.4)$ \\
\hline TX & $2.2(1.6-3.0)$ & $1.8(1.2-2.5)$ & $3.1(1.7-5.7)$ \\
\hline \multicolumn{4}{|l|}{$\mathrm{N}$ stage of primary tumour } \\
\hline No & 1.0 & 1.0 & 1.0 \\
\hline $\mathrm{N}+$ & $4.0(2.2-7.3)$ & $3.5(1.9-6.4)$ & $8.4(1.1-63.9)$ \\
\hline $\mathrm{Nx}$ & $9.3(5.1-16.9)$ & $6.7(3.6-12.6)$ & $26.9(3.6-199.0)$ \\
\hline \multicolumn{4}{|c|}{ Differentiation grade of primary tumour } \\
\hline Well/moderately & 1.0 & 1.0 & 1.0 \\
\hline Poorly/undifferentiated & $1.2(0.9-1.5)$ & $1.2(0.9-1.5)$ & $1.1(0.7-1.7)$ \\
\hline Unknown & $1.2(0.9-1.5)$ & $1.1(0.8-1.5)$ & $1.3(0.8-2.1)$ \\
\hline \multicolumn{4}{|l|}{ Tumour morphology } \\
\hline Adenocarcinoma (non signet / linitis) & 1.0 & 1.0 & 1.0 \\
\hline Signet ring cell & $1.7(1.4-2.2)$ & $1.8(1.4-2.4)$ & $1.2(0.8-1.8)$ \\
\hline Linitis plastica & $2.0(1.5-2.8)$ & $2.5(1.8-3.6)$ & $1.0(0.6-1.7)$ \\
\hline \multicolumn{4}{|l|}{ Tumour localization } \\
\hline Non cardia & 1.0 & 1.0 & 1.0 \\
\hline Cardia & $0.4(0.3-0.5)$ & $0.4(0.3-0.6)$ & $0.5(0.3-0.8)$ \\
\hline Overlapping lesions/ NOS & $1.3(1.0-1.6)$ & $1.0(0.8-1.3)$ & $1.7(1.2-2.4)$ \\
\hline
\end{tabular}

PC: peritoneal carcinomatosis; OR: odds ratio; NOS: not otherwise specified 


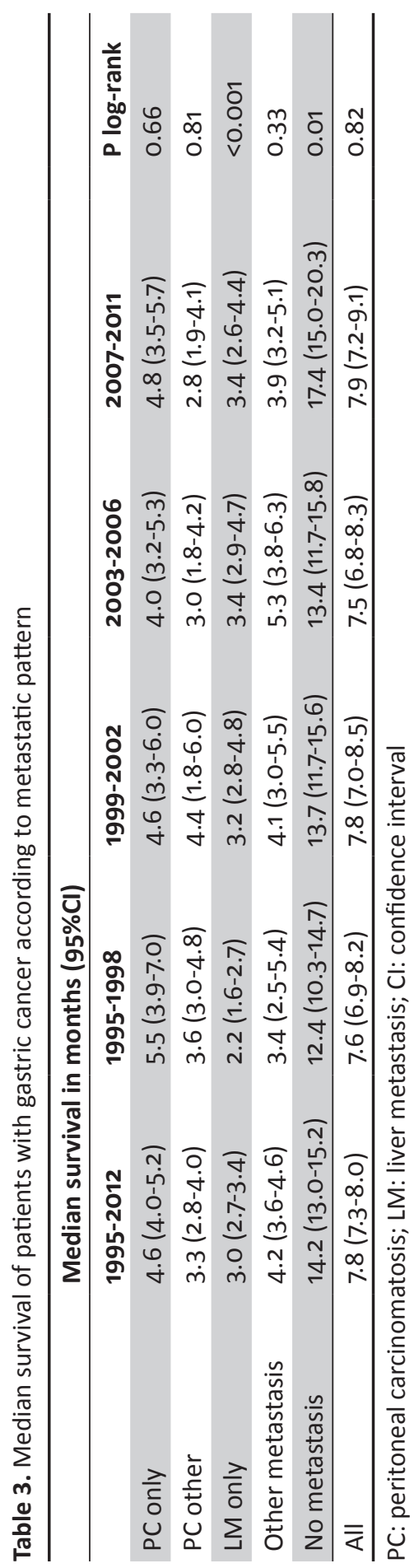


Table 4. Median survival of patients with gastric cancer according to metastatic pattern and type of treatment

\begin{tabular}{|c|c|c|c|c|c|c|}
\hline & \multicolumn{3}{|c|}{ PC only $(n=491)$} & \multicolumn{3}{|c|}{$\begin{array}{l}\text { PC and other metastases } \\
(n=215)\end{array}$} \\
\hline & $\mathbf{N}$ & MS & $95 \% \mathrm{Cl}$ & $\mathbf{N}$ & MS & $95 \% \mathrm{Cl}$ \\
\hline \multicolumn{7}{|l|}{ Surgical exploration } \\
\hline Yes & 33 & 3.7 & $3.0-5.2$ & 7 & $*$ & \\
\hline No & 458 & 4.6 & $4.3-5 \cdot 3$ & 208 & & \\
\hline \multicolumn{7}{|l|}{ Resection of primary tumour } \\
\hline Yes & 114 & 9.9 & 7.7-11.9 & 24 & 5.3 & $3.3-9.3$ \\
\hline No & 377 & 3.7 & $3.4-4.4$ & 191 & 3.0 & $2.3-3.8$ \\
\hline \multicolumn{7}{|l|}{ Metastasectomy } \\
\hline Yes & 0 & $*$ & & 15 & 4.5 & $2.4-7.3$ \\
\hline No & 491 & & & 200 & 3.2 & $2.5-3.9$ \\
\hline \multicolumn{7}{|l|}{ Chemotherapy } \\
\hline Yes & 113 & 8.0 & $6.8-9.3$ & 54 & 7.0 & $4.5-8.9$ \\
\hline No & 378 & 3.7 & $3 \cdot 3-4.4$ & 161 & 2.6 & $1.9-3.2$ \\
\hline \multicolumn{7}{|l|}{ Radiotherapy } \\
\hline Yes & 27 & 7.8 & $4.7-8.4$ & 9 & $*$ & \\
\hline No & 467 & 4.4 & $3.8-5.1$ & 209 & & \\
\hline
\end{tabular}

$* \mathrm{n}<10$

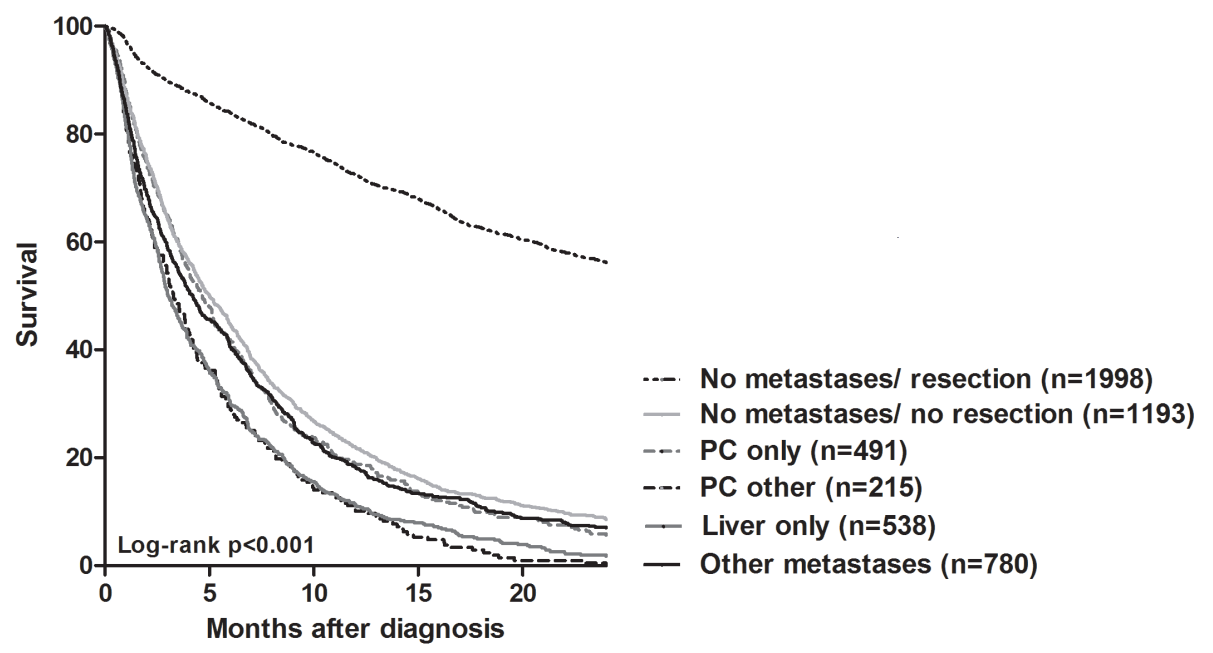

Figure 2. Survival in patients with gastric cancer according to site of metastasis 


\section{Discussion}

This study is the first to provide detailed population-based data on the incidence of PC in gastric cancer patients, revealing that $14 \%$ of these patients presented with synchronous PC, which is more than a third of all patients presenting with metastatic gastric cancer. These data are in line with a previous single-institute report by Abassi et al. ${ }^{6}$ In their cohort of 162 patients treated for advanced gastric cancer, an incidence of $43 \%$ of patients with PC was reported.

\section{Risk factors}

The present study showed a positive correlation between a more advanced T-stage and $\mathrm{N}$-stage and the risk of presenting with PC. In literature, these factors were also associated with worse survival. ${ }^{13}$ This has been documented before in patients with colorectal cancer, which supports to the hypothesis that PC is caused by serosal infiltration of the primary tumour and subsequent shedding of malignant cells into the peritoneal cavity. ${ }^{14-18}$ Also, a younger age as a risk factor to develop PC is shown, which is in line with findings in colorectal cancer patients. ${ }^{14}$

Furthermore, patients with a primary signet ring cell or linitis plastica tumour had a higher risk of being diagnosed with synchronous PC as was recently also shown for the development of metachronous PC..$^{19}$ Identification of signet ring cell tumours may be important as this histological subtype has also shown to have a negative prognostic impact on survival and has a poor response to chemotherapy. ${ }^{20,21}$

\section{Survival}

The presence of PC had a profound negative impact on survival with a median survival of only 4 months. In a study of 13,840 patients with advanced gastric cancer (not further specified), a median survival of 4 months was shown. ${ }^{22}$ This negative impact of PC on survival is also observed in patients with other types of cancer. In patients with pancreatic cancer the addition of PC caused a drop in median survival from 24 to 6 weeks. ${ }^{23}$ In addition, colon cancer patients diagnosed with PC had a median survival of 34-35 weeks, while patients without PC can possibly be cured. ${ }^{24,25}$

\section{Treatment}

In an attempt to treat advanced gastric cancer, different chemotherapeutic regimens have been investigated. In 2010, a Cochrane review and meta-analysis demonstrated a convincing benefit for chemotherapy over best supportive care ( 3 studies, $n=184$ )..$^{7}$ In total, 35 trials with a total of 5726 patients were included, which showed that combination chemotherapy, including 5-FU, anthracyclines and cisplatin gave best results compared to conventional chemotherapy. A method to surgically treat PC of gastric origin was described by Hioki et al. ${ }^{5}$ Resection of the primary tumor showed favorable results in patients with limited PC, with median survival of 18 and 15 months compared to 9 months in patients with extensive PC. In addition, Liu et al. ${ }^{26}$ reported a 5 -year survival rate of $24 \%$ in patients with microscopic PC compared to $37 \%$ in patients without PC. Nevertheless, this microscopic PC has a much better prognosis compared to patients with macroscopic PC. ${ }^{26}$ 


\section{Multimodality approach of PC of gastric origin}

Recently, the implementation of a multimodality treatment including aggressive cytoreductive surgery combined with heated intraperitoneal chemotherapy (HIPEC) has led to promising results in selected patients with peritoneal malignancies of various origins, including colonic and ovarian cancer, mesothelioma and pseudomyxoma peritonei..$^{27-29}$ Given the prosperous results obtained in these tumours, it was postulated that HIPEC may also be of benefit for patients with PC of gastric origin. In a meta-analysis of 10 studies ( $n=144,1$ non-randomized prospective controlled trial, 6 prospective case series and 3 retrospective case series) by Gill et al. ${ }^{8}$ The use of complete cytoreductive surgery combined with intraperitoneal chemotherapy in patients with PC from gastric cancer showed a median survival of 8 months. Survival even increased to 15 months in patients in whom a macroscopical complete cytoreduction could be established. Another review, by Glehen and Sugarbaker ${ }^{30}$ showed a median survival of 7 to 16 months in 459 patients from 8 studies. The reported median survival rates may be regarded as promising in contrast to the median survival of only 4 months observed in the present study. However, this treatment is associated with considerable morbidity (21.5\%$50 \%)$ and mortality (4.8\%). ${ }^{8,}{ }^{31}$ Overall, the results of the use of complete cytoreductive surgery combined with intraperitoneal chemotherapy seem less encouraging than those obtained for other peritoneal surface malignancies, as colorectal and ovarian carcinoma and further research is warranted. ${ }^{30}$

\section{Prevention}

Over $70 \%$ of gastric cancer patients undergoing surgery with curative intent will develop intra-abdominal recurrence in the course of the disease. Spread of malignant cells into the peritoneal cavity during surgery is one of the possible mechanisms for this phenomenon. Given the bad prognosis of peritoneal dissemination, a strategy aimed at the prevention of PC by aggressive local treatment of patients at risk seems a realistic approach. Treatment with intraperitoneal chemotherapy in addition to resection of the primary tumour showed a survival benefit in a meta-analysis of 10 RCTs $(n=1648) \cdot{ }^{32}$ As risk factors to develop PC were identified in this study, PC can be diagnosed in earlier stages, which can increase the success rate of treatment with CRS and HIPEC.

\section{Conclusion}

$\mathrm{PC}$ is a frequent condition in patients presenting with gastric cancer, especially in younger patients with advanced tumour stages. In the present study several risk factors were identified associated with the occurrence of PC. Given the detrimental influence of PC on survival, efforts should be undertaken to further explore the promising results that were obtained in preventing or treating this condition with multi-modality strategies. 


\section{References}

1. Crew KD, Neugut AI. Epidemiology of gastric cancer. World J Gastroenterol 2006;12:354-62.

2. Sugarbaker $\mathrm{PH}$, Yonemura Y. Clinical pathway for the management of resectable gastric cancer with peritoneal seeding: best palliation with a ray of hope for cure. Oncology 2000;58:96-107.

3. Gretschel S, Siegel R, Estevez-Schwarz L, Hunerbein M, Schneider U, Schlag PM. Surgical strategies for gastric cancer with synchronous peritoneal carcinomatosis. Br J Surg 2006;93:1530-5.

4. Bonenkamp JJ, Sasako M, Hermans J, van de Velde CJ. Tumor load and surgical palliation in gastric cancer. Hepatogastroenterology 2001;48:1219-21.

5. Hioki M, Gotohda N, Konishi M, Nakagohri T, Takahashi S, Kinoshita T. Predictive factors improving survival after gastrectomy in gastric cancer patients with peritoneal carcinomatosis. World journal of surgery 2010;34:555-62.

6. Abbasi SY, Taani HE, Saad A, Badheeb A, Addasi A. Advanced gastric cancer in jordan from 2004 to 2008: a study of epidemiology and outcomes. Gastrointest Cancer Res 2010;4:122-7.

7. Wagner AD, Unverzagt $S$, Grothe $W$, et al. Chemotherapy for advanced gastric cancer. Cochrane Database Syst Rev 2010:CD004064.

8. Gill RS, Al-Adra DP, Nagendran J, et al. Treatment of gastric cancer with peritoneal carcinomatosis by cytoreductive surgery and HIPEC: a systematic review of survival, mortality, and morbidity. Journal of surgical oncology 2011;104:692-8.

9. Rossi $C R$, Pilati $P$, Mocellin $S$, et al. Hyperthermic intraperitoneal intraoperative chemotherapy for peritoneal carcinomatosis arising from gastric adenocarcinoma. I supplementi di Tumori : official journal of Societa italiana di cancerologia ... [et al.] 2003;2:S54-7.

10. Glehen $O$, Schreiber V, Cotte E, et al. Cytoreductive surgery and intraperitoneal chemohyperthermia for peritoneal carcinomatosis arising from gastric cancer. Archives of surgery 2004;139:20-6.

11. Yonemura Y, Fujimura T, Nishimura G, et al. Effects of intraoperative chemohyperthermia in patients with gastric cancer with peritoneal dissemination. Surgery 1996;119:437-44.

12. Schouten LJ, Hoppener P, van den Brandt PA, Knottnerus JA, Jager JJ. Completeness of cancer registration in Limburg, The Netherlands. International journal of epidemiology 1993;22:369-76.

13. Zu H, Wang F, Ma Y, Xue Y. Stage-stratified analysis of prognostic significance of tumor size in patients with gastric cancer. PLoS One 2013;8:e54502.

14. Lemmens VE, Klaver YL, Verwaal VJ, Rutten HJ, Coebergh JW, de Hingh IH. Predictors and survival of synchronous peritoneal carcinomatosis of colorectal origin: a population-based study. Int J Cancer 2010;128:2717-25.

15. Ceelen WP, Bracke ME. Peritoneal minimal residual disease in colorectal cancer: mechanisms, prevention, and treatment. Lancet Oncol 2009;10:72-9.

16. Knorr C, Reingruber B, Meyer T, Hohenberger W, Stremmel C. Peritoneal carcinomatosis of colorectal cancer: incidence, prognosis, and treatment modalities. Int J Colorectal Dis 2004;19:181-7.

17. Sadeghi B, Arvieux C, Glehen O, et al. Peritoneal carcinomatosis from non-gynecologic malignancies: results of the EVOCAPE 1 multicentric prospective study. Cancer 2000;88:358-63.

18. Sugarbaker $\mathrm{PH}$. Intraperitoneal chemotherapy for treatment and prevention of peritoneal carcinomatosis and sarcomatosis. Dis Colon Rectum 1994;37:S115-22.

19. Honore $C$, Goere $D$, Messager $M$, et al. Risk factors of peritoneal recurrence in eso-gastric signet ring cell adenocarcinoma: Results of a multicentre retrospective study. Eur J Surg Oncol 2013;39:235-41.

20. Messager M, Lefevre JH, Pichot-Delahaye V, Souadka A, Piessen G, Mariette C. The impact of perioperative chemotherapy on survival in patients with gastric signet ring cell adenocarcinoma: a multicenter comparative study. Annals of surgery 2011;254:684-93; discussion 693.

21. Piessen G, Messager $M$, Leteurtre $E$, Jean-Pierre $T$, Mariette $C$. Signet ring cell histology is an independent predictor of poor prognosis in gastric adenocarcinoma regardless of tumoral clinical presentation. Ann Surg 2009;250:878-87. 
22. Yang D, Hendifar A, Lenz C, et al. Survival of metastatic gastric cancer: Significance of age, sex and race/ethnicity. J Gastrointest Oncol 2011;2:77-84.

23. Thomassen I, Lemmens VE, Nienhuijs SW, Luyer MD, Klaver YL, de Hingh IH. Incidence, Prognosis, and Possible Treatment Strategies of Peritoneal Carcinomatosis of Pancreatic Origin: A Population-Based Study. Pancreas 2012.

24. Klaver YL, Lemmens VE, Creemers GJ, Rutten HJ, Nienhuijs SW, de Hingh IH. Population-based survival of patients with peritoneal carcinomatosis from colorectal origin in the era of increasing use of palliative chemotherapy. Ann Oncol 2011;22:2250-6.

25. Verwaal VJ, Bruin S, Boot H, van Slooten G, van Tinteren H. 8-year follow-up of randomized trial: cytoreduction and hyperthermic intraperitoneal chemotherapy versus systemic chemotherapy in patients with peritoneal carcinomatosis of colorectal cancer. Annals of surgical oncology 2008;15:242632.

26. Liu X, Cai H, Sheng W, Wang Y. Long-term results and prognostic factors of gastric cancer patients with microscopic peritoneal carcinomatosis. PLoS One 2012;7:e37284.

27. Verwaal VJ, Bruin S, Boot H, van Slooten G, van Tinteren H. 8-year follow-up of randomized trial: cytoreduction and hyperthermic intraperitoneal chemotherapy versus systemic chemotherapy in patients with peritoneal carcinomatosis of colorectal cancer. Ann Surg Oncol 2008;15:2426-32.

28. Dovern E, de Hingh IH, Verwaal VJ, van Driel WJ, Nienhuijs SW. Hyperthermic intraperitoneal chemotherapy added to the treatment of ovarian cancer. A review of achieved results and complications. European journal of gynaecological oncology 2010;31:256-61.

29. Chua TC, Moran BJ, Sugarbaker PH, et al. Early- and long-term outcome data of patients with pseudomyxoma peritonei from appendiceal origin treated by a strategy of cytoreductive surgery and hyperthermic intraperitoneal chemotherapy. J Clin Oncol 2012;30:2449-56.

30. Glehen OYY, Sugarbaker PH. Cytoreductive Surgery \& Perioperative Chemotherapy for Peritoneal Surface Malignancy: Ciné-Med; 2013.

31. Costa WL, Jr., Coimbra FJ, Ribeiro HS, et al. Safety and preliminary results of perioperative chemotherapy and hyperthermic intraperitoneal chemotherapy (HIPEC) for high-risk gastric cancer patients. World J Surg Oncol 2012;10:195.

32. Yan TD, Black D, Sugarbaker PH, et al. A systematic review and meta-analysis of the randomized controlled trials on adjuvant intraperitoneal chemotherapy for resectable gastric cancer. Ann Surg Oncol 2007;14:2702-13. 


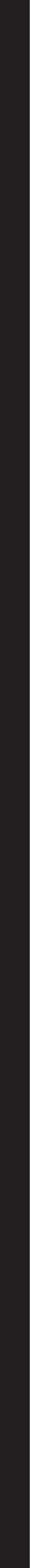




\section{Chapter 5}

Incidence, prognosis and possible treatment strategies of peritoneal carcinomatosis of pancreatic origin: a populationbased study

Irene Thomassen, Valex, E.P.P. Lemmens, Simon W. Nienhuijs, Misha D. Luyer, Yvonne L. Klaver, Ignace H.J.T. de Hingh.

Pancreas. 2013 Jan;42(1):72-5

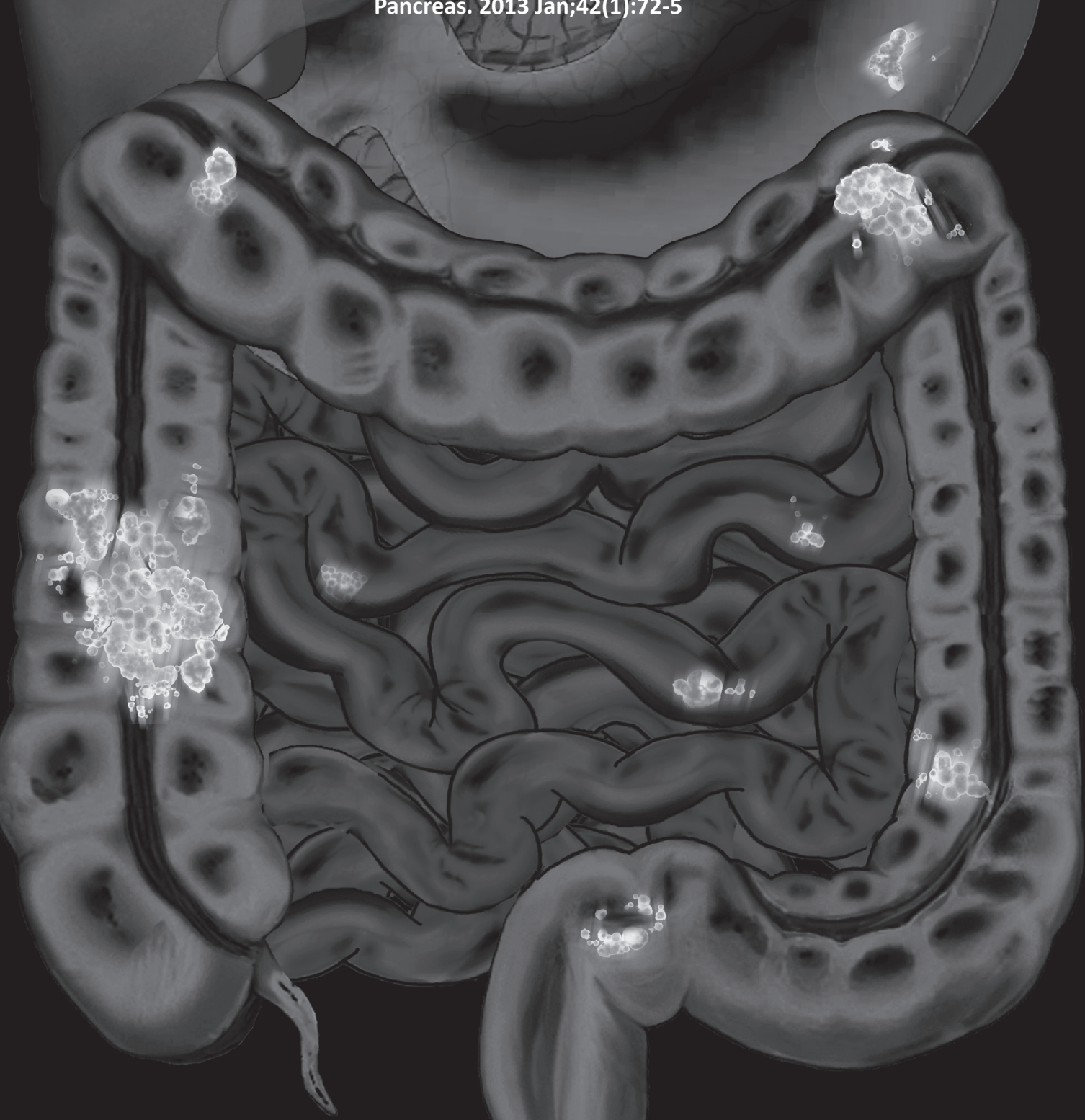





\section{Abstract}

\section{Objectives}

Peritoneal carcinomatosis (PC) is an important cause of morbidity and mortality among patients with pancreatic cancer. In an era where therapeutic options for PC of multiple origins are emerging, our aim was to provide population based data on incidence, treatment, and prognosis of PC of pancreatic origin.

\section{Methods}

All patients diagnosed with non-endocrine pancreatic cancer between 1995-2009 in the area of the Eindhoven Cancer Registry were included.

\section{Results}

In total, 2924 patients were diagnosed with pancreatic cancer of which 265 patients (9\%) presented with synchronous PC. An increasing trend could be noted in patients treated with chemotherapy in more recent years (11\% in 1995-1999, 22\% in 2005-2009. $p=0.060$ ). Median survival in patients presenting with PC was only 6 weeks ( $95 \% \mathrm{Cl} 5-7$ ) and did not improve over time, contrasting improvements among patients with non-metastasised disease (from 19 to 30 weeks) and patients with metastasised disease confined to the liver (from 8 to 12 weeks).

\section{Conclusion}

Prognosis of pancreatic cancer patients presenting with PC remains extremely poor. Treatment options are scarce and given the magnitude of the problem, efforts should be undertaken to develop effective treatments in experimental and clinical studies. 


\section{Introduction}

Peritoneal carcinomatosis (PC) is defined as the presence of malignant cells in the peritoneal cavity. ${ }^{1,2}$ Although the organ of origin of such malignant cells may differ, the clinical syndrome resulting from $\mathrm{PC}$ is usually similar with bowel obstruction and formation of massive amounts of malignant ascites being the most characteristic feature.

Traditionally, PC has been regarded as an untreatable condition requiring palliative measures at most with an invariable fatal outcome. However, introduction of locoregional therapies combining cytoreductive surgery and heated intra-peritoneal chemotherapy (HIPEC) about two decades ago has changed the view on PC. Furthermore, this treatment strategy opens therapeutic opportunities for selected patients with PC of appendiceal or colorectal origin with promising results. ${ }^{3}$ Very recently, encouraging results have also been published using this technique in patients suffering from PC of gastric and ovarian cancer. ${ }^{4,5}$ This has raised the question whether other types of cancer associated with PC may also respond to HIPEC. In pancreatic cancer, the peritoneal cavity is a frequently encountered metastatic site and although this is well recognized as a negative factor for survival, relatively little is known about the incidence, prognosis and treatment possibilities. Given the recent achievements in the treatment of PC of various origins, the aim of the current study was to provide insight in the current status of PC of pancreatic origin. This was done by providing reliable populationbased data on the incidence and prognosis of this condition and by reviewing the literature for possible treatment options.

\section{Methods}

All newly diagnosed patients with pancreatic cancer in the southern part of the Netherlands are registered by the Eindhoven Cancer Registry. This area includes six pathology departments, 10 community hospitals and two radiotherapy institutions, comprising 2.4 million inhabitants. For this study, all patients diagnosed between 1995 and 2009 with non-endocrine pancreatic cancer in the Eindhoven Cancer Registry area were included. Information on patient and tumour characteristics is routinely extracted from the medical records by specially trained administrators of the cancer registry. Anatomical sites of distant metastasis are registered according to ICD-O (International Classification of Disease-Oncology). By means of an independent case ascertainment method, the completeness of the registration is estimated to exceed 95\%.6 The vital status of all patients diagnosed until December 31st, 2009, was assessed on January 1st, 2010, through merging with the Municipal Administrative Databases in which all deceased and emigrated persons in The Netherlands are registered.

\section{Statistical analysis}

Differences in patient and tumour characteristics were tested by means of a Chi-square test. Trends in treatment over time were evaluated using the Cochran-Armitage trend test. Survival time was defined as the time from diagnosis until death; patients still alive at January 1st 2010, were censored. Patient and tumour characteristics of patients with different sites of metastasis were compared and analysed using a Chi-square test. All tests of statistical 
significance were two sided. SAS/STAT statistical software (SAS system 9.1, SAS Institute, Cary, NC) was used for all analyses.

\section{Results}

Between 1995 and 2009, a total of 2924 patients were diagnosed with non-endocrine pancreatic cancer in the Eindhoven Cancer Registry. Patient characteristics are shown in table 1 . The majority of patients $(51.7 \%)$ initially presented with non-metastasized disease. The predominant site of synchronous metastases was the liver $(27.9 \%)$, while $9.1 \%$ of the patients presented with synchronous PC. In 113 patients the peritoneal cavity was the only metastatic site (3.9\% of total) while 152 patients (5.2\%) also presented with metastases on other locations. Significantly more male patients presented with PC $(\mathrm{p}<0.05)$ with a peak incidence between the age of 60 and 69 years. During the study period, the incidence of patients diagnosed with pancreatic cancer increased. Moreover, the proportion of patients presenting with metastatic disease increased sharply over time being the most prominent for patients presenting with synchronous PC (from $6.7 \%$ to $11.7 \%, p<0.001$ ).

None of the patients with PC underwent surgery with curative intent and only a minority of patients (18.5\%) was treated with palliative chemotherapy (table 2). No significant change in treatment was noted over time, although a trend could be noted from $10.9 \%$ palliative chemotherapy in 1995-1999 to 22.1\% palliative chemotherapy in 2005-2009 ( $P=0.060)$. In contrast, the proportion of patients with liver metastases treated with palliative chemotherapy increased significantly over time ( $p<0.001)$. Also in patients with non-metastasized disease, the number of patients that was offered treatment increased significantly (table 3). Surgical resection rates increased from $13.7 \%$ to $23.5 \%$ and the number of patients receiving palliative chemotherapy increased from $5.7 \%$ to $17.4 \%(p<0.001)$.

Median survival in patients with synchronous PC is only 6 weeks ( $95 \% \mathrm{Cl} 5-7$ ) and did not improve over time (figure 1). Median survival in patients with liver metastases is significantly longer compared to patients with PC ( $p<0.001)$, but remains poor with only 9 weeks $(95 \%$ $\mathrm{Cl}$ 9-10). However, median survival improved significantly over time to 12 weeks in the most recent period $(p<0.001)$.

As shown in figure 2, median survival of patients without metastasis was highest with 24 weeks (95\% Cl 22-26). Also in these patients a significant improvement in survival was observed from 19 weeks in the earliest period to 30 weeks in the most recent period ( $p<0.001$, figure 3 ). 
Table 1. Patient characteristics of patients with pancreatic cancer

\begin{tabular}{|c|c|c|c|c|c|c|c|c|}
\hline & \multirow{2}{*}{$\begin{array}{c}\text { Whole } \\
\text { group }\end{array}$} & \multicolumn{2}{|c|}{$\begin{array}{l}\text { Synchronous } \\
\text { peritoneal } \\
\text { carcinomatosis }\end{array}$} & \multicolumn{2}{|c|}{$\begin{array}{c}\text { Synchronous } \\
\text { liver } \\
\text { metastasis }\end{array}$} & \multicolumn{2}{|c|}{ No metastasis } & \multirow[t]{2}{*}{ p-value* } \\
\hline & & $N=265$ & $\%$ & $\mathrm{~N}=815$ & $\%$ & $N=1512$ & $\%$ & \\
\hline Gender & & & & & & & & 0.0184 \\
\hline Male & 1535 & 147 & 55.5 & 461 & 56.6 & 761 & 50.3 & \\
\hline Female & 1389 & 118 & 44.5 & 354 & 43.4 & 751 & 49.7 & \\
\hline Age & & & & & & & & $<.0001$ \\
\hline$<60$ & 617 & 55 & 20.8 & 184 & 22.6 & 297 & 19.6 & \\
\hline $60-69$ & 879 & 93 & 35.1 & 270 & 33.1 & 393 & 26.0 & \\
\hline $70-79$ & 1002 & 88 & 33.2 & 263 & 32.3 & 551 & 36.4 & \\
\hline$>79$ & 426 & 29 & 10.9 & 98 & 12.0 & 271 & 17.9 & \\
\hline Comorbidity & & & & & & & & $<.0001$ \\
\hline none & 755 & 76 & 28.7 & 214 & 26.3 & 375 & 24.8 & \\
\hline 1 & 776 & 73 & 27.5 & 221 & 27.1 & 378 & 25.0 & \\
\hline$>1$ & 966 & 93 & 35.1 & 277 & 33.6 & 493 & 32.6 & \\
\hline Unknown & 427 & 23 & 8.7 & 103 & 12.6 & 266 & 17.6 & \\
\hline Period of diagnosis & & & & & & & & $<.0001$ \\
\hline 1995-1999 & 813 & 55 & 20.8 & 201 & 24.7 & 496 & 32.8 & \\
\hline 2000-2004 & 881 & 65 & 24.5 & 260 & 31.9 & 454 & 30.0 & \\
\hline $2005-2009$ & 1230 & 145 & 54.7 & 354 & 43.4 & 562 & 37.2 & \\
\hline
\end{tabular}

*P-value was calculated using Chi-square test, comparing different stages of pancreatic cancer.

Table 2. Treatment of patients with peritoneal carcinomatosis of pancreatic origin

\begin{tabular}{|c|c|c|c|c|c|c|c|c|}
\hline & & \multicolumn{2}{|c|}{ 1995-1999 } & \multicolumn{2}{|c|}{ 2000-2004 } & \multicolumn{2}{|c|}{ 2005-2009 } & \multirow[t]{2}{*}{ p-value* } \\
\hline & & $N=55$ & $\%$ & $N=65$ & $\%$ & $N=145$ & $\%$ & \\
\hline \multirow[t]{3}{*}{ Chemotherapy } & & & & & & & & 0.1795 \\
\hline & Yes & 6 & 10.9 & 11 & 16.9 & 32 & 22.1 & \\
\hline & No & 49 & 89.1 & 54 & 83.1 & 113 & 77.9 & \\
\hline \multirow[t]{3}{*}{ Surgery } & & & & & & & & N.A. \\
\hline & Yes & $\mathrm{o}$ & 0 & $\mathrm{o}$ & $\mathrm{o}$ & 0 & $\mathrm{o}$ & \\
\hline & No & 55 & 100 & 65 & 100 & 145 & 100 & \\
\hline
\end{tabular}

*P-value was calculated using Chi-square test

N.A.: not appilcable 
Table 3. Surgery and chemotherapy in patients with pancreatic cancer without metastasis

\begin{tabular}{lccccccccc}
\hline & \multicolumn{1}{c}{$1995-1999$} & $2000-2004$ & $2005-2009$ & p-value* $^{*}$ \\
\hline & & $\mathbf{N}=496$ & $\%$ & $\mathbf{N}=454$ & $\%$ & $\mathbf{N}=562$ & $\%$ & \\
\hline Chemotherapy & & & & & & & & $<.0001$ \\
& Yes & 28 & 5.7 & 47 & 10.4 & 98 & 17.4 & \\
& No & 468 & 94.4 & 407 & 89.7 & 464 & 82.6 & \\
Surgery & & & & & & & & $<.0001$ \\
& Yes & 68 & 13.7 & 71 & 15.6 & 132 & 23.5 & \\
& No & 428 & 86.3 & 383 & 84.4 & 430 & 76.5 & \\
\hline
\end{tabular}

*P-value was calculated using Chi-square test

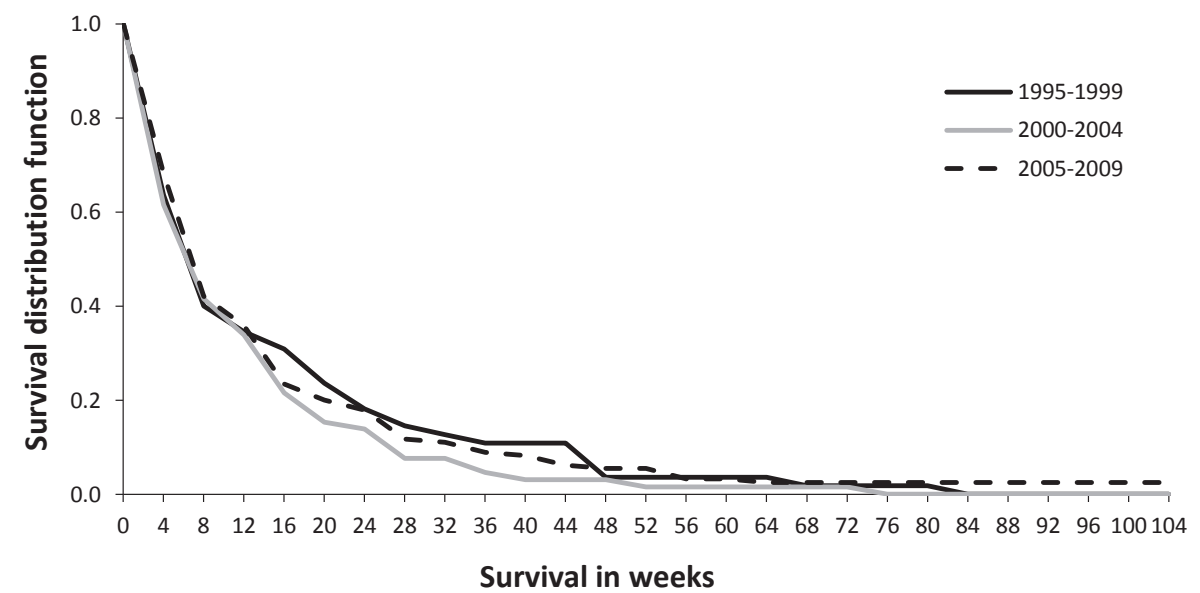

Figure 1. Survival of patients with pertitoneal carcinomatosis of pancreatic origin comparing periods

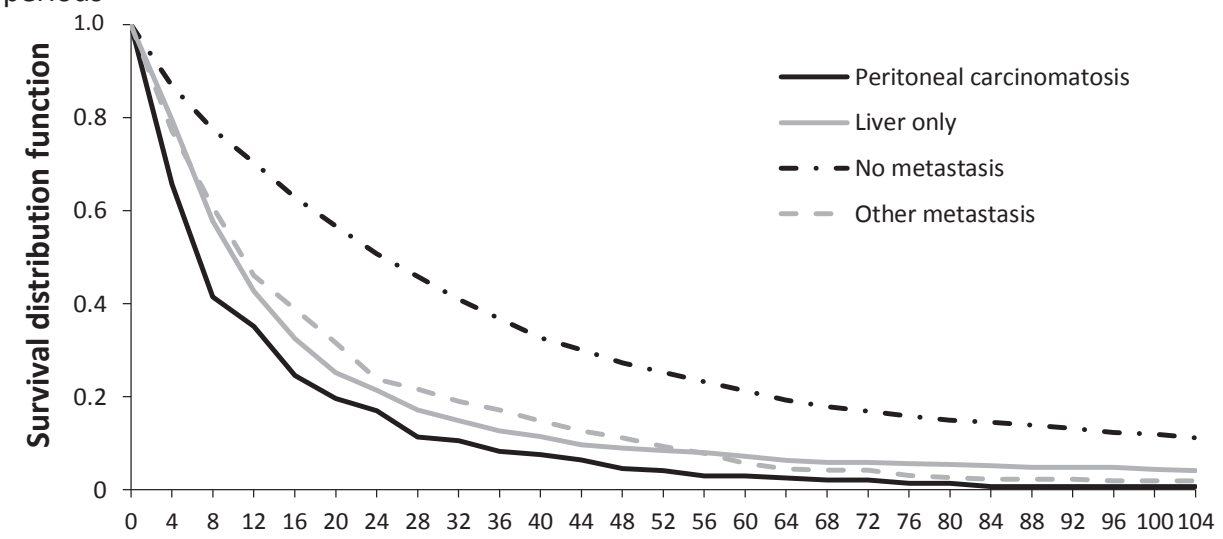

Survival in weeks

Figure 2. Survival of patients with pancreatic cancer according to metastatic pattern 


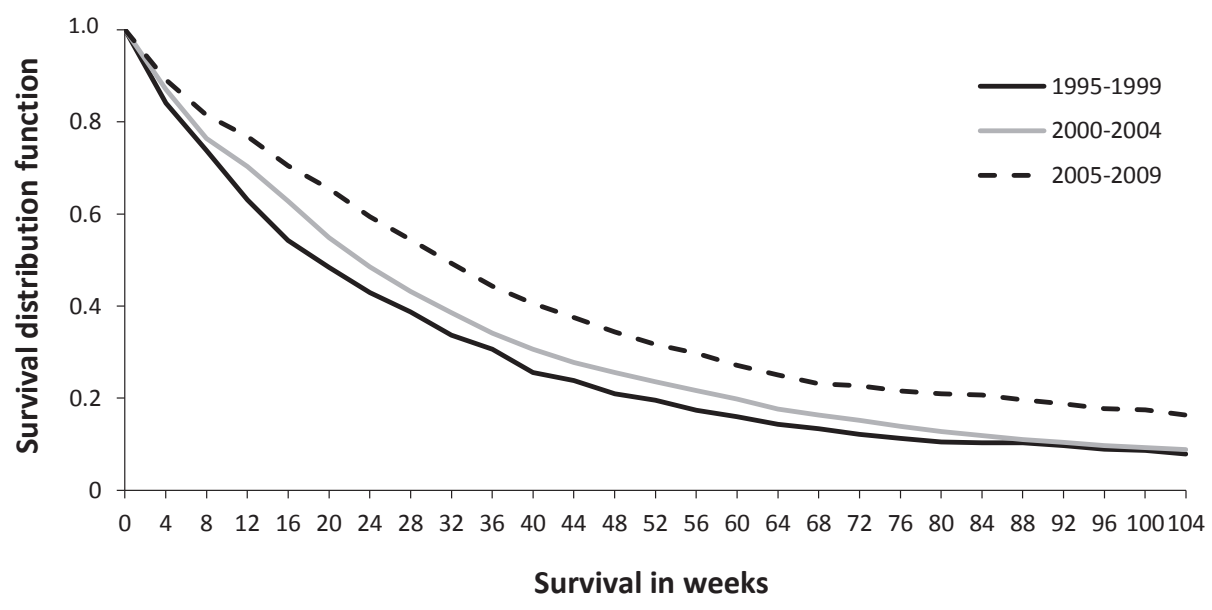

Figure 3. Survival of patients with pancreatic cancer without metastasis comparing periods

\section{Discussion}

The incidence of pancreatic cancer is steadily increasing in many countries around the world. ${ }^{7}$ Early signs and symptoms of pancreatic cancer are often non-specific and therefore the majority of patients present with advanced local disease and metastases in various organs at the time of diagnoses. ${ }^{7-9}$ Together with its typical aggressive local growth and rapid systemic spread this explains the grim prognosis of this disease. One of the metastatic pathways of pancreatic cancer is the peritoneal cavity, resulting in peritoneal carcinomatosis. So far, PC of pancreatic origin has received little interest in medical literature. Recent developments in the treatment of PC of colorectal, appendiceal, ovarian and gastric origin have changed the attitude towards PC. ${ }^{3,4,10}$ For this reason the incidence, prognosis and treatment of PC of pancreatic origin were investigated in this study.

Until now, data on the incidence of PC of pancreatic origin were not available on a population-based level. Although a population-based study from the United States including 10.612 patients showed that $50.6 \%$ of patients presented with metastatic disease, no data were given on the actual incidence of PC. ${ }^{11}$ Recently, an autopsy study showed that PC was present in $22 \%$ of the patients who died from pancreatic cancer. ${ }^{7} \mathrm{~A}$ similar percentage was recently published by Morizane et al. ${ }^{12}$ but this involved a selected group of patients receiving palliative chemotherapy for advanced pancreatic cancer. In the present study it was shown that synchronous PC was diagnosed in $9.1 \%$ of the patients at the time of diagnosis. Interestingly, the incidence of PC showed a steep increase in the most recent period. This probably reflects the increased usage and quality of radiological imaging, especially CT-scans, in these patients. Despite improved diagnostic accuracy of PC, the reported incidence of PC in the most recent period of this study (11.7\%) may even be an underestimation since PC is generally hard to detect on imaging studies due to the small size of the peritoneal tumour 
implants. This study reveals that at least 1 in every 8 patients presents with synchronous PC being much more frequent than for instance colorectal cancer. ${ }^{1}$

None of the patients in our study population underwent surgical resection with curative intent and only a minority was treated with palliative chemotherapy. Most patients were offered palliative care only resulting in survival of 6 weeks. Treatment results of PC of pancreatic origin are only scarcely reported in current medical literature. Two case series have described an exclusively surgical approach, combining resection of the primary tumour with radical debulking of the peritoneal deposits..$^{9,13}$ Both groups conclude that such approach may be feasible but results in a high complication rate without a benefit in survival.

Recently, some progress has been achieved with systemic chemotherapy in patients with metastasized pancreatic cancer. Gemcitabine was shown to be more effective than 5-fluorouracil (5-FU) in alleviating disease-related symptoms and median survival was significantly longer (5.7 months vs 4.4 months, $p=0.003) .{ }^{14}$ When gemcitabine and 5-FU were combined median survival was even longer, when compared to gemicitabine alone, but this did result in a statistically significant difference (6.7 months vs 5.4 months, $p=0.09$ )..$^{15}$ No beneficial effect on survival was noted with bevacizumab with or without docetaxel and gemcitabine with or without bevacizumab. ${ }^{16,17}$ In a meta-analysis of randomized trials a significant survival benefit was shown when gemcitabine was either combined with platinum analogs or fluoropyrimidines. ${ }^{17}$ Based on a preliminary subgroup analysis, pancreatic cancer patients with a good performance status appear to benefit from gemcitabine-based cytotoxic combinations, whereas patients with a poor performance status seem to have no survival benefit from combination chemotherapy. Recently, a combination of chemotherapeutic agents (FOLFIRINOX) has been shown to significantly improve survival in patients with metastatic disease. ${ }^{18,19}$

Despite these recent advances achieved with systemic chemotherapy, it remains questionable whether patients with PC also benefit. There are no studies available that specifically investigated the effect of chemotherapy on PC of pancreatic origin. The biological response to systemic chemotherapy may be different in patients suffering from PC as compared for instance with patients suffering from liver metastasis. The increased usage of chemotherapy in colorectal cancer patients with PC for example did not result in a significant survival benefit as opposed to patients with liver metastases. ${ }^{20}$ Possible explanations may be a difference in blood-supply to metastatic sites or biological response to cytotoxic agents. Interestingly, FOLFIRINOX was shown to be effective in sub-group analysis in patients with hepatic and pulmonary metastases but the subgroup suffering from PC was not mentioned, suggesting that such beneficial effect of FOLFIRINOX was not seen in this group. ${ }^{18}$

Inspired by the results obtained by combining radical surgery with HIPEC in colorectal cancer patients, Farma et al. ${ }^{21}$ performed this procedure in 7 patients using heated cisplatin for 90 minutes in patients with PC of pancreatic origin. Although the reported median survival of 16 months compares favourable to our series and may give some way to optimism, there 
was a high incidence of invalidating complications and the authors conclude that such treatment should currently not be offered. A Japanese case report described the success of intra-peritoneal paclitaxel combined with systemic chemotherapy of S-1 and gemcitabine for locally advanced pancreatic cancer with peritoneal carcinomatosis. ${ }^{22}$ After 5 courses of treatment ascites had disappeared and CA19-9 and CA125 levels normalized. After 20 months all peritoneal deposits had disappeared and a radical resection of the tumour was performed.

Given the dreadful prognosis of PC one may attempt to prevent the occurrence of metachronous PC after a curative surgical resection by applying gemcitabine intraperitoneally. The rationale for such a treatment was recently advocated by Kamath et al. ${ }^{23}$ but in the absence of any data to support this rationale this should be regarded as experimental. Taken together, data on treatment of PC from pancreatic cancer are extremely sparse in the literature and reports from surgical efforts, chemotherapeutic treatment or the combination of both do not convincingly direct towards any effective treatment at all.

In conclusion, synchronous peritoneal carcinomatosis is a frequently encountered entity currently affecting at least 1 in every 8 patients presenting with pancreatic cancer and resulting in an horrendous prognosis of only 6 weeks, leaving a short therapeutic window. Surgical resection alone does not alter the natural course of the disease and should not be undertaken given the complications. Some patients with a good performance status may benefit from new chemotherapeutic regimens but convincing evidence from randomized studies is not available. Combining surgery with intra-peritoneal chemotherapy may be a possible treatment option but currently there is no evidence to support such practice. Given the magnitude of the problem and its bad prognosis efforts should be undertaken to develop effective treatments in experimental and clinical studies. 


\section{References}

1. Lemmens VE, Klaver YL, Verwaal VJ, et al. Predictors and survival of synchronous peritoneal carcinomatosis of colorectal origin: A population-based study. Int J Cancer. 2011;128:2717-2725.

2. Ceelen WP, Bracke ME. Peritoneal minimal residual disease in colorectal cancer: mechanisms, prevention, and treatment. Lancet Oncol. 2009;10:72-79.

3. Verwaal VJ, Bruin S, Boot $\mathrm{H}$, et al. 8-year follow-up of randomized trial: cytoreduction and hyperthermic intraperitoneal chemotherapy versus systemic chemotherapy in patients with peritoneal carcinomatosis of colorectal cancer. Ann Surg Oncol. 2008;15:2426-2432.

4. Gill RS, Al-Adra DP, Nagendran J, et al. Treatment of gastric cancer with peritoneal carcinomatosis by cytoreductive surgery and HIPEC: A systematic review of survival, mortality, and morbidity. J Surg Oncol. 2011.

5. Dovern E, de Hingh IH, Verwaal VJ, et al. Hyperthermic intraperitoneal chemotherapy added to the treatment of ovarian cancer. A review of achieved results and complications. Eur J Gynaecol Oncol. 2010;31:256-261.

6. Schouten $\amalg$, Hoppener $P$, van den Brandt PA, et al. Completeness of cancer registration in Limburg, The Netherlands. Int J Epidemiol. 1993;22:369-376.

7. Blastik M, Plavecz E, Zalatnai A. Pancreatic carcinomas in a 60-year, institute-based autopsy material with special emphasis of metastatic pattern. Pancreas. 2011;40:478-480.

8. Clark CJ, Traverso LW. Positive peritoneal lavage cytology is a predictor of worse survival in locally advanced pancreatic cancer. Am J Surg. 2010;199:657-662.

9. Seelig SK, Burkert B, Chromik AM, et al. Pancreatic resections for advanced M1-pancreatic carcinoma: the value of synchronous metastasectomy. HPB Surg. 2010;2010:579672.

10. Munoz-Casares FC, Rufian S, Arjona-Sanchez A, et al. Neoadjuvant intraperitoneal chemotherapy with paclitaxel for the radical surgical treatment of peritoneal carcinomatosis in ovarian cancer: a prospective pilot study. Cancer Chemother Pharmacol. 2011.

11. Cress RD, Yin D, Clarke L, et al. Survival among patients with adenocarcinoma of the pancreas: a population-based study (United States). Cancer Causes Control. 2006;17:403-409.

12. Morizane $\mathrm{C}$, Okusaka T, Morita S, et al. Construction and validation of a prognostic index for patients with metastatic pancreatic adenocarcinoma. Pancreas. 2011;40:415-421.

13. Shrikhande SV, Kleeff J, Reiser C, et al. Pancreatic resection for M1 pancreatic ductal adenocarcinoma. Ann Surg Oncol. 2007;14:118-127.

14. Burris HA, 3rd, Moore MJ, Andersen J, et al. Improvements in survival and clinical benefit with gemcitabine as first-line therapy for patients with advanced pancreas cancer: a randomized trial. J Clin Oncol. 1997;15:2403-2413.

15. Berlin JD, Catalano P, Thomas JP, et al. Phase III study of gemcitabine in combination with fluorouracil versus gemcitabine alone in patients with advanced pancreatic carcinoma: Eastern Cooperative Oncology Group Trial E2297. J Clin Oncol. 2002;20:3270-3275.

16. Astsaturov IA, Meropol NJ, Alpaugh RK, et al. Phase II and coagulation cascade biomarker study of bevacizumab with or without docetaxel in patients with previously treated metastatic pancreatic adenocarcinoma. Am J Clin Oncol. 2011;34:70-75.

17. Kindler HL, Niedzwiecki D, Hollis D, et al. Gemcitabine plus bevacizumab compared with gemcitabine plus placebo in patients with advanced pancreatic cancer: phase III trial of the Cancer and Leukemia Group B (CALGB 80303). J Clin Oncol. 2010;28:3617-3622.

18. Conroy T, Desseigne F, Ychou M, et al. FOLFIRINOX versus gemcitabine for metastatic pancreatic cancer. N Engl J Med. 2011;364:1817-1825.

19. Conroy T, Paillot B, Francois E, et al. Irinotecan plus oxaliplatin and leucovorin-modulated fluorouracil in advanced pancreatic cancer--a Groupe Tumeurs Digestives of the Federation Nationale des Centres de Lutte Contre le Cancer study. J Clin Oncol. 2005;23:1228-1236. 
20. Klaver YL, Lemmens VE, Creemers GJ, et al. Population-based survival of patients with peritoneal carcinomatosis from colorectal origin in the era of increasing use of palliative chemotherapy. Ann Oncol. 2011;22:2250-2256.

21. Farma JM, Pingpank JF, Libutti SK, et al. Limited survival in patients with carcinomatosis from foregut malignancies after cytoreduction and continuous hyperthermic peritoneal perfusion. J Gastrointest Surg. 2005;9:1346-1353.

22. Kimura $H$, Fushida $S$, Mukawa $A$. [A resected case of effective treatment with $S-1 /$ gemcitabine and Paclitaxel combination chemotherapy for advanced pancreatic cancer with peritoneal and liver metastases]. Gan To Kagaku Ryoho. 2009;36:1191-1194.

23. Kamath A, Yoo D, Stuart OA, et al. Rationale for an intraperitoneal gemcitabine chemotherapy treatment for patients with resected pancreatic cancer. Recent Pat Anticancer Drug Discov. 2009;4:174179. 


\section{Chapter 6}

Population-based incidence, treatment, and survival of patients with peritoneal metastases of unknown origin

Irene Thomassen, Rob HA Verhoeven, Yvette RBM van Gestel, Agnes J van de Wouw, Valery EPP Lemmens, Ignace HJT de Hingh.

(.eक:

Eur J Cancer. 2014 Jan;50(1):50-6

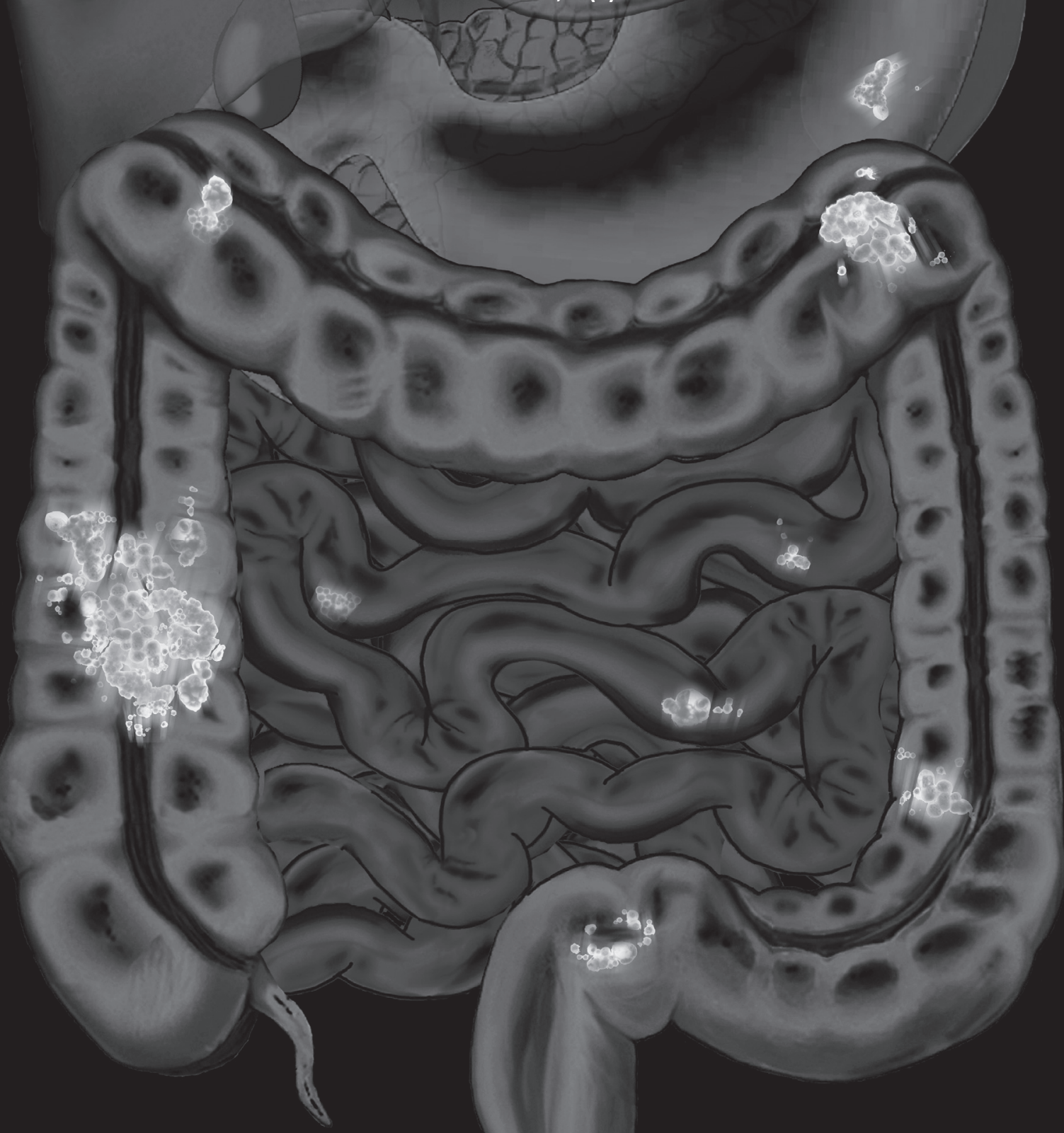





\section{Abstract}

\section{Aim}

Until recently, peritoneal metastases (PM) were regarded as an untreatable condition, regardless of the organ of origin. Currently, promising treatment options are available for selected patients with PM from colorectal, appendiceal, ovarian or gastric carcinoma. The aim of this study was to investigate the incidence, treatment, and survival of patients presenting with PM in whom the origin of PM remains unknown.

\section{Methods}

Data from patients diagnosed with PM of unknown origin during 1984-2010 were extracted from the Eindhoven Cancer Registry. European age-standardized incidence rates were calculated and data on treatment and survival were analyzed.

\section{Results}

In total 1,051 patients were diagnosed with PM of unknown origin. In 606 patients (58\%) the peritoneum was the only site of metastasis, and 445 patients also had other metastases. Chemotherapy usage has increased from $8 \%$ in the earliest period to $16 \%$ in most recent years $(p=.016)$. Median survival was extremely poor with only 42 days ( $95 \% \mathrm{Cl} 39-47$ days) and did not change over time. Median survival of patients not receiving chemotherapy was significantly worse than of those receiving chemotherapy (36 vs. 218 days, $p<.0001$ ).

\section{Conclusion}

The prognosis of PM of unknown origin is extremely poor and did not improve over time. Given the recent progress that has been achieved in selected patients presenting with PM, maximum efforts should be undertaken in order to diagnose the origin of PM as accurately as possible. Potentially effective treatment strategies should be further explored for patients in whom the organ of origin remains unknown. 


\section{Introduction}

Peritoneal metastases (PM) are described as the presence of malignant cells in the peritoneal cavity, resulting in bowel obstruction and the formation of malignant ascites. PM can be a metastatic site of cancer from different origins: $5 \%$ of colorectal cancer patients present with PM at the time of diagnosis, $9 \%$ of pancreatic cancer patients and $46 \%$ of women diagnosed with ovarian cancer are diagnosed with PM..$^{1-3}$ Of all patients presenting with metastatic disease, a group of patients remain without diagnosis of the primary tumor, commonly referred to as Unknown Primary Tumor (UPT). Overall, UPT accounts for $3-5 \%$ of all cancers. ${ }^{4}$ The prognosis of patients suffering from UPT is generally very poor with a median survival of 2 to 12 months. ${ }^{4,5}$ Around $10 \%$ of UPT patients are known to present with PM. ${ }^{5,6}$

Until recently, the presence of PM regardless of the organ of origin was regarded as a virtually untreatable condition, since it appears to be resistant to systemic chemotherapy. ${ }^{7}$ Identification of the primary tumor may therefore have been regarded as futile and clinically irrelevant. This has changed since the introduction of a treatment combining complete cytoreductive surgery of the PM with intraperitoneal chemotherapy. Promising results of this multimodality treatment are now reported in selected patients with PM from colorectal, appendiceal, ovarian and gastric cancer. ${ }^{8-10}$ Therefore, it is of increasing importance to assess the origin of PM as accurately as possible.

Literature regarding PM of UPT is limited, with no data on its true incidence and prevalence. Therefore, the aim of this population-based study was to investigate the incidence, treatment and survival of patients presenting with PM of unknown origin.

\section{Methods}

The Eindhoven Cancer Registry registers all newly diagnosed cancer patients in the southern part of the Netherlands. This area includes 10 community hospitals, 6 pathology departments and 2 radiotherapy institutions, comprising 2.4 million inhabitants. All patients diagnosed between 1984 and 2011 with metastases at the peritoneum with an unknown primary location and registered in the Eindhoven Cancer Registry were included in this study. UPT was defined as a metastasis for which no primary tumor was identified during life, regardless of the amount of diagnostic tests that a patient underwent. Primary tumors of the peritoneum (mesotheliomas) were not included. Two groups of patients were identified according to the ESMO guidelines; patients with favorable prognosis and patients with an unfavorable prognosis. ${ }^{11}$ Women with serous papillary adenocarcinoma of the peritoneum (only one metastatic site) and patients with carcinoids were classified into the favorable group. Information on patient and tumor characteristics was routinely extracted from the medical records, by specially trained administrators of the cancer registry, and anatomical sites of distant metastasis are registered according to ICD-O (International Classification of DiseaseOncology). By means of an independent case ascertainment method, the completeness of the registration is estimated to exceed $95 \% .{ }^{12}$ The vital status of all patients was assessed on 
January 1st, 2012 through merging with the Municipal Administrative Databases in which all deceased and emigrated persons in The Netherlands are registered.

\section{Statistical analysis}

Differences in patient and tumor characteristics were tested by means of a Chi-square test. Period of diagnosis was categorized into three groups; 1984-1992, 1993-2001 and 2002-2010. 5-Year moving average European age-standardized incidence rates (ESR) were calculated. Crude survival was determined by the Kaplan-Meier method and compared using a log-rank test. A multivariable proportional hazards regression analysis on overall survival was performed to determine the independent influence of relevant patient and tumor characteristics. Survival time was defined as the time from diagnosis until death; patients still alive at January 1 st2012 were censored. All tests of statistical significance were two sided. SAS/STAT statistical software (SAS system 9.3, SAS Institute, Cary, NC) was used for all analyses.

\section{Results}

Of the 9,643 patients diagnosed with UPT, 1,051 patients (11\%) were diagnosed with PM, of whom 606 patients (58\%) had PM as the only metastatic site and 445 patients $(42 \%)$ also had other metastases. Patient characteristics are shown in Table 1, showing the difference in patients with favorable and unfavorable prognosis according to the ESMO guidelines.

In the most recent period significantly less patients were diagnosed with PM as the only metastatic site and chemotherapy usage has increased from $8 \%$ in the earliest period to $16 \%$ in most recent years $(p=0.003$ and $p=.016$ respectively). During the entire study period $15 \%(n=98)$ of the females were treated with chemotherapy, as compared to $10 \%$ of males $(p=.021)$. Also, patients who received chemotherapy were younger and had less comorbidities (both $p<.0001$ ). Figure 1 shows the age-standardized incidence in males and females with PM of unknown origin according to year of diagnosis. Since 2005 the incidence is relatively stable, for both males and females at around 1.5 per 100.000 person-years.

Median overall survival was extremely poor with only 42 days ( $95 \% \mathrm{Cl} 39-47$ days) in the total group, which did not change over time (Table 2). Patients with PM as only metastatic site had a median survival of 44 days compared to 40 days in patients with PM combined with other metastases. Median survival of patients who received no chemotherapy (31 days) was significantly worse as compared to median survival of patients receiving chemotherapy (218 days, $p<.0001$, Table 3 ). Patients with a carcinoid had a much better median survival than patients with other types of tumor histology (Table 4). Patients with a favorable prognosis exhibited a median survival of 7.3 weeks, compared to 5.6 weeks for to patients with an unfavorable prognosis according to the ESMO guidelines ( $p<0.001$, Figure 2 ).

Multivariable proportional hazards regression analyses showed that patients with a higher age, more comorbidities, unfavorable prognosis according to the ESMO guidelines and no chemotherapy have a higher risk of death (table 5). 
Table 1. Patient and tumor characteristics of patients with peritoneal metastases of unknown origin according to groups with favorable and unfavorable prognosis according to the ESMO guidelines.

\begin{tabular}{|c|c|c|c|c|c|c|c|}
\hline & \multicolumn{2}{|c|}{ Total } & \multicolumn{2}{|c|}{$\begin{array}{l}\text { Favorable } \\
\text { prognosis }\end{array}$} & \multicolumn{2}{|c|}{$\begin{array}{l}\text { Unfavorable } \\
\text { prognosis }\end{array}$} & \multirow[t]{2}{*}{ P-value } \\
\hline & $N=1051$ & $\%$ & 294 & $\%$ & 757 & $\%$ & \\
\hline Gender & & & & & & & $<.0001$ \\
\hline Male & 398 & 38 & 8 & 3 & 390 & 52 & \\
\hline Female & 653 & 62 & 286 & 97 & 367 & 48 & \\
\hline Age & & & & & & & $<.0001$ \\
\hline$<50$ years & 70 & 7 & 7 & 2 & 63 & 8 & \\
\hline 50-59 years & 104 & 10 & 23 & 8 & 81 & 11 & \\
\hline $60-69$ years & 240 & 23 & 53 & 18 & 187 & 25 & \\
\hline 70-79 years & 352 & 33 & 90 & 31 & 262 & 35 & \\
\hline $80+$ years & 285 & 27 & 121 & 41 & 164 & 22 & \\
\hline Comorbidity & & & & & & & 0.012 \\
\hline No comorbidity & 221 & 21 & 55 & 19 & 166 & 22 & \\
\hline 1 comorbidity & 241 & 23 & 56 & 19 & 185 & 24 & \\
\hline 2 or more comorbidities & 262 & 25 & 70 & 24 & 192 & 25 & \\
\hline Comorbidity missing or unknown & 327 & 31 & 113 & 38 & 214 & 28 & \\
\hline Histology & & & & & & & $<.0001$ \\
\hline $\begin{array}{l}\text { Adenocarcinoma well } \\
\text { differentiated }\end{array}$ & 109 & 10 & 37 & 13 & 72 & 10 & \\
\hline $\begin{array}{l}\text { Adenocarcinoma, poorly/ } \\
\text { undifferentiated }\end{array}$ & 172 & 16 & 46 & 16 & 126 & 17 & \\
\hline $\begin{array}{l}\text { Adenocarcinoma, differentiation } \\
\text { grade unknown }\end{array}$ & 474 & 45 & 194 & 66 & 280 & 37 & \\
\hline $\begin{array}{l}\text { Carcinoma, not otherwise } \\
\text { specified }\end{array}$ & 173 & 16 & 0 & 0 & 173 & 23 & \\
\hline Carcinoid & 17 & 2 & 17 & 6 & 0 & 0 & \\
\hline Other & 106 & 10 & 0 & 0 & 106 & 14 & \\
\hline Extent of metastatic disease & & & & & & & $<.0001$ \\
\hline Only PM & 606 & 58 & 12 & 4 & 433 & 57 & \\
\hline PM and other metastases & 445 & 42 & 282 & 96 & 324 & 43 & \\
\hline Treatment & & & & & & & 0.193 \\
\hline Chemotherapy & 138 & 13 & 45 & 15 & 93 & 12 & \\
\hline No chemotherapy & 913 & 87 & 249 & 85 & 664 & 88 & \\
\hline
\end{tabular}

PM: peritoneal metastases

P-value: difference between patients with favorable and unfavorable prognosis 


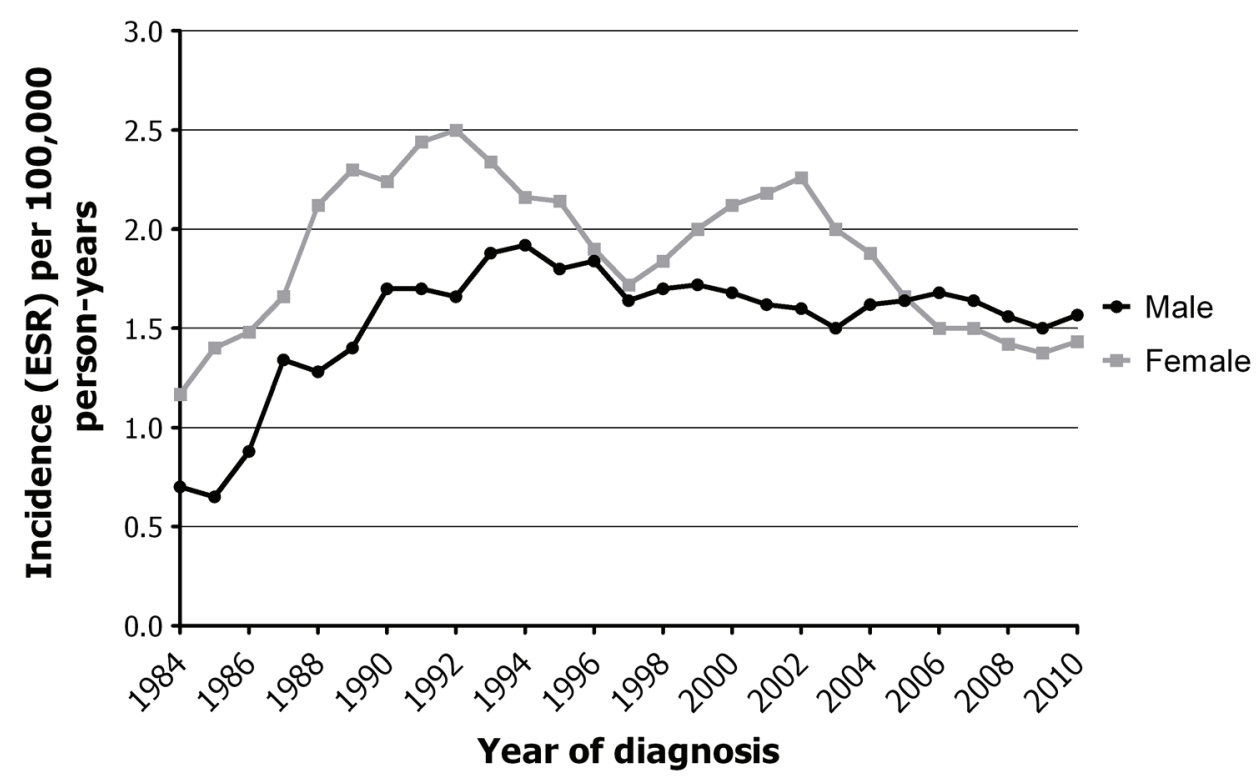

Figure 1. Five-year moving average European age-standardized incidence rate of males and females with peritoneal metastases of unknown origin according to year of diagnosis.

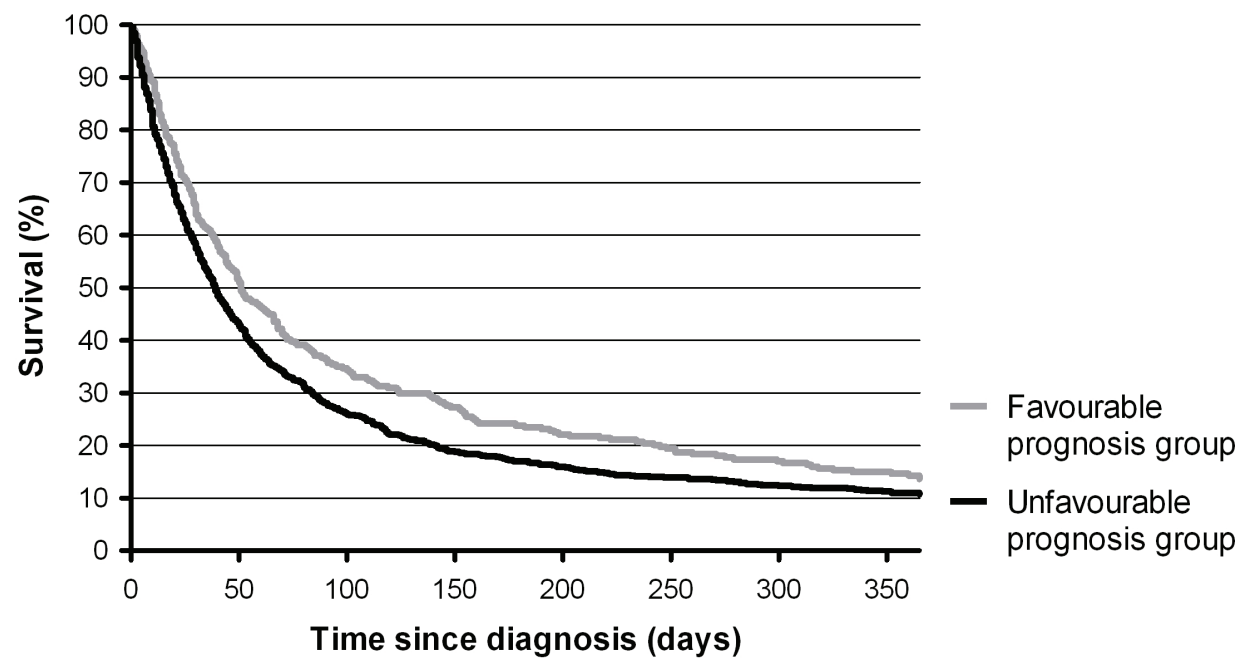

Figure 2. Survival according to groups of favorable and unfavorable prognosis according to the ESMO guidelines. 

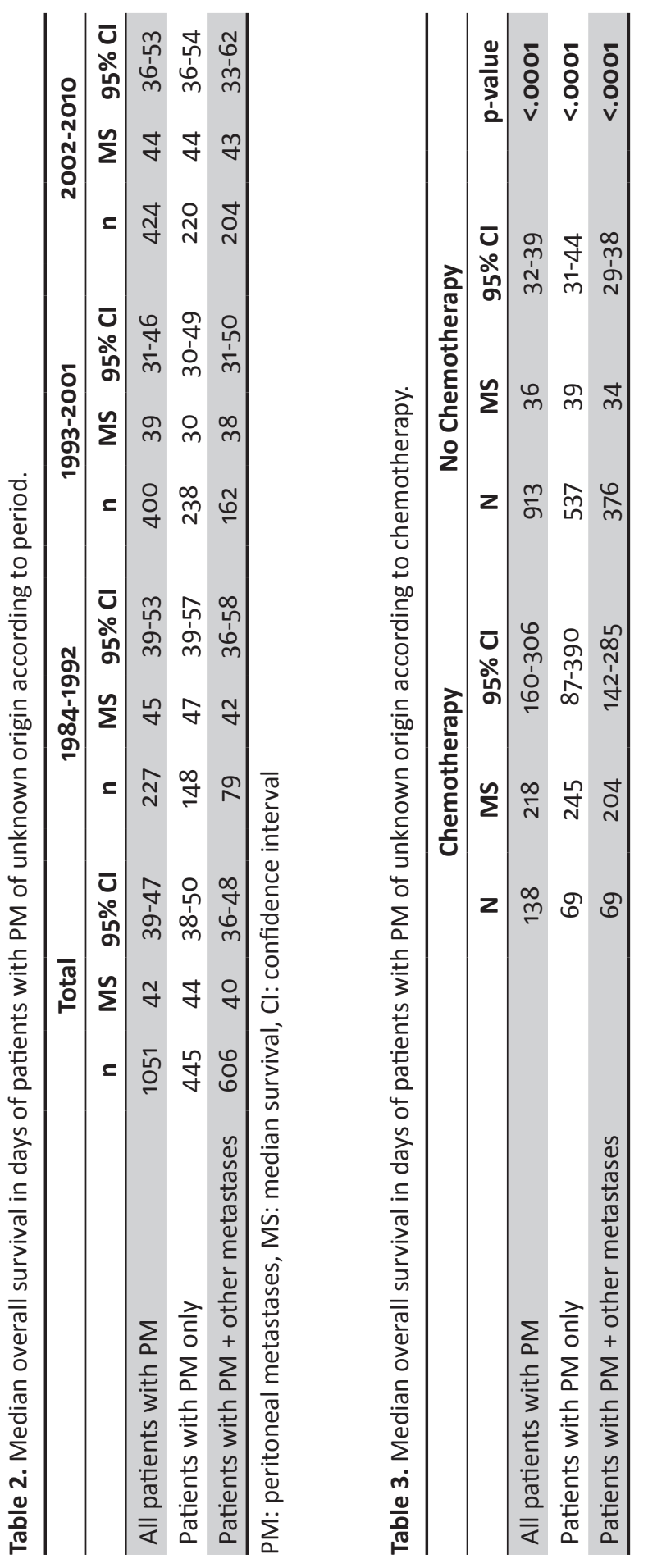
Table 4. Median overall survival in days of patients with PM of unknown origin according to histological type of tumor.

\begin{tabular}{lccc}
\hline Histology & $\mathbf{n}$ & $\mathbf{M S}$ & $\mathbf{9 5 \%} \mathbf{C I}$ \\
\hline Adenocarcinoma well differentiated & 109 & 69 & $49-96$ \\
\hline Adenocarcinoma, poorly/undifferentiated & 172 & 47 & $37-64$ \\
Adenocarcinoma, differentiation grade unknown & 474 & 45 & $40-51$ \\
Carcinoma, not otherwise specified & 173 & 26 & $21-39$ \\
Carcinoid & 17 & 315 & $83-2580$ \\
Other & 106 & 28 & $20-34$ \\
\hline
\end{tabular}

MS: median survival, $\mathrm{Cl}$ : confidence interval

Table 5. Multivariable proportional hazards regression analysis modeling the risk of death among patients with peritoneal carcinomatosis of unknown primary tumor.

\begin{tabular}{lcc}
\hline & HR & 95\%Cl \\
\hline Age & & \\
$<50$ years & 0.98 & $0.74-1.29$ \\
$50-59$ years & 0.88 & $0.69-1.12$ \\
60-69 years & Ref & \\
$70-79$ years & 1.40 & $1.18-1.66$ \\
$80+$ years & 1.56 & $1.29-1.87$ \\
Comorbidity & & \\
No comorbidity & Ref & \\
1 comorbidity & 1.22 & $1.01-1.48$ \\
2 or more comorbidities & 1.23 & $1.01-1.49$ \\
Comorbidity missing or unknown & 1.09 & $0.91-1.30$ \\
Prognosis group & & \\
Favorable & Ref & \\
Unfavorable & 1.35 & $1.17-1.55$ \\
Chemotherapy & & \\
\hline No & Ref & \\
Yes & 0.50 & $0.41-0.61$ \\
\hline
\end{tabular}

HR: hazard ratio

$\mathrm{Cl}$ : confidence interval

Ref: reference category $(\mathrm{HR}=1.00)$ 


\section{Discussion}

Metastatic disease originating from an unknown primary tumor is a relatively frequent diagnosis, being the seventh most common malignant disease in the Netherlands. ${ }^{5} \mathrm{~A}$ significant part of these patients (11\%) presents with peritoneal metastases, representing over 1000 patients in the region of the Eindhoven Cancer Registry since 1984. Treating patients with peritoneal metastases is extremely challenging and this is even more so when the primary tumor is unknown. This is reflected by the horrendous prognosis of these patients being only 42 days after diagnosis.

Previously, determination of the origin of the primary tumor may have been regarded as futile given the prognosis of PM in general. Now, with promising results for selected patients it is of increasing importance to diagnose PM and the primary tumor as accurately as possible.

To do so, a thorough physical examination should be performed first, followed by radiological testing with CT-scans of thorax, abdomen and pelvis. Furthermore, it is proposed in several studies that PET-CT (24-40\%) detects more primary sites than CT or MRI (20-27\%) in patients with an unidentified primary tumor. ${ }^{13-15}$ PET-CT has shown to change patient management in $35 \%$ of UPT patients. ${ }^{16,17}$ However, PET-CT is not a standard diagnostic procedure and the utility might be limited in patients with widespread peritoneal metastases because it may remain difficult to distinguish the primary tumor from the metastases.

It is proposed to determine tumor markers, since CA 125 has been shown to be elevated in over $80 \%$ of women with advanced ovarian cancer. ${ }^{18}$ However, CA 125 levels cannot be reliably interpreted in patients with peritoneal involvement, since the antigen to CA 125 is produced by the epithelia of the peritoneum and is shown to be elevated in $97.8 \%$ of the patients with ascites. ${ }^{19}$

In addition, immunohistochemistry may now be used to determine the organ of origin of peritoneal metastases, based on the immunohistochemistry staining pattern of multiple markers. ${ }^{13}$ Serum assessment of $\alpha$-fetoprotein (AFP), human chorionic gonadotrophin (hCG), plasma chromogranin A and PSA are suggested in male patients to exclude potentially curable extragonadal germ cell tumors, neuroendocrine tumors and prostate cancers amenable to hormonal treatment. ${ }^{11}$ In the near future also molecular profiling may become an important diagnostic modality for patients with UPT, by identifying specific and characteristic gene mutations. ${ }^{13,20}$

The ESMO guidelines for diagnosis, treatment and follow-up of patients with cancer of unknown primary sites distinguish two groups of patients with CUP. ${ }^{11}$ Of patients with PC, women with serous papillary adenocarcinoma and patients with primary neuroendocrine tumors are classified as patients with a favorable prognosis, who respond well to chemotherapy and have a favorable prognosis. The latter of the patients with PC are classified as patients with unfavorable prognosis, with poor response to chemotherapy and survival of maximum 6-10 months. In this study median survival of patients with unfavorable prognosis 
was 5.6 weeks, compared to 7.3 weeks for patients with favorable prognosis $(p<0.001)$. In patients with unfavorable prognosis according to the ESMO lactate dehydrogenase (LDH) and performance status have shown to be prognostic factors. ${ }^{11,21}$ A median life expectancy of 1 year has been described in patients with normal LDH and good performance status, and a median survival of less than 4 months has been described for patients with one or both of these prognostic factors. Recently Petrakis et al. ${ }^{22}$ showed that leucocytosis, clinicopathological subgroup and performance status were independent predictors of survival in 311 patients. A prognostic algorithm, including these parameters, was developed classifying patients with low, intermediate and high-risk with median survival times of 36 , 11-14 and 5-8 months.

Overall, median survival in the current study was 42 days, which is comparable to the results of the EVOCAPE 1 study. In that study 43 of 370 patients (12\%) had PM from UPT, and median survival time was 1.5 months. ${ }^{23}$

Patients who were treated with chemotherapy had a much better survival as compared to patients not receiving chemotherapy. From our data it is impossible to conclude whether this is a beneficial effect of the chemotherapy itself or mainly a result of selection bias. It should be kept in mind that the median survival of the entire cohort did not improve despite a significant increase in the usage of chemotherapy.

Results on chemotherapeutic treatment were previously published by Pentheroudakis et al. ${ }^{24}$ treated 47 patients with PM of UPT with platinum-taxane based chemotherapy. In $53 \%$ of the patients an overall tumor regression was reported, resulting in a median survival of 15 months. Sebbag et al. ${ }^{25}$ treated 15 patients with PM of UPT with cytoreductive surgery and intraperitoneal chemotherapy establishing a median survival of 19 months, with a morbidity rate of $27 \%$ and a short-term mortality rate of $7 \%$. These results seem promising but again a selection bias should probably be taken into account when interpreting these results.

For the current study, UPT was defined as "a metastasis for which no primary tumor was identified during life". This is different than a Carcinoma of Unknown Primary (CUP), since the latter requires thorough investigations before the diagnosis may be confirmed. A part of the currently described cohort of UPT patients may be regarded as true CUP patients in whom the primary tumor cannot be found despite extensive diagnostic tests, probably representing metastases from a primary tumor that completely regressed, or as the result of an occult primary site, including ectopic embryonic remnants. ${ }^{26}$

However, given the poor survival of the current cohort it is conceivable that a significant part of these patients was in a too poor clinical condition at the time of diagnosis to start examinations for the identification of the primary tumor. The nature and amount of examinations that were performed in every patient were not recorded in the cancer registry and therefore the percentage of true CUP-patients in the current cohort cannot be determined. 
As previously stated, some patients with PM may now be treated with a chance of longterm survival. This is especially true for patients suffering from pseudomyxoma peritonei of appendiceal origin. In these patients, cytoreductive surgery combined with hyperthermic intraperitoneal chemotherapy (HIPEC) has resulted in median survival rates of 16 years even in cases with widespread disease. ${ }^{27}$ Large case series have also shown median survival rates of up to 30 months for patients with PM of colorectal origin after cytoreductive surgery and HIPEC. ${ }^{28}$ Promising results of cytoreductive surgery and HIPEC have also been published for ovarian and gastric cancer. 9,10 Recently, the addition of biological agents to systemic chemotherapy was shown to prolong median survival in selected patients with PC from colorectal origin who could not undergo surgery with curative intend. ${ }^{29}$ In ovarian carcinoma, up to $80 \%$ of the patients are known to respond to first-line treatment with platinum-based chemotherapy..$^{30}$ In patients with PM from a carcinoid, somatostatin analogs have been proven to be efficient in addition to chemotherapy. ${ }^{31}$ Octreotide has shown to significantly increase time to disease progression compared with placebo..$^{32} \mathrm{As}$ a result, also these patients may hope for long-term survival with adequate treatment as also illustrated in the current study, showing a median survival of nearly 1 year.

In conclusion, PM from an unknown primary tumor currently carries a very bad prognosis. However, since effective treatments are now available for selected patient categories, every effort should be undertaken to identify the primary tumor whenever possible and feasible. Besides, potentially effective treatment strategies should be further explored for patients in whom the organ of origin remains unknown. 


\section{References}

1. Lemmens VE, Klaver YL, Verwaal VJ, Rutten HJ, Coebergh JW, de Hingh IH. Predictors and survival of synchronous peritoneal carcinomatosis of colorectal origin: A population-based study. Int J Cancer. 2011; 128: 2717-25.

2. Thomassen I, Lemmens VE, Nienhuijs SW, Luyer MD, Klaver YL, de Hingh IH. Incidence, prognosis, and possible treatment strategies of peritoneal carcinomatosis of pancreatic origin: a population-based study. Pancreas. 2013; 42: 72-5.

3. Heintz AP, Odicino F, Maisonneuve P, Quinn MA, Benedet JL, Creasman WT, et al. Carcinoma of the ovary. FIGO 26th Annual Report on the Results of Treatment in Gynecological Cancer. Int J Gynaecol Obstet. 2006; 95 Suppl 1: S161-92.

4. Stella GM, Senetta R, Cassenti A, Ronco M, Cassoni P. Cancers of unknown primary origin: current perspectives and future therapeutic strategies. J Transl Med. 2012; 10: 12.

5. Verhoeven RH, de Hingh IH, Van de Wouw AJ, Lemmens VE. Incidence and survival of carcinoma of unknown primary: a population based study. In press.

6. van de Wouw AJ, Janssen-Heijnen ML, Coebergh JW, Hillen HF. Epidemiology of unknown primary tumours; incidence and population-based survival of 1285 patients in Southeast Netherlands, 19841992. Eur J Cancer. 2002; 38: 409-13.

7. Boku N. Chemotherapy for metastatic disease: review from JCOG trials. International journal of clinical oncology / Japan Society of Clinical Oncology. 2008; 13: 196-200.

8. Verwaal VJ, Bruin S, Boot H, van Slooten G, van Tinteren H. 8-year follow-up of randomized trial: cytoreduction and hyperthermic intraperitoneal chemotherapy versus systemic chemotherapy in patients with peritoneal carcinomatosis of colorectal cancer. Ann Surg Oncol. 2008; 15: 2426-32.

9. Dovern E, de Hingh IH, Verwaal VJ, van Driel WJ, Nienhuijs SW. Hyperthermic intraperitoneal chemotherapy added to the treatment of ovarian cancer. A review of achieved results and complications. Eur J Gynaecol Oncol. 2010; 31: 256-61.

10. Gill RS, Al-Adra DP, Nagendran J, Campbell S, Shi X, Haase E, et al. Treatment of gastric cancer with peritoneal carcinomatosis by cytoreductive surgery and HIPEC: A systematic review of survival, mortality, and morbidity. J Surg Oncol. 2011; 104: 692-8

11. Fizazi K, Greco FA, Pavlidis N, Pentheroudakis G. Cancers of unknown primary site: ESMO Clinical Practice Guidelines for diagnosis, treatment and follow-up. Ann Oncol. 2011; 22 Suppl 6: vi64-8.

12. Schouten LJ, Hoppener $P$, van den Brandt PA, Knottnerus JA, Jager JJ. Completeness of cancer registration in Limburg, The Netherlands. Int J Epidemiol. 1993; 22: 369-76.

13. Kim KW, Krajewski KM, Jagannathan JP, Nishino M, Shinagare AB, Hornick JL, et al. Cancer of unknown primary sites: what radiologists need to know and what oncologists want to know. AJR Am J Roentgenol. 2013; 200: 484-92.

14. Latief KH, White CS, Protopapas Z, Attar S, Krasna MJ. Search for a primary lung neoplasm in patients with brain metastasis: is the chest radiograph sufficient? AJR Am J Roentgenol. 1997; 168: 1339-44.

15. Ambrosini V, Nanni C, Rubello D, Moretti A, Battista G, Castellucci P, et al. 18F-FDG PET/CT in the assessment of carcinoma of unknown primary origin. Radiol Med. 2006; 111: 1146-55.

16. Keller F, Psychogios G, Linke R, Lell M, Kuwert T, Iro H, et al. Carcinoma of unknown primary in the head and neck: Comparison between positron emission tomography (PET) and PET/CT. Head \& neck. 2011; 33:1569-75

17. Seve P, Billotey C, Broussolle C, Dumontet C, Mackey JR. The role of 2-deoxy-2-[F-18]fluoro-D-glucose positron emission tomography in disseminated carcinoma of unknown primary site. Cancer. 2007; 109: 292-9.

18. Buys SS, Partridge E, Greene MH, Prorok PC, Reding D, Riley TL, et al. Ovarian cancer screening in the Prostate, Lung, Colorectal and Ovarian (PLCO) cancer screening trial: findings from the initial screen of a randomized trial. Am J Obstet Gynecol. 2005; 193: 1630-9.

19. Sevinc A, Camci C, Turk HM, Buyukberber S. How to interpret serum CA 125 levels in patients with serosal involvement? A clinical dilemma. Oncology. 2003; 65: 1-6. 
20. Oien KA, Dennis JL. Diagnostic work-up of carcinoma of unknown primary: from immunohistochemistry to molecular profiling. Ann Oncol. 2012; 23 Suppl 10: x271-7.

21. Culine S, Kramar A, Saghatchian M, Bugat R, Lesimple T, Lortholary A, et al. Development and validation of a prognostic model to predict the length of survival in patients with carcinomas of an unknown primary site. J Clin. 2002; 20: 4679-83.

22. Petrakis D, Pentheroudakis $G$, Voulgaris $E$, Pavlidis N. Prognostication in cancer of unknown primary (CUP): Development of a prognostic algorithm in 311 cases and review of the literature. Cancer Treat Rev. 2013; S0305-7372: 00040-6

23. Sadeghi B, Arvieux C, Glehen O, Beaujard AC, Rivoire M, Baulieux J, et al. Peritoneal carcinomatosis from non-gynecologic malignancies: results of the EVOCAPE 1 multicentric prospective study. Cancer. 2000; 88: 358-63.

24. Pentheroudakis G, Briasoulis E, Karavassilis V, Fountzilas G, Xeros N, Samelis G, et al. Chemotherapy for patients with two favourable subsets of unknown primary carcinoma: active, but how effective? Acta Oncol. 2005; 44: 155-60.

25. Sebbag G, Shmookler BM, Chang D, Sugarbaker PH. Peritoneal carcinomatosis from an unknown primary site. Management of 15 patients. Tumori. 2001; 87: 67-73.

26. Mugerwa S, Lekharaju V, Kiire CF. Management of peritoneal carcinomatosis secondary to metastatic cancer of unknown primary in men. Eur J Cancer Care (Engl). 2009; 18: 22-7.

27. Chua TC, Moran BJ, Sugarbaker PH, Levine EA, Glehen O, Gilly FN, et al. Early- and long-term outcome data of patients with pseudomyxoma peritonei from appendiceal origin treated by a strategy of cytoreductive surgery and hyperthermic intraperitoneal chemotherapy. J Clin. 2012; 30: 2449-56.

28. Elias D, Gilly F, Boutitie F, Quenet F, Bereder JM, Mansvelt B, et al. Peritoneal colorectal carcinomatosis treated with surgery and perioperative intraperitoneal chemotherapy: retrospective analysis of 523 patients from a multicentric French study. J Clin. 2010; 28: 63-8.

29. Klaver YL, Leenders BJ, Creemers GJ, Rutten HJ, Verwaal VJ, Lemmens VE, et al. Addition of biological therapies to palliative chemotherapy prolongs survival in patients with peritoneal carcinomatosis of colorectal origin. American journal of clinical oncology. 2013; 36: 157-61.

30. Ozols RF, Bundy BN, Greer BE, Fowler JM, Clarke-Pearson D, Burger RA, et al. Phase III trial of carboplatin and paclitaxel compared with cisplatin and paclitaxel in patients with optimally resected stage III ovarian cancer: a Gynecologic Oncology Group study. J Clin. 2003; 21: 3194-200.

31. de Mestier L, Neuzillet C, Hentic O, Kianmanesh R, Hammel P, Ruszniewski P. Prolonged survival in a patient with neuroendocrine tumor of the cecum and diffuse peritoneal carcinomatosis. Case Rep Gastroenterol. 2012; 6: 205-10.

32. Rinke A, Muller HH, Schade-Brittinger $C$, Klose KJ, Barth $P$, Wied M, et al. Placebo-controlled, doubleblind, prospective, randomized study on the effect of octreotide LAR in the control of tumor growth in patients with metastatic neuroendocrine midgut tumors: a report from the PROMID Study Group. J Clin. 2009; 27: 4656-63. 


\section{Chapter 7}

Chemotherapy as palliative treatment for peritoneal carcinomatosis of gastric origin

Irene Thomassen, Nienke Bernards, Yvette RBM van Gestel, Geert-Jan Creemers, Esther MJ Jacobs, Valery EPP Lemmens, Ignace HJT de Hingh. gif.

Acta Oncol. 2014 Mar;53(3):429-32

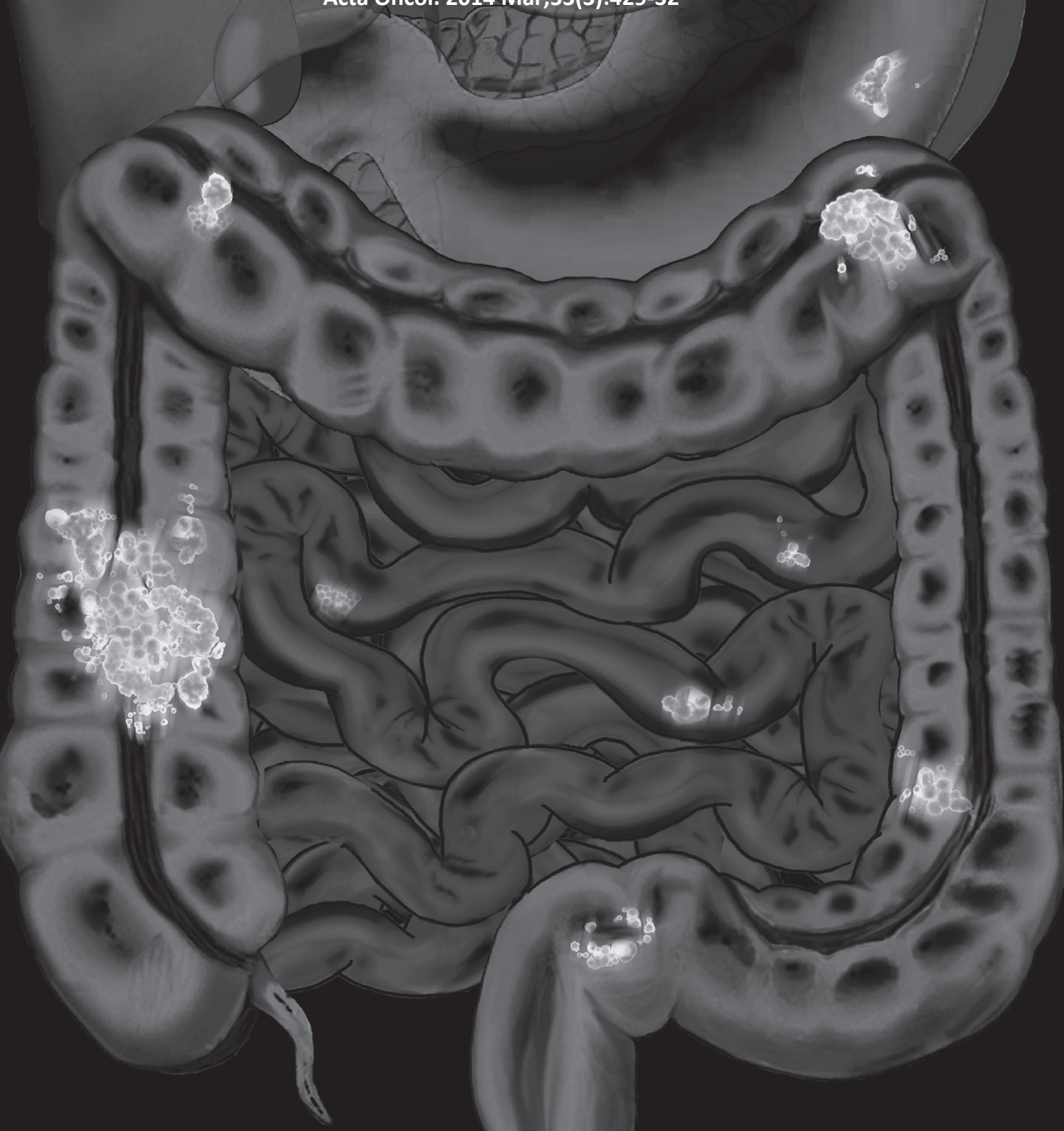





\section{To the editor,}

Gastric cancer is known for its aggressive natural history and most patients present with advanced, inoperable or metastatic disease. In the absence of curative treatment modalities, systemic chemotherapy can be considered as a reasonable treatment option for these patients. Previous studies showed that, in selected patients, chemotherapy is superior to 'best supportive care' in terms of prolonged survival, reduction of disease-related symptoms and improved quality of life. ${ }^{1}$ Therefore, national and international guidelines recommend palliative chemotherapy with a two or three drug regimen for patients with metastatic gastric cancer. ${ }^{2,3}$

In patients with metastatic gastric cancer, dissemination to the peritoneum is one of the most common sites. Up to $39 \%$ of the gastric cancer patients presents with metastatic disease and $14 \%$ of all the newly diagnosed patients presents with peritoneal carcinomatosis (PC). ${ }^{4}$ The efficacy of palliative chemotherapy for the subset of patients with PC from gastric origin is not known. It is hypothesized that the effect of intravenous chemotherapy on peritoneal metastases is limited due to the peritoneal blood barrier, and peritoneal dissemination is established as an adverse prognostic factor. ${ }^{5}$ Comprehensive data regarding the use and effectiveness of systemic chemotherapy for this subset of patients in particular is virtually absent. Therefore, the aim of this population-based study was to evaluate trends in systemic treatment and survival of patients with peritoneal carcinomatosis of gastric origin.

\section{Material and Methods}

The Eindhoven Cancer Registry registers all newly diagnosed cancer patients in the southern part of the Netherlands, including 10 community hospitals, 6 pathology departments and 2 radiotherapy institutions, comprising 2.4 million inhabitants. All patients diagnosed between 1995 and 2011 with an adenocarcinoma of gastric origin were included. These 5,220 patients were previously described. ${ }^{4}$ Information on patient and tumor characteristics is routinely extracted from the medical records by specially trained administrators of the cancer registry. Anatomical sites of distant metastases are registered according to the ICD-O (International Classification of Disease-Oncology). By means of an independent case ascertainment method, the completeness of the registration is estimated to exceed $95 \% .{ }^{6}$ Chemotherapy (yes vs no) was defined as receiving intravenous cytostatic drugs of any kind. The vital status of all patients was assessed on January $1^{\text {st }}, 2012$ through merging with the Municipal Administrative Databases in which all deceased and emigrated persons in the Netherlands are registered.

\section{Statistical analysis}

Differences between patients who were treated with palliative chemotherapy and patients who were not, were tested by means of a Chi-square test. To investigate trends in treatment and survival, patients were categorized into four groups by period of diagnosis: 1995-1998, 1999-2002, 2003-2006 and 2007-2011. Survival time was defined as the time from cancer diagnosis until death; patients still alive at January $1^{\text {st }} 2012$ were censored. Crude survival was determined by the Kaplan-Meier method and compared using a log-rank test. Cox regression 
analysis, adjusting for age, gender, period of diagnosis, co-morbidity, tumor differentiation grade, tumor stage, lymph node stage, and surgery, was used to determine the relationship between chemotherapy and 2-year mortality among patients with PC. A hazard ratio (HR) was provided with the $95 \%$ confidence interval $(\mathrm{Cl})$. All tests of statistical significance were two sided. SAS/STAT statistical software (SAS system 9.3, SAS Institute, Cary, NC) was used for all analyses.

\section{Results}

Between 1995 and 2012, 5,220 patients were diagnosed with gastric cancer, of whom 2,029 patients (39\%) had metastatic disease at presentation. ${ }^{4}$ Of these patients 706 patients $(34 \%)$ were diagnosed with PC, of whom 491 patients had PC as the only metastatic site and 215 patients had PC combined with other metastases. 168 Patients (24\%) were treated with palliative chemotherapy. Younger patients, patients with less comorbidities and patients with lower $\mathrm{N}$-stage were significantly more likely to be treated with chemotherapy (Supplementary table 1: available in the online version of the journal. Please find this material with the direct link to the article: http//www.informahealthcare.com). Furthermore, the percentage of patients treated with chemotherapy increased over time $(P<.001$, figure 1$)$. In the period $1995-1998,11 \%$ of the patients with PC was treated with chemotherapy as compared with $42 \%$ in the most recent period.

Median survival of patients with PC was 4 months. For those who received chemotherapy it was 7.7 months compared to 3.4 months in patients who were not treated $(P<.001$, Table 1). Crude median survival did not significantly increase over time among all $P C$ patients and among patients treated with chemotherapy $(P=.740$ and $p=.310$ respectively). Crude survival of patients who did not receive chemotherapy decreased over time $(P<.0001)$. After adjusting for age, gender, period of diagnosis, co-morbidity, tumor differentiation grade, tumor stage, lymph node stage, and surgery, patients with PC who were treated with palliative chemotherapy had a reduced risk to die within 2 years after gastric cancer diagnosis ( $\mathrm{HR}=0.48,95 \% \mathrm{Cl} 0.38-0.60$, table 2 ). 


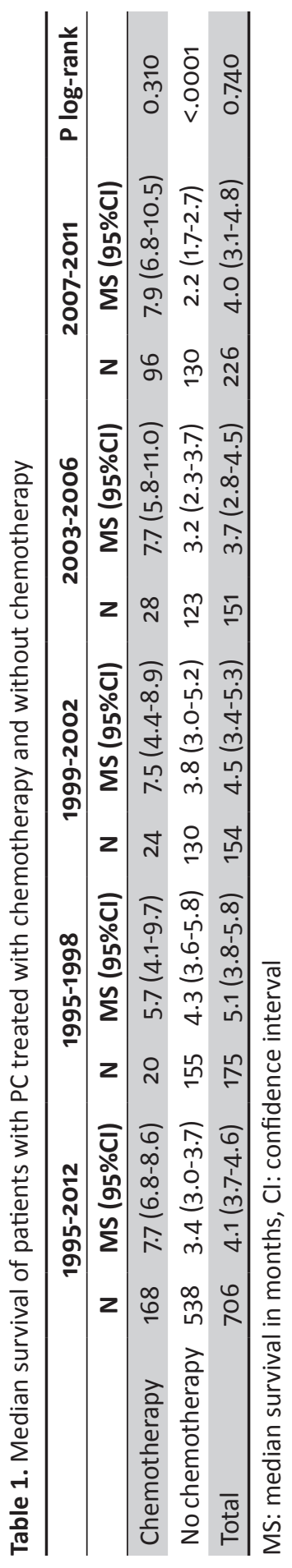




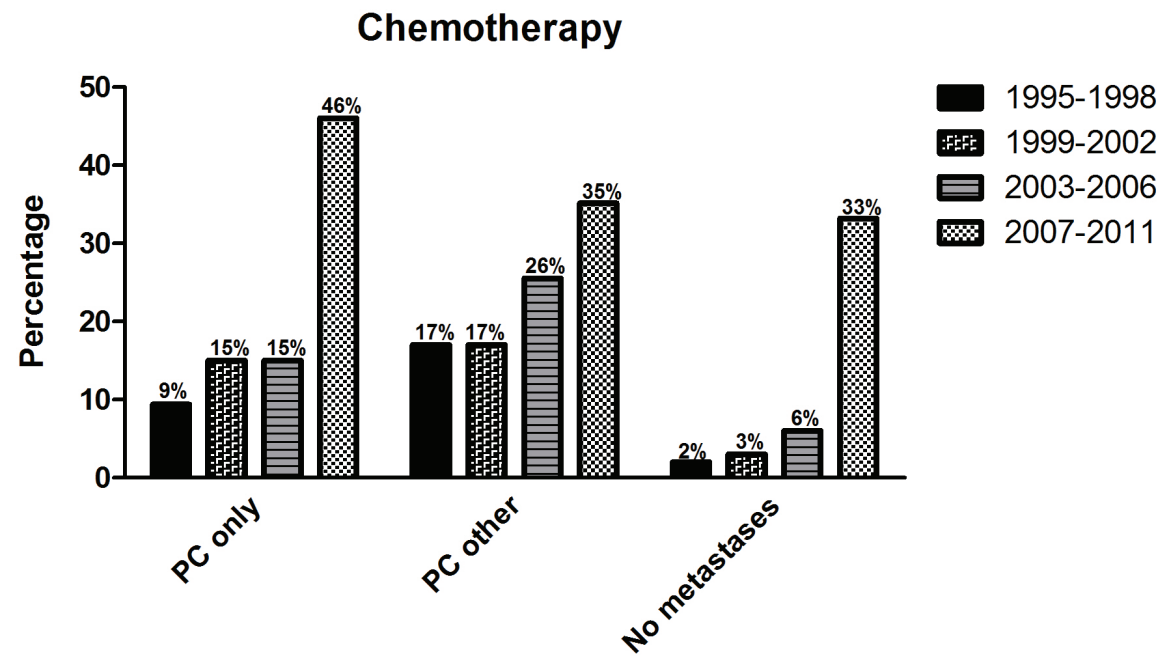

Figure 1. Percentage of patients with gastric cancer treated with chemotherapy, according to period of diagnosis

PC only: PC without other metastases

PC other: PC and other metastases

Table 2. Multivariable logistic regression modeling the risk to die within 2 years after gastric cancer diagnosis among patients with PC of gastric origin

\begin{tabular}{ll}
\hline Age & OR (95\%CI) \\
$<60$ & 1.0 \\
$60-69$ & $1.0(0.8-1.2)$ \\
$70-79$ & $1.2(1.0-1.5)$ \\
$\geq 80$ & $1.4(1.1-1.9)$ \\
Gender & \\
\hline Male & 1.0 \\
Female & $0.9(0.7-1.0)$ \\
Period of diagnosis & \\
\hline $1995-1998$ & 1.0 \\
$1999-2002$ & $1.0(0.8-1.3)$ \\
$2003-2006$ & $1.1(0.9-1.4)$ \\
$2007-2011$ & $1.3(1.0-1.7)$ \\
\hline
\end{tabular}

Table 2 continues on next page 


\begin{tabular}{ll}
\hline T stage of primary tumour & \\
T1,2 & 1.0 \\
T3 & $0.8(0.6-1.1)$ \\
T4 & $0.9(0.7-1.2)$ \\
TX & $1.5(1.1-2.0)$ \\
N stage of primary tumour & \\
\hline No & 1.0 \\
N+ & $1.4(0.7-2.8)$ \\
Nx & $1.8(0.7-4.3)$ \\
\hline Differentiation grade of primary tumour & \\
\hline Well/moderately & 1.0 \\
Poorly/undifferentiated & $1.4(1.1-1.8)$ \\
Unknown & $1.4(1.1-1.8)$ \\
\hline Surgery & \\
\hline Yes & $0.6(0.3-1.2)$ \\
No & 1.0 \\
\hline Chemotherapy & \\
\hline Yes & $0.5(0.4-0.6)$ \\
No & 1.0 \\
\hline
\end{tabular}

OR: odds ratio; $\mathrm{Cl}$ : confidence interval

\section{Discussion}

Gastric cancer is the second most common cause of death from cancer worldwide, accounting for 740,000 deaths per year. ${ }^{7}$ All over the world, epidemiological features of gastric cancer patients are changing. In the Netherlands the age-standardized incidence rates decreased in the last decades but stage distribution worsened over time. ${ }^{8}$ As a result, a growing proportion of patients now presents with locally advanced or metastatic disease with peritoneal dissemination being the most commonly affected metastatic site. The growing experience with combination chemotherapy in the treatment of gastric cancer, especially after the publication of the REAL-2 and MAGIC-trial in 2005 and 2006, has resulted in a strong increase in the administration of chemotherapy for advanced gastric cancer in the Netherlands since 2007..$^{9,10}$ Also in the current study, the usage of chemotherapy appeared to have significantly increased over time. However, crude median survival did not significantly increase over time among PC patients. This observation suggests that palliative chemotherapy is of limited value for gastric cancer patients suffering from PC. This seems in conflict with the multivariable logistic regression model showing that treatment with chemotherapy results in a reduced risk to die within 2 years after the diagnosis. However, additional patient characteristics such as performance score, nutritional status and disease related symptoms also influence the prescription of palliative chemotherapy and therefore it is conceivable that selection bias probably has played a major role. 
Previously, it has been hypothesized that the effect of intravenous chemotherapy may be limited in PC patients due to the peritoneal blood barrier. Ross et al. ${ }^{11}$ revealed that patients with PC had a $15 \%$ response rate to chemotherapy compared to a response rate of $43 \%$ in patients with other metastatic sites of advanced gastric cancer. Our study demonstrated that younger patients, patients with less comorbidities and patients with a lower $\mathrm{N}$-stage were more likely to be treated with chemotherapy, which is in line with previous studies, also revealing reluctance to prescribe chemotherapy to old and frail patients. ${ }^{12}$

Only few clinical studies have reported on the effect of chemotherapy in gastric cancer patients with PC. In a study reporting on 172 patients with PC of gastric origin receiving chemotherapy, an improved 1-year survival of $23.9 \%$ versus $4.6 \%$ was reported, but this survival benefit was not significant in the multivariate analysis $(P=.082) .{ }^{13}$ Shigeyasu et al. ${ }^{14}$ established a median survival of 15.3 months in a small phase II study, including 19 patients with PC of gastric origin treated with S-1 and docetaxel. Izuishi et al. ${ }^{15}$ reported retrospectively collected data of a palliative gastrectomy and chemotherapy and found that S-1 containing chemotherapy showed a significant survival benefit over 5-FU containing chemotherapy. However, the most promising results were reported by studies using multimodality treatment including cytoreductive surgery and intra-peritoneal administration of chemotherapy, showing that median survival improved from 7.9 months to 15 months for patients with completeness of cytoreduction. ${ }^{16}$

In conclusion, the usage of chemotherapy increased in patients with PC of gastric origin but this did not result in prolongation of survival on a population-based level. Therefore, the beneficial effect of current chemotherapy regimens remains questionable at least in this patient category. Given the bad prognosis of these patients if left untreated, further research should be performed to optimize therapy, which may include multi-modality treatment with intraperitoneal chemotherapy. 


\section{References}

1. Wagner, AD, Unverzagt S, Grothe W, Kleber G, Grothey A, Haerting J, et al. Chemotherapy for advanced gastric cancer. Cochrane Database Syst Rev 2010; CD004064.

2. National Comprehensive Cancer Network, NCCN Guideline Gastric Cancer 2012.

3. Landelijke werkgroep Gastro-Intestinale Tumoren, Dutch guideline: gastric carcinoma 2009.

4. Thomassen I, van Gestel YRBM, van Ramshorst B, Luyer MD, Bosscha K, Nienhuijs SW, et al. Peritoneal carcinomatosis of gastric origin: a population-based study on incidence, risk-factors and prognosis. Int J Cancer 2013; doi: 10.1002/ijc.28373.

5. Lee J, Lim T, Uhm JE, Park KW, Park SH, Lee SC, et al. Prognostic model to predict survival following first-line chemotherapy in patients with metastatic gastric adenocarcinoma. Ann Oncol 2007; 18: 88691.

6. Schouten LJ, Hoppener P, van den Brandt PA, Knottnerus JA, Jager JJ. Completeness of cancer registration in Limburg, The Netherlands. International journal of epidemiology 1993; 22: 369-76.

7. Crew KD, Neugut AI. Epidemiology of gastric cancer. World J Gastroenterol 2006; 12: 354-62.

8. Dassen AE, Lemmens VE, van de Poll-Franse LV, Creemers GJ, Brenninkmeijer SJ, Lips DJ, et al. Trends in incidence, treatment and survival of gastric adenocarcinoma between 1990 and 2007: a populationbased study in the Netherlands. Eur J Cancer 2010; 46: 1101-10.

9. Chong G, Cunningham D. Can cisplatin and infused 5-fluorouracil be replaced by oxaliplatin and capecitabine in the treatment of advanced oesophagogastric cancer? The REAL 2 trial. Clin Oncol 2005; $17:$ 79-80.

10. Cunningham D, Allum WH, Stenning SP, Thompson JN, Van de Velde CJ, Nicolson M, et al. Perioperative chemotherapy versus surgery alone for resectable gastroesophageal cancer. N Engl J Med 2006; 355: 11-20.

11. Ross $\mathrm{P}$, Nicolson $\mathrm{M}$, Cunningham $\mathrm{D}$, Ishibashi $\mathrm{H}$, Mizumoto $\mathrm{A}$, Miura $\mathrm{M}$, et al. Prospective randomized trial comparing mitomycin, cisplatin, and protracted venous-infusion fluorouracil (PVI 5-FU) With epirubicin, cisplatin, and PVI 5-FU in advanced esophagogastric cancer. J Clin Oncol 2002; 20: 19962004.

12. van Gils CW, Koopman M, Mol L, Uyl-de Groot CA, Punt CJ. Adjuvant chemotherapy in stage III colon cancer: guideline implementation, patterns of use and outcomes in daily practice in The Netherlands. Acta Oncol 2012; 51: 57-64.

13. Zhu G, Zhang M, Zhang H, Gao H, Xue Y. Survival predictors of patients with gastric cancer with peritoneal metastasis. Hepatogastroenterology 2010; 57: 997-1000.

14. Shigeyasu K, Kagawa S, Uno F, Nishizaki M, Kishimoto H, Gochi A, et al. Multicenter phase II study of S-1 and docetaxel combination chemotherapy for advanced or recurrent gastric cancer patients with peritoneal dissemination. Cancer Chemother Pharmacol 2013; 71:937-43.

15. Izuishi K, Haba R, Kushida Y, Kadota K, Takebayashi R, Sano T, et al. S-1 and the treatment of gastric cancer with peritoneal dissemination. Exp Ther Med 2011; 2: 985-990.

16. Gill RS, Al-Adra DP, Nagendran J, Campbell S, Shi X, Haase E, et al. Treatment of gastric cancer with peritoneal carcinomatosis by cytoreductive surgery and HIPEC: a systematic review of survival, mortality, and morbidity. Journal of surgical oncology 2011; 104: 692-8. 
Supplementary table 1. General characteristics of patients diagnosed between 1995 and 2012 in the South of the Netherlands with peritoneal carcinomatosis of gastric origin

\begin{tabular}{|c|c|c|c|c|c|}
\hline & \multicolumn{2}{|c|}{ Chemotherapy } & \multicolumn{2}{|c|}{$\begin{array}{c}\text { No } \\
\text { chemotherapy }\end{array}$} & \multirow[b]{2}{*}{ p-value } \\
\hline & $N=168$ & $\%$ & $N=538$ & $\%$ & \\
\hline Age (years) & & & & & $<.0001$ \\
\hline$<60$ & 82 & 40 & 121 & 60 & \\
\hline $60-69$ & 51 & 25 & 150 & 75 & \\
\hline $70-79$ & 34 & 16 & 182 & 84 & \\
\hline$>80$ & 1 & 1 & 85 & 99 & \\
\hline Gender & & & & & 0.743 \\
\hline Male & 102 & 24 & 319 & 76 & \\
\hline Female & 66 & 23 & 219 & 77 & \\
\hline PC & & & & & 0.586 \\
\hline No other metastases & 114 & 23 & 377 & 77 & \\
\hline Combined with other metastases & 54 & 25 & 161 & 75 & \\
\hline Period & & & & & $<.0001$ \\
\hline $1995-1998$ & 20 & 11 & 155 & 89 & \\
\hline 1999-2002 & 24 & 16 & 130 & 84 & \\
\hline $2003-2006$ & 28 & 19 & 123 & 81 & \\
\hline $2007-2011$ & 96 & 42 & 130 & 58 & \\
\hline Number of comorbid conditions & & & & & 0.006 \\
\hline 0 & 71 & 32 & 153 & 68 & \\
\hline 1 & 77 & 20 & 308 & 80 & \\
\hline$\geq 2$ & 12 & 18 & 56 & 82 & \\
\hline Unknown & 8 & 28 & 21 & 72 & \\
\hline Localisation of primary tumor & & & & & 0.002 \\
\hline Cardia NOS & 29 & 32 & 63 & 68 & \\
\hline Fundus of stomach & 2 & 20 & 8 & 80 & \\
\hline Body of stomach & 24 & 30 & 55 & 70 & \\
\hline Gastric antrum & 19 & 15 & 112 & 85 & \\
\hline Pylorus & 3 & 9 & 31 & 91 & \\
\hline Lesser curvature & 4 & 13 & 28 & 87 & \\
\hline Greater curvature & 9 & 43 & 12 & 57 & \\
\hline Overlapping lesions/ NOS & 78 & 25 & 229 & 75 & \\
\hline
\end{tabular}

Supplementary table 1 . continues on next page 


\begin{tabular}{|c|c|c|c|c|c|}
\hline \multicolumn{5}{|c|}{ T stage of primary tumor $\mathrm{cT}$ in case of unknown $(\mathrm{y}) \mathrm{pT}$} & \multirow[t]{2}{*}{0.086} \\
\hline To & 0 & 0 & 1 & 100 & \\
\hline $\mathrm{T} 1$ & 1 & 20 & 4 & 80 & \\
\hline $\mathrm{T} 2$ & 17 & 22 & 59 & 78 & \\
\hline T3 & 27 & 27 & 73 & 73 & \\
\hline T4 & 30 & 21 & 115 & 79 & \\
\hline $\mathrm{Tx}$ & 93 & 25 & 286 & 75 & \\
\hline \multicolumn{5}{|c|}{$\mathrm{N}$ stage of primary tumor $\mathrm{cN}$ in case of unknown pN } & 0.012 \\
\hline No & 33 & 35 & 62 & 65 & \\
\hline $\mathrm{N} 1$ & 9 & 14 & 57 & 86 & \\
\hline$>\mathrm{N} 2$ & 11 & 18 & 50 & 82 & \\
\hline $\mathrm{Nx}$ & 115 & 31 & 260 & 69 & \\
\hline \multicolumn{5}{|c|}{ Differentiation grade of primary tumor } & 0.061 \\
\hline Well/moderately & 21 & 18 & 97 & 82 & \\
\hline Poorly/undifferentiated & 87 & 23 & 294 & 77 & \\
\hline Unknown & 60 & 29 & 147 & 71 & \\
\hline \multicolumn{5}{|l|}{ Tumor histology } & 0.483 \\
\hline Adenocarcinoma & 97 & 22 & 341 & 78 & \\
\hline Signet ring cell & 45 & 28 & 116 & 72 & \\
\hline Linitis plastica & 22 & 25 & 65 & 75 & \\
\hline Other & 4 & 20 & 16 & 80 & \\
\hline \multicolumn{5}{|l|}{ Resection } & 0.081 \\
\hline Yes & 25 & 18 & 113 & 82 & \\
\hline No & 143 & 75 & 425 & 25 & \\
\hline
\end{tabular}

PC: peritoneal carcinomatosis; NOS: not otherwise specified

cT: clinical T-stage, (y)pT: pathological T-stage with or without neoadjuvant therapy $\mathrm{cN}$ : clinical N-stage, pN: pathological N-stage 


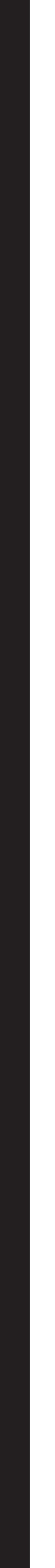




\section{Summary and future perspectives}





\section{Summary}

Peritoneal carcinomatosis (PC) is defined as the spread of malignant cells in the peritoneal cavity, originating from different types of primary tumors, mostly from colorectal, gastric, ovarian or pancreatic origin. The percentage of patients presenting with PC is different for each type of primary tumor. In colorectal cancer $4.8 \%$ of the patients is described to have PC at diagnosis, in pancreatic cancer $9 \%$ is diagnosed with PC and in ovarian cancer up to $46 \%$ of the patients are diagnosed with PC at the time of diagnosis. Chemotherapy has been shown to have a lower response rate in patients with PC compared to patients with other metastases. Moreover, failure of treatment with chemotherapy was highest in patients with PC. The introduction of cytoreductive surgery (CRS) combined with intraperitoneal chemotherapy (IPC) made PC potentially curable, which has made PC a topic of extensive research.

The aim of this thesis was to present reliable population-based data on the incidence, prognosis and treatment of PC of various origins, and to further characterize these patients in terms of risk-factors, treatment possibilities and survival.

Given the poor visibility of PC on radiological imaging, $\mathrm{PC}$ is often diagnosed during surgery for the primary tumor. Laparoscopic surgery is claimed to be safe and is associated with a lower risk of mortality, major morbidity, prolonged hospital stay and irradical resections. However, no data are currently available on intra-operative findings with regard to the diagnosis of synchronous peritoneal metastases. Therefore the aim of chapter 1 was to compare the proportions of patients diagnosed with PC during laparoscopic resection (LR) and open resection (OR) of a colorectal tumor. Between 2008 and 2012, 6,687 patients underwent resection for colorectal cancer in the Eindhoven Cancer Registry area. Of these patients $24 \%$ underwent LR, 70\% underwent OR and in 6\% surgery started laparoscopically but was converted to open surgery mostly due to adhesions and fixation of the tumor. Patients who were treated by LR had a lower chance to be diagnosed with PC during surgery than patients undergoing OR. Since effective treatment is currently available for selected patients with PC, a thorough inspection of the peritoneal cavity during surgery is of paramount importance to offer these patients a chance for long-term survival and even cure.

In patients with PC of colorectal origin, CRS combined with IPC has resulted in long-term survival of up to 63 months. This treatment with CRS and IPC is based on the hypothesis that PC is considered to be a locoregional disease and not a systemic disease. Therefore, only patients with PC without hematogenous metastases qualify for this treatment. Since liver metastases (LM) are considered to be hematogenous spread, patients with combined PC and LM currently do not qualify for treatment with CRS and IPC in most HIPEC-centers. This results in a dilemma in young, fit and motivated patients with combined LM and PC. In the absence of reliable data, the aim of chapter $\mathbf{2}$ was to provide population-based data on such patients and to review the literature for possible treatment options. Therefore all patients diagnosed between 1995 to 2010 with synchronous PC and LM were identified from the Eindhoven Cancer Registry, and incidence and survival were analyzed. In total 27,632 patients were diagnosed with colorectal cancer, of whom $20 \%$ presented with metastasized 
disease. Synchronous LM and PC were present in 440 patients, being $11 \%$ of patients with $\mathrm{LM}, 34 \%$ of patients with PC, $8 \%$ of patients with metastasized disease and $2 \%$ of all patients diagnosed with colorectal cancer. Median survival for patients with LM and PC was 5 months, as compared to 95 months for patients without metastases. None of the patients underwent treatment with curative intent during this period, and no improvement in survival was noted over time. In literature, CRS and IPC for PC and metastasectomy or RFA for LM reported median survival rates ranging from 6 to 36 months. The combination of these treatments is the only possible curative option for patients with combined LM and PC. Therefore, median survival rates of up to 36 months as published in literature may be regarded as promising for selected patients.

The majority of the patients with a colorectal carcinoma does not have metastases at time of diagnosis. However, a part of these patients develops metachronous PC after curative therapy for the primary tumor. No extensive data on this patient catagory are currently available. The aim of chapter $\mathbf{3}$ was to investigate the incidence and risk factors for developing metachronous PC, as well as survival since the diagnosis of PC. Therefore, data on metachronous metastases were collected for all patients diagnosed with $\mathrm{M} 0$ colorectal cancer between 2003 and 2008 in the Dutch Eindhoven Cancer Registry. During followup, $18 \%$ of the patients were diagnosed with metastatic disease, and $3.5 \%$ of the patients developed metachronous PC. The peritoneal surface was the only site of metastasis in $41 \%$ of the patients while $59 \%$ of the patients were diagnosed with both PC and metastases elsewhere. Median survival after diagnosis of PC was 6 months compared to 15 months for patients with distant metastases in other organs. Patients with an advanced primary tumour stage, positive lymph nodes at initial diagnosis, primary mucinous adenocarcinoma, positive resection margin and a primary tumour located in the colon were at increased risk of developing metachronous PC. Identifying patients at high risk for developing metachronous $P C$ is important as it may contribute to more accurate patient information, tailor-made follow-up schemes, and more adequate treatment.

The primary goal of the study described in chapter 4 was to provide reliable populationbased data on the incidence, risk factors and survival of PC of gastric origin. Between 1995 and 2011, 5,220 patients were diagnosed with gastric cancer, of whom 39\% presented with metastatic disease. PC was present in 706 patients of whom 491 patients had PC as the only metastatic site. Younger age, female gender, advanced $\mathrm{T}$ - and $\mathrm{N}$-stage, primary tumour of signet ring cells or linitis plastica, and primary tumours covering multiple anatomical locations of the stomach were all associated with a higher risk to develop PC. Median survival of patients without metastases was 14 months, but decreased to only 4 months for patients with PC.

PC of pancreatic origin is a relatively frequent condition with an extremely poor survival, leaving a very small therapeutic window. Since no population-based data on incidence and prognosis were available in literature, we described this in chapter 5. All patients with nonendocrine pancreatic cancer between 1995 and 2009 in the area of the Eindhoven Cancer 
Registry were included. In total, 2924 patients were diagnosed with pancreatic cancer, of which 265 patients presented with synchronous PC. An increasing trend was noted in patients treated with chemotherapy in more recent years. Median survival in patients presenting with PC was only 6 weeks and did not improve over time, contrasting improvements among patients with non-metastasized disease (19-30 weeks) and patients with metastasized disease confined to the liver (8-12 weeks). Literature on treatment is very scarce, with two case series that have described an exclusively surgical approach, combining resection of the primary tumor with radical debulking of the peritoneal deposits. However, they concluded that this this approach may be feasible but results in a high complication rate without benefit in survival. A combination of systemic chemotherapeutic agents (FOLFIRINOX) has shown to significantly improve survival in patients with metastatic disease. However, the effect on the subgroup of patients with PC of pancreatic origin was not analyzed.

Of all patients presenting with metastatic disease, a group of patients remains without diagnosis of the primary tumor, commonly referred to as Unknown Primary Tumor (UPT). Overall, UPT accounts for 3-5\% of all cancers. Since promising treatment options with IPC are now available for patients presenting with PC from colorectal, ovarian or gastric carcinoma, it is of increasing importance to diagnose patients presenting with PC as accurately as possible. The aim of the study described in chapter 6 was to investigate the incidence, treatment and survival of patients presenting with PC of unknown origin. Data from patients diagnosed with PC of unknown origin during between 1984-2010 were extracted from the Eindhoven Cancer Registry. European age-standardized incidence rates were calculated and data on treatment and survival were analyzed. In total 1,051 patients were diagnosed with PC of unknown origin. In 606 patients the peritoneum was the only site of metastasis, and 445 patients also had other metastases. In patients with PC chemotherapy usage has increased from $8 \%$ in the earliest period to $16 \%$ in most recent years. Median survival was extremely poor with only 42 days and did not change over time. Median survival of patients not receiving chemotherapy was significantly worse than of those receiving chemotherapy. Given the recent progress that has been achieved in patients presenting with PC from various origins, more efforts should be undertaken in order to diagnose the origin of PC more accurately and to explore potentially effective treatment strategies in this specific category of patients.

An increasing trend in the prescription of chemotherapy is shown in most previous chapters. Data on trends in systemic treatment and survival for patients with PC of gastric origin were described in chapter 7. Patients who were treated with chemotherapy were younger, had less comorbidities, a lower $\mathrm{N}$-stage and were diagnosed more recently. In the period 1995$199811 \%$ of the patients with PC were treated with chemotherapy, compared to $42 \%$ in the most recent period. However, median survival only increased from 5.7 to 7.9 months, which was not significantly different $(p=.310)$. This poor survival, which did not increase over time with the increased use of systemic chemotherapy, underlined the importance to further explore the promising results that were obtained in preventing and treating this condition with multi-modality strategies containing intraperitoneal chemotherapy. 


\section{Future perspectives}

In the current thesis it is shown that a relatively high percentage of patients with gastrointestinal cancer is diagnosed with PC during their disease and that the prognosis is currently extremely bad in the absence of an effective therapy in the vast majority of these patients. Therefore, more research is needed to address the problem of PC.

The term 'peritoneal carcinomatosis' has recently become a subject of discussion and is frequently replaced by 'peritoneal metastases'. This because 'metastases' implicates a metastatic site from a primary tumor, which makes a more clear difference between primary peritoneal tumors and metastases. Also, 'peritoneal metastases' implies a treatable condition, such as lymph node metastases, liver metastases and lung metastases from gastrointestinal cancer. Peritoneal metastases can be quantified, with the extent directly correlating with treatment outcome.

Since PC develops from malignant cells shed by a primary tumor, the biology of PC from various origins is different. The metastatic potential and occurrence of PC is determined by gene expression patterns of the primary tumor. In addition, these patterns also determined the response to treatment with chemotherapeutic agents and thereby also the prognosis. Further research may focus on mutations in tumors that are associated with tumor response. IGF-1, HIF1 $\alpha$, VEGF, EGFR and ITGB1 emerge as the most interesting gene mutations. Even though these promising candidate biomarkers have been identified, all of these require extensive further validation prior to clinical application.

Prior to surgery, a CT-scan is performed to visualize the tumor and to diagnose metastases, including PC. In recent years the quality of CT-scanning has improved, however, a low sensitivity to diagnose small lesions remains. This leaves room for potential improvement in the future. To diagnose these small lesions, inspection of the peritoneal cavity is performed during resection of the primary tumor. In patients with PC, staging laparoscopy is sometimes performed prior to CRS and IPC to determine the extent of the PC. This is done to evaluate the resectability of the lesions and the $\mathrm{PCl}$, since the $\mathrm{PCl}$ is directly related to survival. Previous studies have shown that $\mathrm{PCl}$ is a reliable tool for measuring the extent of $\mathrm{PC}$, is easy to use and inter-surgeon concordance is high.

Despite the RCT by Verwaal et al. there remains skepticism towards general acceptance of treating patients with CRS and IPC. The method of treatment of PC with CRS and IPC differs in clinics around the world. Different types of chemotherapy are used, and it can be administered heated or at normal body temperature and is administerd intraoperative or early postoperative. Currently there are multiple randomized controlled trials running. The United States Military Cancer Institute and American College of Surgeons Oncology Group investigates the effect of modern systemic chemotherapy versus CRS and IPC. The Federation Nationale des Centres de Lutte Contre le Cancer started the Hyperthermic Intraperitoneal Chemotherapy Trial, which compares patients undergoing CRS and patients undergoing combined CRS and IPC with oxaliplatin. All patients also received systemic oxaliplatin- 
based chemotherapy. In addition, the Wake forest University Open Labeled Oxaliplatin or Mitomycin C Trial compares patients undergoing CRS and IPC with oxaliplatin or mitomycin C.

In an experimental study in rats, heating the chemotherapy did not show added value, which can be proposed to be studied in humans. Recent studies add fluorescence imaging during surgery to detect small PC leasions. This can be used during curative surgery for M0 tumors as well as during CRS and IPC for PC to perform a complete resection. Furthermore, more research should focus on the side effects, quality of life and recurrence of PC in patients who underwent CRS and IPC.

Since chemotherapy is succesfully administrated intraperitoneal, this has prompted interest to administer other agents intraperitoneal. In experimental studies, the intraperitoneal administration of heparin has been shown to attenuate cancer growth, reduce the formation of postoperative adhesions and possess immunomodulatory properties of oncological benefit. Also, intraperitoneal administration of gene vectors, immunotherapy and monoclonal antibodies are currecntly studied. The most promising agent is catumaxomab, which has been shown to be effective in the treatment of recurrent malignant ascites and is now being evaluated as a potential therapeutic option in PC of ovarian, gastric and non-small cell lung cancers.

Traditional chemotherapeutic agents only have a minor impact on PC. A combination of different therapeutic agents might be beneficial to patients, as FOLFIRINOX has shown to prolong survival in patients with metastatic pancreatic cancer. However, the subgroup of patients with PC was not specifically analyzed. As also implied in chapter 7, in patients with PC of gastric origin it remains questionable if there is a beneficial effect of chemotherapy. Maybe new chemotherapeutics should focus on the inhibition of neoangiogenese, slowing the growth of the tumor and metastases. Also, the introduction of targeted agents might be beneficial in selected patients. Furthermore, adjuvant radioimmunotherapy after CRS is proposed. With this technique, monoclonal antibodies directed against tumor-associated antigens are labeled with radionuclides for targeted radiation.

In 2008 Elias et al. presented a study in which they performed second look surgery 13 months after resection of the primary tumor (MO) to detect PC. In the cohort of 29 patients $55 \%$ was diagnosed with PC during the second look laparotomy which was then concomitantly treated with CRS and IPC. To investigate the effect of this second look surgery, the Institute Gustave Roussy developed the ProphyloCHIP Trial. This is a randomized controlled trial in which second look surgery with IPC is compared to regular surveillance in the follow-up of colorectal cancer. This second look surgery was performed a year after the primary resection in patients with a high risk of getting peritoneal metastases.

In conclusion, there are multiple key points to focus further research on, to improve treatment of patients with PC and to prevent patients from developing PC. This once again outlines the importance of extensive further reseach. 


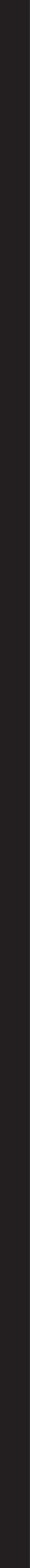




\section{Samenvatting}

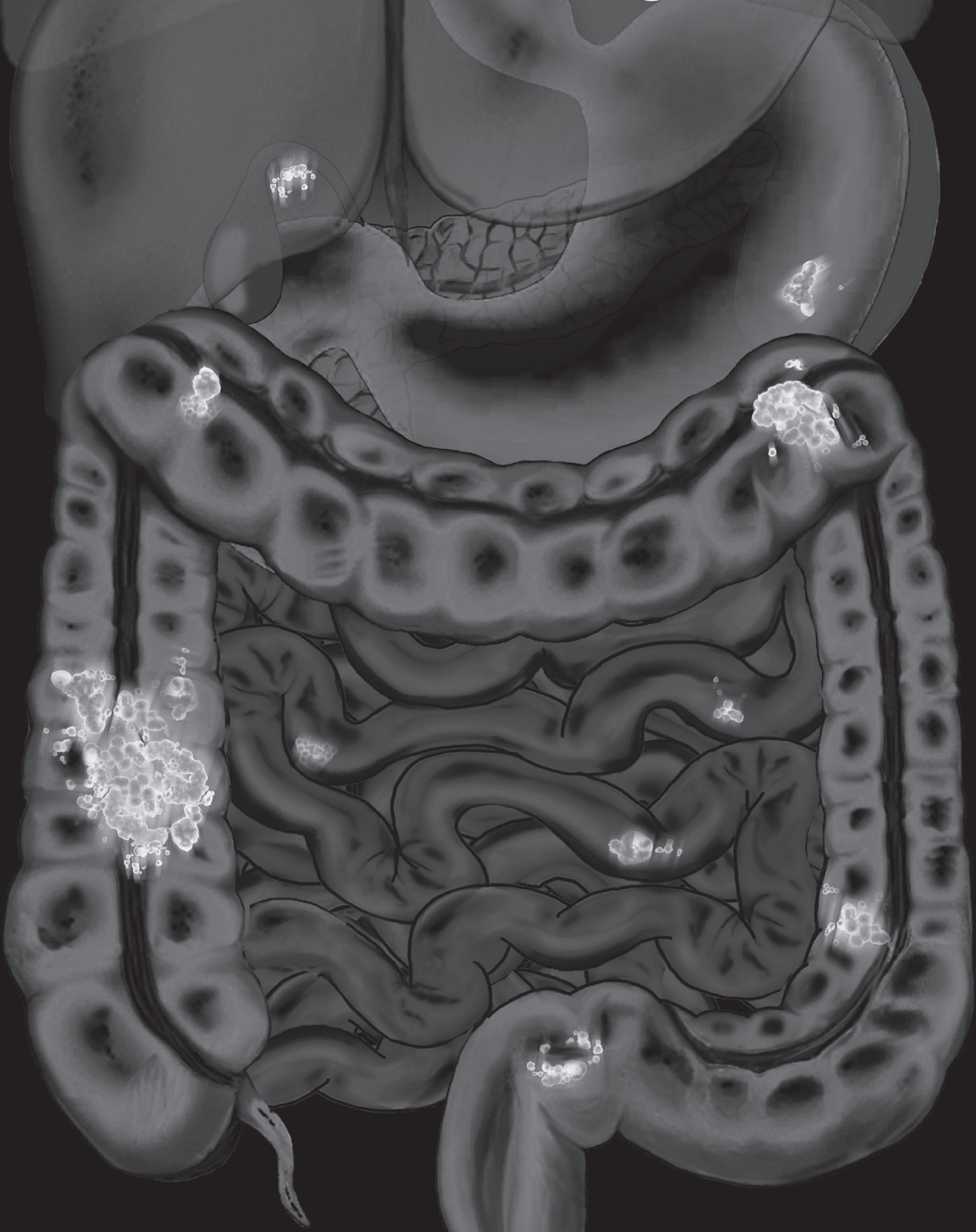





\section{Samenvatting}

Peritoneale metastasen (PM) kunnen ontstaan als maligne cellen vanuit een primaire tumor zich in de peritoneaal holte verspreiden. Het resulterende ziektebeeld wordt ook wel "peritonitis carcinomatosa" genoemd. Verschillende tumoren, zoals het colorectaal carcinoom, maagcarcinoom, ovariumcarcinoom en pancreascarcinoom kunnen PM veroorzaken. Het percentage patiënten dat PM ontwikkelt, verschilt per type tumor. Van de patiënten met een colorectaal carcinoom heeft $4.8 \%$ bij de eerste presentatie PM, voor het pancreascarcinoom geldt dit voor $9 \%$ van de patiënten, terwijl bij het ovariumcarcinoom $46 \%$ van de patiënten zich met PM presenteert. Helaas werkt chemotherapie minder goed bij patiënten met PM in vergelijking tot patiënten met andere metastasen. De introductie van de combinatie van cytoreductieve chirurgie (CRS) met intraperitoneale chemotherapie (IPC) biedt een mogelijk curatieve behandeling van PM. Dit heeft er toe geleid dat er de laatste jaren meer wetenschappelijk onderzoek naar PM is gedaan. In deze studies werd een cohort patiënten experimenteel behandeld. Echter bleef de incidentie van PM bij verschillende tumoren onduidelijk. Om het belang van deze experimentele studies te benadrukken is het belangrijk om de omvang van dit probleem te omschrijven. Het doel van dit proefschrift is het presenteren van betrouwbare population-based data over de incidentie, prognose en behandeling van PM van verschillende origine en om deze patiënten nader te karakteriseren.

PM kunnen worden gediagnosticeerd door middel van diagnostische onderzoeken of als een toevalsbevinding tijdens een operatie. Door de lage sensitiveit van CT- en PET-scans voor kleine laesies, worden PM vaak als toevalsbevinding gediagnosticeerd tijdens een operatie. Meerdere onderzoeken naar de veiligheid van laparoscopische operaties laten een lagere mortaliteit en morbiditeit, minder complicaties, verkort ziekenhuisverblijf en minder irradicale resecties zien dan bij open operaties. Er is momenteel echter geen data over het intra-operatief diagnosticeren van PM beschikbaar. Daarom was het doel van hoofdstuk 1 het in kaart brengen van het aantal patiënten dat bij laparoscopische resectie (LR) van een colorectale tumor met PM gediagnosticeerd wordt, en dit te vergelijken met het aantal patiënten dat tijdens een open resectie (OR) met PM gediagnostiseerd wordt. Tussen 2008 en 2012 ondergingen 6687 patiënten een resectie van een colorectale tumor en werden opgenomen in de Eindhovense kanker registratie. Van deze patiënten onderging $24 \%$ een LR en $70 \%$ een OR. Bij $6 \%$ begon de operatie laparoscopisch, maar werd er geconverteerd naar open resectie. De meest voorkomende redenen hiervoor waren adhesies of fixatie van de tumor. Uit dit onderzoek bleek dat patiënten die een LR ondergingen een lagere kans hadden om met PM gediagnosticeerd te worden tijdens de operatie dan patiënten die een OR ondergingen. Omdat er effectieve behandelingen zijn voor geselecteerde patiënten met $\mathrm{PM}$ is een uitvoerige inspectie van de peritoneaal holte van groot belang om deze patiënten een kans op een goede overleving en zelfs genezing te geven.

Bij patiënten met PM van colorectale origine heeft CRS in combinatie met IPC geleid tot een overleving tot 63 maanden. Deze behandeling is gebaseerd op de hypothese dat PM een locoregionale ziekte is zonder hematogene verspreiding. Vanuit deze hypothese komen alleen patiënten zonder levermetastasen (LM) in aanmerking voor CRS en IPC. Bij jonge, 
fitte en gemotiveerde patiënten met PM die tevens LM hebben, resulteert dit in een lastig dilemma. Daarom was het doel van hoofdstuk 2 om population-based data te presenteren over deze patiënten en literatuuronderzoek te doen naar mogelijke behandelingsstrategieën. Hiervoor werden alle patiënten die tussen 1995 en 2010 gediagnosticeerd werden met PM en LM geïdentificeerd. Zowel de incidentie als de overleving werd geanalyseerd. In totaal werden 27632 patiënten gediagnosticeerd met een colorectaalcarcinoom. Hiervan hadden 440 patiënten synchrone LM en PM. Dit is $11 \%$ van de patiënten met $L M, 34 \%$ van de patiënten met PM en $8 \%$ van alle patiënten met gemetastaseerde ziekte. De mediane overleving was slechts 5 maanden, wat erg laag is vergeleken met 95 maanden voor patiënten zonder metastasen. De patiënten ondergingen palliatieve behandeling en er was geen verbetering van de overleving over tijd. In de literatuur wordt voor de behandeling van deze patiëntenpopulatie CRS en IPC gecombineerd met metastasectomie of radiofrequente ablatie (RFA) voor de LM. Dit zorgt voor een mediane overleving tussen de 6 en 36 maanden. De combinatie van deze behandelingen is de enige curatieve optie voor patiënten met LM en PM, daarom kan de overleving tot 36 maanden als veelbelovend worden beschouwd.

Het grootste deel van de patiënten met een colorectaal carcinoom hebben geen metastasen ten tijde van de eerste presentatie. Een deel van deze patiënten ontwikkelt PM na curatieve behandeling van de primaire tumor. Het doel van hoofdstuk 3 was om de incidentie, risicofactoren en de overleving na de diagnose van metachrone PM te onderzoeken. Hiervoor werden alle patiënten bij wie tussen 2003 en 2008 een Mo colorectaalcarcinoom werd gediagnosticeerd geselecteerd uit de Eindhovense kanker registratie. Tijdens de followup periode ontwikkelde $18 \%$ metastasen, waarvan 3.5\% PM. Hiervan had $41 \%$ alleen PM, terwijl 59\% naast de PM tevens andere metastasen ontwikkelde. De mediane overleving na de diagnose van PM was 6 maanden, vergeleken met 15 maanden voor patiënten met metastasen in andere organen. Patiënten met een vergevorderd tumor stadium, positieve lymfeklieren bij diagnose, primaire mucineuze adenocarcinomen, positieve resectieranden en een tumor in het colon hadden een hoger risico op het ontwikkelen van PM.

Het doel van hoofdstuk 4 was om betrouwbare population-based data te presenteren over de incidentie, risicofactoren en overleving van patiënten met PM uitgaande van een maagcarcinoom. Tussen 1995 en 2011 werden 5220 patiënten met een maagcarcinoom gediagnosticeerd en geregistreerd in de Eindhovense Kanker Registratie. Hiervan had 39\% gemetastaseerde ziekte. 709 Patiënten hadden PM, waarvan 491 patiënten alleen PM hadden zonder andere metastasen. Jongere leeftijd, vrouwelijk geslacht, patiënten met een verder gevorderd $\mathrm{T}$ - en $\mathrm{N}$-stadium, zegelringcel carcinoom, linitis plastica of een primaire tumor die meerdere locaties omvatte, hadden een hoger risico om PM te ontwikkelen. De mediane overleving van patiënten zonder metastasen was 14 maanden, wat daalde naar 4 maanden bij patiënten met PM.

Patiënten met PM vanuit de pancreas hebben een extreem slechte overleving, waardoor er weinig therapeutische opties zijn. Het doel van hoofdstuk $\mathbf{5}$ was om de incidentie en prognose van patiënten met een pancreascarcinoom en PM te beschrijven. Alle patiënten 
met non-endocrien pancreascarcinoom die tussen 1995 en 2009 werden geregistreerd in de database van de Eindhovense kanker registratie werden geïncludeerd. In totaal werden er 2924 patiënten gediagnosticeerd met pancreascarcinoom, waarvan 265 patiënten synchrone PM hadden. Er was een toename van het aantal patiënten dat met chemotherapie werd behandeld, echter bleef de mediane overleving 6 weken. Bij patiënten zonder metastasen verbeterde de mediane overleving van 19 naar 30 weken en bij patiënten met alleen levermetastasen van 8 naar 12 weken. Er is weinig literatuur over de chirurgische behandeling van PM bij pancreascarcinoom en de studies die zijn gedaan laten zien dat er veel complicaties voorkomen. Een combinatie van chemotherapie (FOLFIRINOX) laat een significant verbeterde overleving zien bij patiënten met gemetastaseerd pancreascarcinoom, echter wordt er geen subgroep analyse gedaan voor patiënten met PM.

Bij een deel van de patiënten die zich presenteren met gemetastaseerde ziekte, wordt er geen primaire tumor gevonden, dit wordt 'onbekende primaire tumor' genoemd. Van alle patiënten met kanker blijft in 3-5\% de primaire tumor onbekend. Omdat er nu veelbelovende behandelingen zijn voor PM van colorectaal-, ovarium-, en maagcarcinoom is het belangrijk om de primaire tumor te vinden bij patiënten met PM. Het doel van hoofdstuk 6 was om de incidentie, behandeling en overleving van patiënten met PM van onbekende origine te beschrijven. De patiënten die tussen 1984 en 2010 met PM gediagnosticeerd werden, werden geanalyseerd. Europese voor leeftijd gestandaardiseerde incidentie werd uitgerekend en data over de behandeling en overleving werden geanalyseerd. In totaal werden er 1051 patiënten met PM van onbekende origine gediagnosticeerd. Bij 606 patiënten waren PM de enige metastasen, de overige 445 patiënten hadden ook andere metastasen. Bij patiënten met PM nam de hoeveelheid patiënten die behandeld werd met chemotherapie toe van $8 \%$ tot $16 \%$. De mediane overleving van patiënten die geen chemotherapie kregen was slechter dan van patiënten die wel chemotherapie kregen.

Er werd in de voorafgaande hoofdstukken een toename van behandeling met chemotherapie gezien. Daarom was het doel van hoofdstuk 7 om trends in de behandeling met chemotherapie bij patiënten met maagkanker te beschrijven. Patiënten die jonger waren, minder comorbiditeiten hadden, lager $\mathrm{N}$-stadium en in meer recente periodes zijn gediagnosticeerd kregen vaker chemotherapie. In de periode van 1995 tot 1998 werd $11 \%$ van de patiënten behandeld met chemotherapie, wat in de meest recente periode (2007-2011) steeg naar $42 \%$. De mediane overleving nam toe van 5.7 maanden naar 7.9 maanden, wat niet significant verschillend was. Deze slechte overleving, welke niet verbeterde met systemische chemotherapie, laat het belang van de behandeling met multimodaliteitsstrategieën zien. 


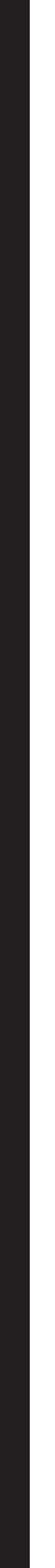




\section{About the author}

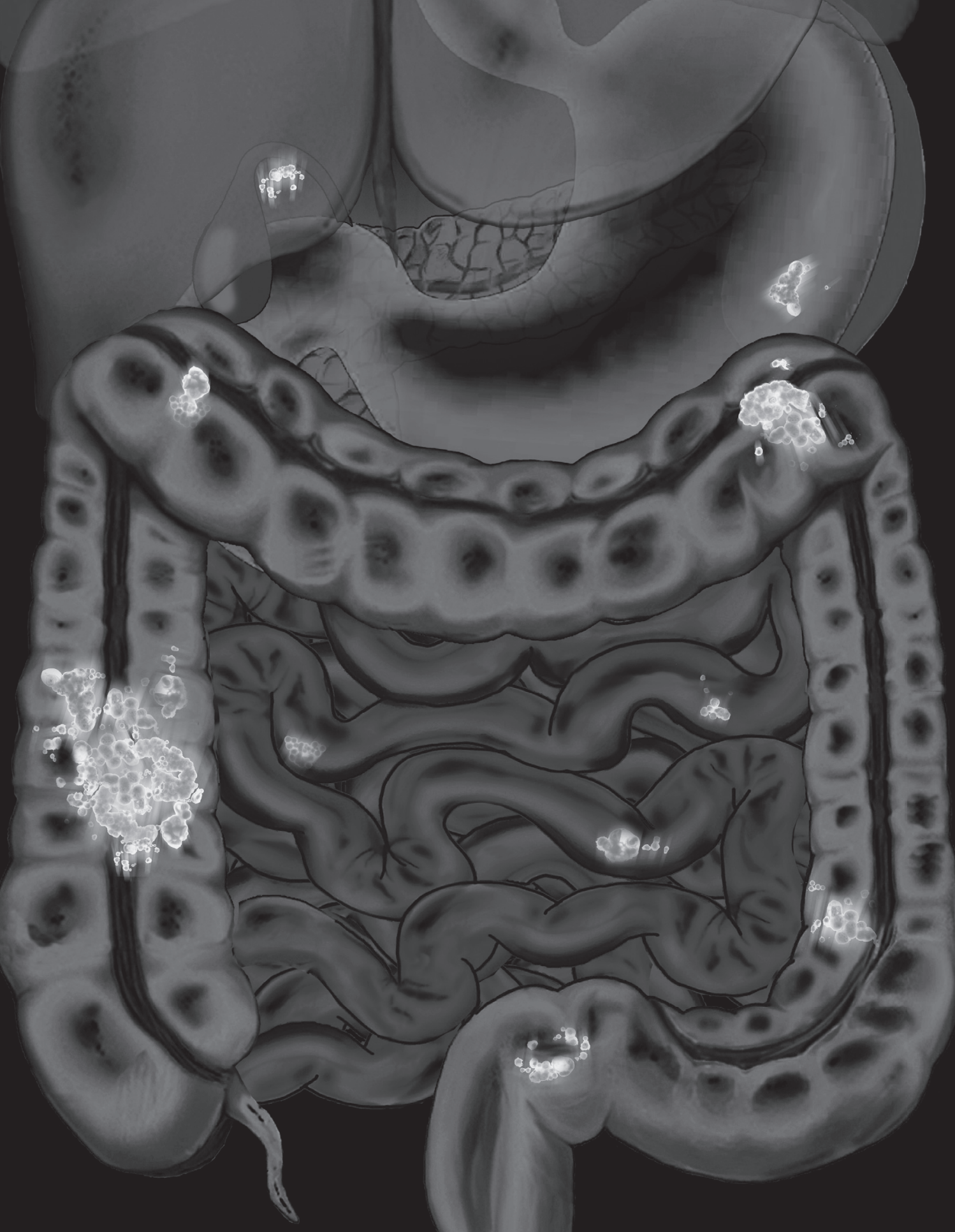





\section{About the author}

Irene Thomassen was born on December $27^{\text {th }} 1986$ in Eindhoven, the Netherlands.

After completing bilingual secondary school at the Stedelijk College Eindhoven and International Secondary School Eindhoven, she started her Medicine study at Maastricht University. She completed all internships at the Catharina Hospital Eindhoven and her last year at the Department of Surgery. There she started her research concerning peritoneal carcinomatosis.

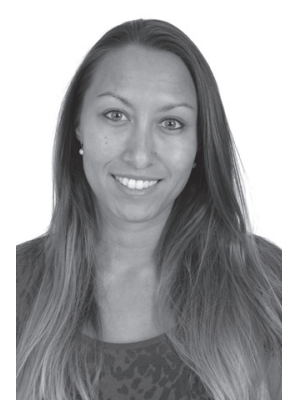

In 2011 Irene received her medical degree and started working as a resident Surgery at the Kennemer Gasthuis in Haarlem. During this clinical work she continued her research about peritoneal carcinomatosis. With a grant from Professor Coebergh, she worked full-time on her research at the Comprehensive Cancer Center the Netherlands (IKNL) from January until June 2013. In Juli 2013 she started her training to become a surgeon at the VU and Kennemer Gasthuis. 


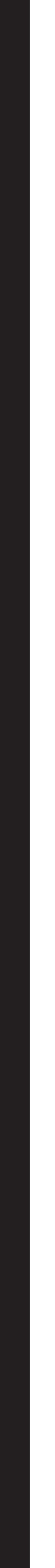




\section{Publications}

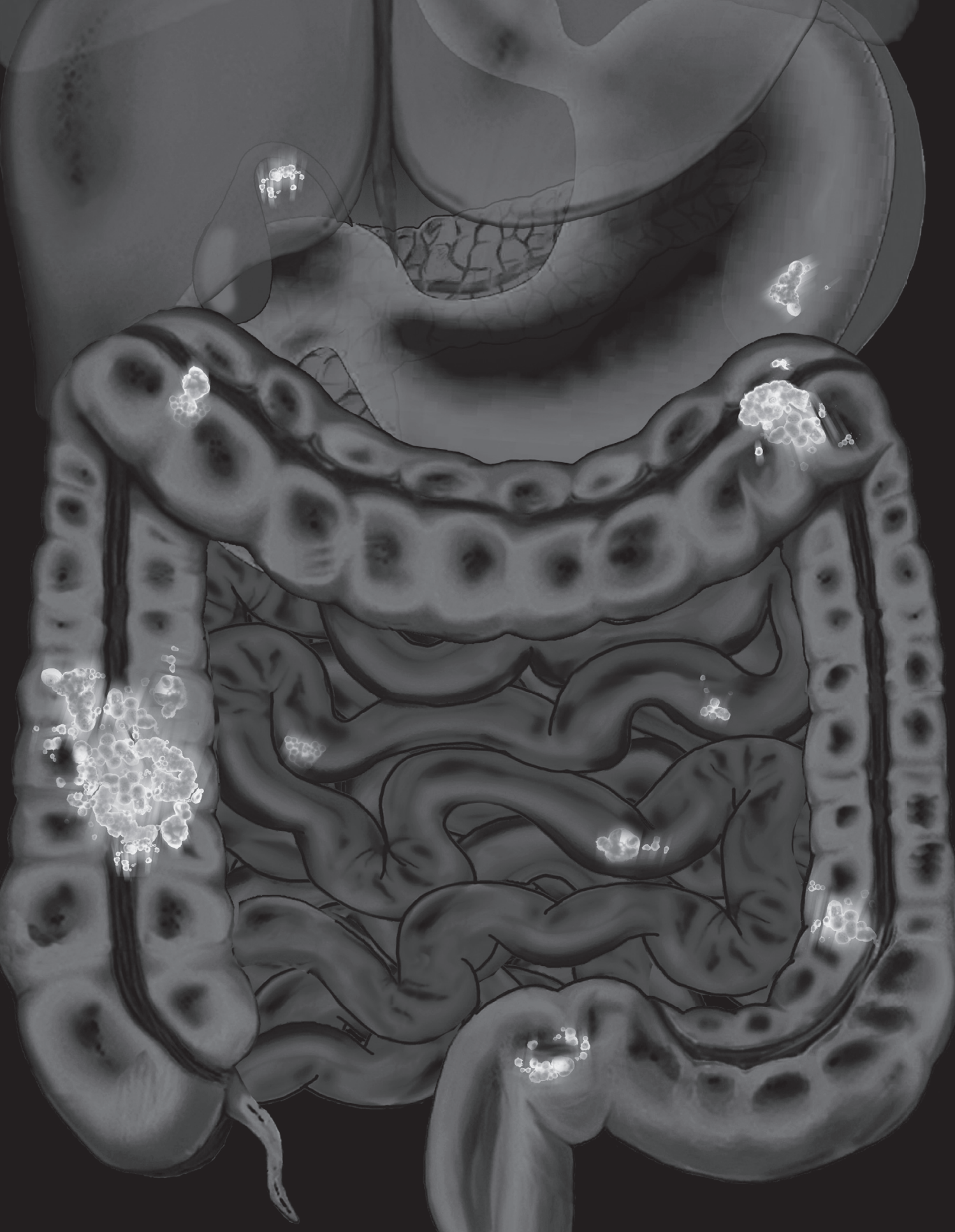





\section{Publications}

\section{In this thesis}

1. Peritoneal carcinomatosis is less frequently diagnosed during laparoscopic surgery compared to open surgery in patients with colorectal cancer in the Netherlands.

Thomassen I, van Gestel YR, Aalbers AG, van Oudheusden TR, Wegdam JA, Lemmens VE, de Hingh IH. Eur J Surg Oncol. 2014 May;40(5):511-4.

2. Chemotherapy as palliative treatment for peritoneal carcinomatosis of gastric origin.

Thomassen I, Bernards N, van Gestel YR, Creemers GJ, Jacobs EM, Lemmens VE, de Hingh IH. Acta Oncol. 2014 Mar;53(3):429-32

3. Incidence, prognosis, and treatment options for patients with synchronous peritoneal carcinomatosis and liver metastases from colorectal origin.

Thomassen I, van Gestel YR, Lemmens VE, de Hingh IH. Dis Colon Rectum. 2013 Dec;56(12):1373-80

4. Metachronous peritoneal carcinomatosis after curative treatment of colorectal cancer. van Gestel YR, Thomassen I, Lemmens VE, Pruijt JF, van Herk-Sukel MP, Rutten HJ, Creemers GJ, de Hingh IH. Eur J Surg Oncol. 2014 Aug;40(8):963-9

5. Population-based incidence, treatment and survival of patients with peritoneal metastases of unknown origin.

Thomassen I, Verhoeven RH, van Gestel YR, van de Wouw AJ, Lemmens VE, de Hingh IH. Eur J Cancer. 2014 Jan;50(1):50-6

6. Peritoneal carcinomatosis of gastric origin: a population-based study on incidence, survival and risk factors.

Thomassen I, van Gestel YR, van Ramshorst B, Luyer MD, Bosscha K, Nienhuijs SW, Lemmens VE, de Hingh IH. Int J Cancer. 2014 Feb 1;134(3):622-8

7. Incidence, prognosis, and possible treatment strategies of peritoneal carcinomatosis of pancreatic origin: a population-based study.

Thomassen I, Lemmens VE, Nienhuijs SW, Luyer MD, Klaver YL, de Hingh IH.

Pancreas. 2013 Jan;42(1):72-5

\section{Not in this thesis}

8. Treatment of temporal artery pseudoaneurysms.

Thomassen I, Klompenhouwer EG, Willigendael EM, Teijink JA. Vascular 2014, Vol.22(4) 274-279

9. Een man met een bult op zijn voorhoofd na val.

Klompenhouwer EG, Thomassen I, Teijink JA. Ned Tijdschr Geneeskd. 2013;157(8):A4231.

10. Steroid use is associated with clinically irrelevant biopsies in patients with suspected giant cell arteritis.

Thomassen I, den Brok AN, Konings CJ, Nienhuijs SW, van de Poll MC. Am Surg. 2012 Dec;78(12):1362-8.

11. Ultrasound-guided ilioinguinal/iliohypogastric nerve blocks for chronic pain after inguinal hernia repair.

Thomassen I, van Suijlekom JA, van de Gaag A, Ponten JE, Nienhuijs SW. Hernia. 2013 Jun;17(3):329-32.

12. Een 13-jaar oude jongen met pijn in de rechter onderbuik.

Thomassen I, Klinkhamer PJ, van de Poll MC. Ned Tijdschr Geneeskd. 2012;156(18):A3566.

13. Intervention techniques for chronic postherniorrhaphy pain.

Thomassen I, van Suijlekom HA, van der Gaag A, Nienhuijs SW. Eur Surg. 2012, June (44)3: 132-137

14. A collective review on mesh-based repair of umbilical and epigastric hernia. Ponten JE, Thomassen I, Nienhuijs SW. Indian J Surg 17 April 2013, DOI 10.1007/s12262-013-0920-6

15. Small bowel perforation caused by advanced melanoma. den Uil SH, Thomassen I, Vermeulen EG, Vuylsteke RJ, Stockmann HB, de Vries M. Tumori, 100:e140-e143, 2014 


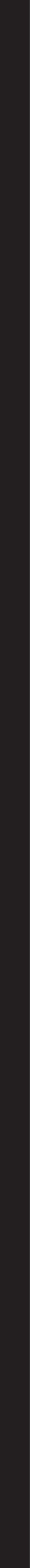




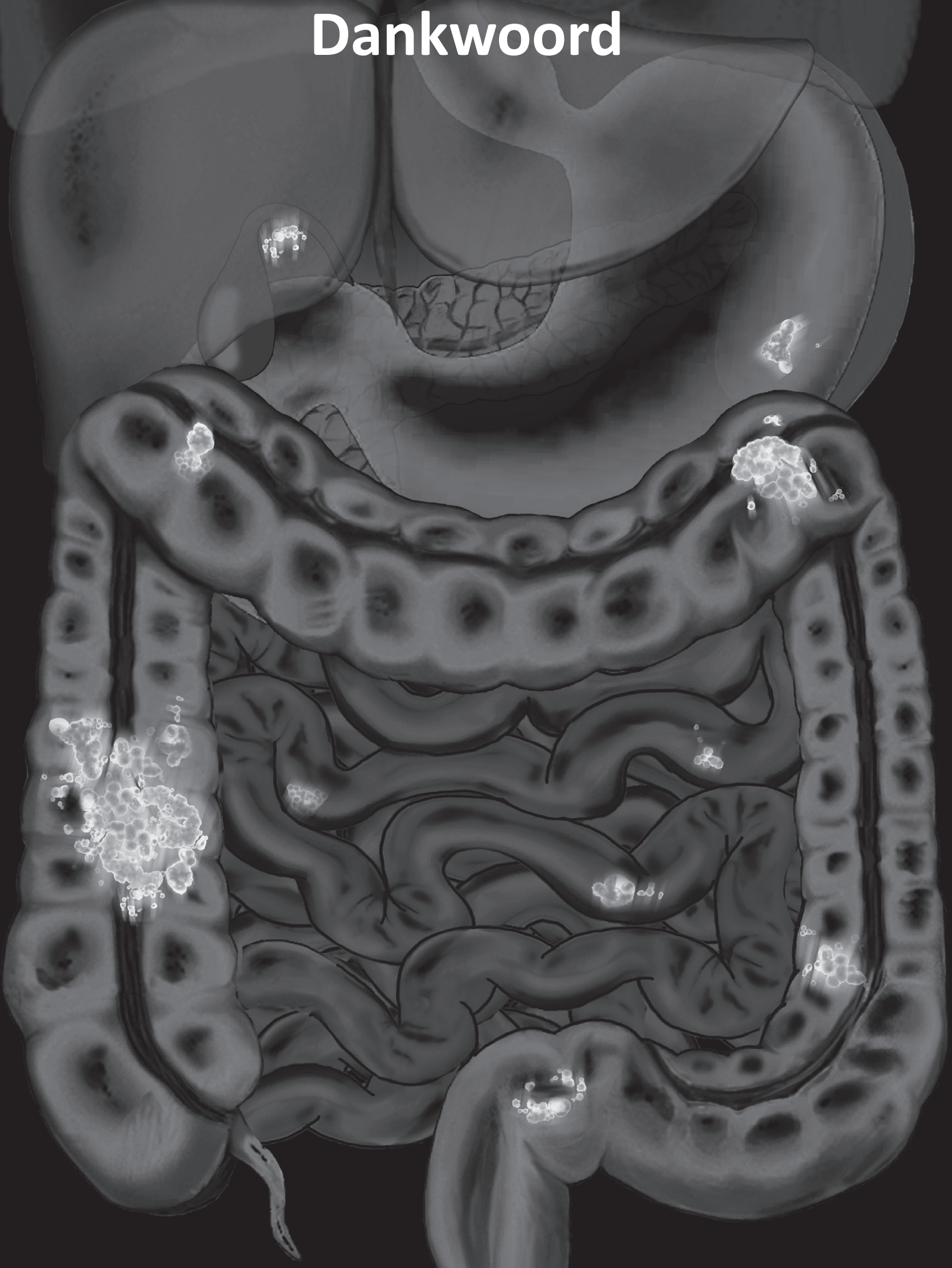





\section{Dankwoord}

Het is dan eindelijk zover, het dankwoord. Waarschijnlijk het meest gelezen deel van mijn proefschrift. Hierbij wil ik iedereen ontzettend bedanken die er voor heeft gezorgd dat dit onderzoek kon plaatsvinden en het tot een succes heeft gemaakt. Graag wil ik een aantal mensen persoonlijk bedanken.

Prof. dr. Rutten, beste Harm, pas in een later stadium werd jij betrokken bij mijn proefschrift. Meteen was je erg enthousiast. Ik heb veel steun aan je gehad bij het afronden van mijn proefschrift en het regelen van alles er omheen, bedankt daarvoor.

Prof. dr. Lemmens, beste Valery, ik weet nog onze eerste ontmoeting in het Catharina ziekenhuis. Even samen zitten om te kijken of we een mooi artikel konden schrijven over peritonitis carcinomatosa. Één artikel werden er twee, en twee werden er 7. Ik hoop dat er nog meer zullen volgen, maar dat komt goed, het begin is al gemaakt. Verder maakten jouw enthousiasme en gezelligheid de congressen tot een groot feest. Ik vind het geweldig dat ik jouw eerste promovenda mag zijn.

Dr. de Hingh, beste Ignace, zonder jouw inspanningen was dit proefschrift nooit tot stand gekomen. Jouw enorm aanstekelijke drive wist je op mij over te brengen. Het is bewonderingswaardig hoe jij onderzoekslijnen uitzet en deze tot een succes maakt. Je bent een groot voorbeeld voor mij als chirurg en wetenschapper. Dank voor al je support en vertrouwen in mij. Ik hoop dat we nog lang zullen samenwerken.

Leden van de lees-/promotiecommissie, dr. Verwaal, dr. van Ramshorst, prof. dr. TjanHeijnen, prof. dr. Dejong. Ik wil jullie allen bedanken voor het lezen van het manuscript en bereidheid zitting te nemen in mijn promotiecommissie.

Prof. dr. Coebergh, beste Jan-Willem, door jouw vertrouwen in mij als onderzoeker kreeg ik de mogelijkheid om een aantal maanden full-time aan mijn onderzoek te werken. Jouw aanvullingen op mijn onderzoek waren altijd zeer welkom. Dank voor je continue interesse in mijn proefschrift.

Janny van den Einden - van Raay, bedankt dat je mij de mogelijkheid hebt gegeven om fulltime aan dit onderzoek te werken. De collega's van het IKZ/IKNL. Allemaal waren jullie bereid om te helpen met statistische analyses en mijn vragen te beantwoorden. Bovenal zorgden jullie voor een gezellige en leerzame tijd. Verder niet te vergeten de registratiemedewerkers voor het bijhouden van de database. Zoals Valery en Ignace altijd zeggen: deze mooie database is een goudmijn, en dat is dankzij jullie.

Yvette van Gestel, beste Yvette, tijdens het schrijven van mijn artikelen was jij mijn steun en toeverlaat. Je had altijd tijd voor overleg en hielp mij waar je kon. Bedankt voor alles, zonder jou was het moeilijker en vooral veel minder leuk geweest. 
De maatschap chirurgen van het Kennemer Gasthuis met in het bijzonder opleider dr. Herman Rijna. Vooral bedankt voor jullie vertrouwen in mij en steun bij mijn sollicitatie voor de opleiding heelkunde.

Collega arts-assistenten in het Kennemer Gasthuis, bedankt voor de goede sfeer, prettige samenwerking en gezelligheid in de afgelopen en komende jaren.

De maatschap chirurgen van het Catharina ziekenhuis. Mijn enthousiasme voor de heelkunde is tijdens mijn co-schap en semi-arts stage bij jullie ontstaan. Dr. Simon Nienhuis, bedankt voor de begeleiding bij het schrijven van mijn eerste wetenschappelijke artikelen. Voor ik aan mijn wetenschappelijke stage begon had ik geen zin in onderzoek doen, maar mede dankzij jou is mijn enthousiasme voor de wetenschap ontstaan.

Overige mede-auteurs, bedankt voor het becommentariëren van de manuscripten, de samenwerking heeft tot een beter resultaat geleid.

Judith Thijs, paranimf, nog een paar jaartjes en dan zal je mij volgen. Onze brainstorm avondjes hielpen me als ik even niet wist hoe ik dingen aan moest pakken. Hopelijk kan ik over niet te lange tijd hetzelfde voor je betekenen, maar gelukkig hebben we voor jou al een aantal stellingen verzonnen. Ik ben blij met onze vriendschap en ben blij dat je mijn paranimf wil zijn.

Ariana Madani, mijn maatje in het ziekenhuis. Sinds dag één dat jij in het KG werkt zijn wij een team. Taart bakken kunnen we als de beste! Bedankt dat je mijn paranimf wil zijn, ik ben blij dat jij naast mij staat.

Zonder iedereen persoonlijk te noemen, wil ik jullie allemaal bedanken voor de onvoorwaardelijke steun die ik heb gekregen. Alle etentjes, feestjes, tripjes en zonneuren aan het strand zorgden voor de noodzakelijke afleiding tijdens het schrijven van dit proefschrift. Al mijn lieve vrienden bedankt!

Lieve pap, lieve mam, jullie hebben mij de kans gegeven om te doen wat ik nu doe en hebben mij altijd gestimuleerd mijn dromen te volgen. Boven alles leerden jullie mij dat liefde en gezondheid belangrijk zijn in het leven. Zeker bij een proefschrift als dit, waarin patiënten met een korte levensduur centraal staan, krijgt deze boodschap nog meer waarde.

Tot slot bedank ik mijn grote liefde, Robert, mijn husband-to-be. Wat is het mooi om te zien, hoe trots jij op mij bent. Samen maken we de mooiste reizen en ontdekken we de hele wereld. Zelfs dan vind je het niet vervelend als ik stiekem even aan mijn artikelen werk. Lieve Robert, bedankt voor je onvoorwaardelijke steun. Ik hou van je. 